Discussion

Papers

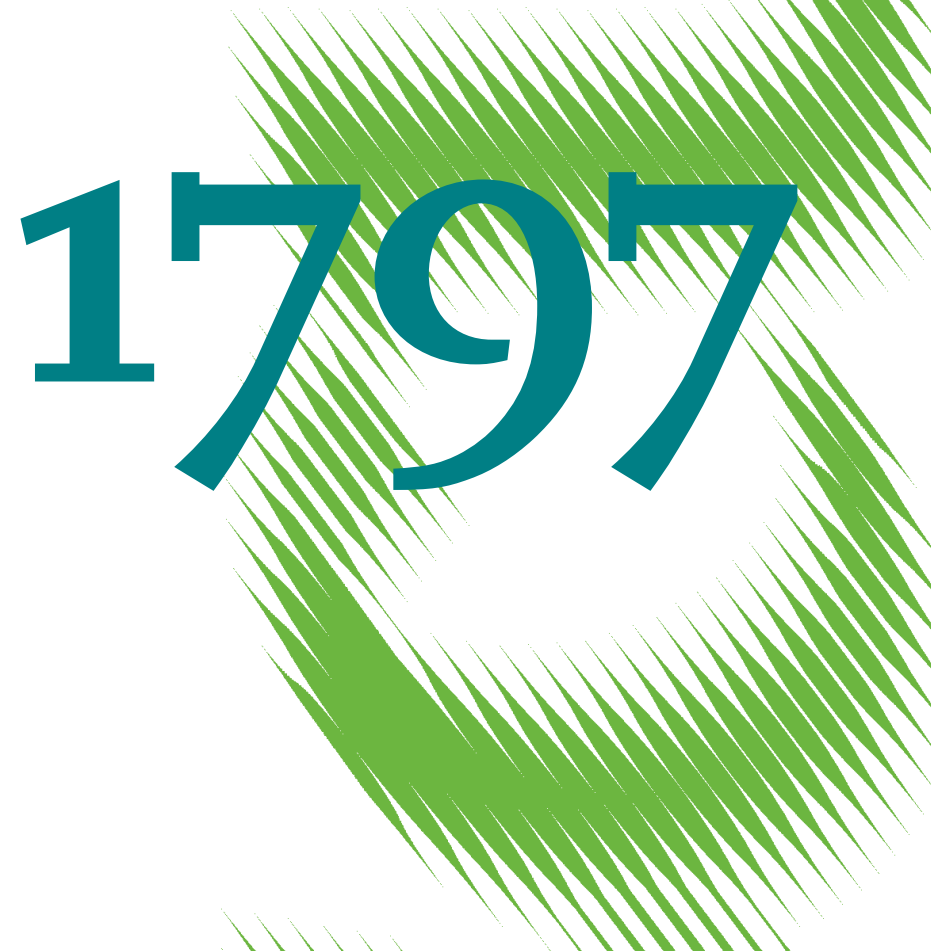

25 Years of European Merger Control 
Opinions expressed in this paper are those of the author(s) and do not necessarily reflect views of the institute.

IMPRESSUM

(C) DIW Berlin, 2019

DIW Berlin

German Institute for Economic Research

Mohrenstr. 58

10117 Berlin

Tel. +49 (30) $89789-0$

Fax +49 (30) $89789-200$

http://www.diw.de

ISSN electronic edition 1619-4535

Papers can be downloaded free of charge from the DIW Berlin website:

http://www.diw.de/discussionpapers

Discussion Papers of DIW Berlin are indexed in RePEc and SSRN:

http://ideas.repec.org/s/diw/diwwpp.html

http://www.ssrn.com/link/DIW-Berlin-German-Inst-Econ-Res.html 


\title{
25 Years of European Merger Control*
}

\author{
Pauline Affeldt, Tomaso Duso ${ }^{\ddagger}$ and Florian Szücs§
}

April 2, 2019

\begin{abstract}
We study the evolution of the EC's merger decision procedure over the first 25 years of European competition policy. Using a novel dataset constructed at the level of the relevant markets and containing all merger cases over the 1990-2014 period, we evaluate how consistently arguments related to structural market parameters were applied over time. Using non-parametric machine learning techniques, we find that the importance of market shares and concentration measures has declined while the importance of barriers to entry and the risk of foreclosure has increased in the EC's merger assessment following the 2004 merger policy reform.
\end{abstract}

JEL Classification: K21; L40

Keywords: Merger policy; DG Competition; causal forests

\footnotetext{
*We thank Ivan Mitkov, Fabian Braesemann, David Heine, Juri Simons and Isabel Stockton for their help with data collection. ${ }^{\dagger}$ Deutsches Institut für Wirtschaftsforschung (DIW Berlin) \& Technische Universität (TU) Berlin

${ }^{\ddagger}$ Deutsches Institut für Wirtschaftsforschung (DIW Berlin), Technische Universität (TU) Berlin, Centre for Economic and Policy Research (CEPR) \& CESifo

$\S$ Wirtschaftsuniversität Wien
} 


\section{Introduction}

Competition policy, that is, the design and enforcement of competition rules, is a cornerstone of the European Union (EU)'s program to enhance the European single market and foster growth. ${ }^{1}$ The European Commission's (EC) Directorate General for Competition (DG Comp) ensures the application of EU competition rules and retains jurisdiction over community-wide competition matters, representing the lead antitrust agency in the European context. Competition policy covers several areas ranging from monitoring and blocking anticompetitive agreements - in particular hardcore cartels - to abuses by dominant firms, to mergers and acquisitions as well as to state aid. Among these areas of antitrust enforcement, merger control plays a peculiar role. First, it is the only area where there is ex-ante enforcement. Second, it has important implications for the other areas of antitrust: if anticompetitive mergers that reduce competition and strengthen the dominant position of the merging firms are not prevented, it might make the ex-post control of abusive behaviors more difficult. Finally, mergers are the area of antitrust where the largest consensus on best practices exists. Therefore, among competition policy tools, it is an area that attracted much policy interest and economic research.

The European Communities Merger Regulation (ECMR), the legal basis for common European merger control, came into force in 1990. Over the course of the next 25 years, European merger control saw significant changes. While in the early 1990s there were approximately 50 notified cases per year, the annual workload increased significantly in the late 1990s and has averaged around 280 cases in the 2000s. DG Comp's enforcement activity reflects these changes. Procedurally, many novelties were implemented in the 2004 amendment to the ECMR: not only were new horizontal merger guidelines and the office of the chief economist introduced, but also, more importantly, a new substantive test, the so called "significant impediment of effective competition" (SIEC) test and an efficiency defense were introduced. These amendments marked a substantial change in the legal basis for merger control enforcement in Europe. Yet, the pressure for these changes began much earlier with the increasing belief that a mere form-based assessment of mergers could often result in wrong decisions. The three overturned prohibitions by the Court of First Instance at the beginning of the 2000s marked the peak of this process.

In this paper, we employ a new dataset containing all merger cases with an official decision documented by DG Comp (more than 5000 individual decisions) to evaluate the time dynamics of the EC's decision procedures (see Affeldt et al. (2018)). Specifically, we assess how consistently different arguments related to the so called structural market parameters - market shares, concentration, likelihood of entry, and foreclosure - put forward to motivate a particular decision were applied over time. In order to obtain a more fine-grained picture of the decision determinants, we extend our analysis to the specific relevant product and geographic markets concerned by a merger. Thus, instead of only looking at the determinants of a merger decision in the aggregate, we also investigate the factors that caused competitive concerns in specific sub-markets and how they have changed over time. This step is particularly important because larger mergers typically affect many different product markets in many different geographic regions. For example, the mergers in our data affect an average of six markets. Therefore, by analyzing individual markets, thus conducting a more disaggregate analysis, we better model the process that lead to a specific merger decision. Thus, the scope and depth of

\footnotetext{
${ }^{1}$ Gutiérrez and Philippon (2018) claim that since the 1990s, European markets have become more competitive than their US counterparts because of the increased economic integration and the enactment of the European single market. They attribute a key role in this process to the tough enforcement of competition policy rules.
} 
our data allow us to go beyond the existing literature by i) not relying on a sample of decisions but instead reporting patterns for the whole population of merger cases examined by DG Comp; and ii) allowing for heterogeneity within merger cases by examining the individual product and geographic markets concerned.

In a first step, and in line with the existing literature, we start by estimating the probability of intervention as a function of merger characteristics at the merger level. We find that the existence of barriers to entry, the increase of concentration measures and, in particular, the share of product markets with competitive concerns are positively associated with the likelihood of an intervention. This approach naturally extends to the level of the individual markets: instead of estimating the overall probability of an intervention, we estimate the likelihood that competitive concerns are found in that specific product/geographical market under consideration. We find that, again, barriers to entry, but also the risk of foreclosure play a role. While tightly defined (national) markets increase the probability of concerns, the number of active competitors decreases it. Structural indicators of market shares and concentration show the expected positive and significant correlation with the likelihood of competitive concerns. After this static investigation, we then study the dynamics of the impact of a number of key determinants over time. We find that the importance of 'structural' indicators of market power has declined over the years, though we observe a large volatility in the estimates over time.

In a second step, we bring well-developed non-parametric prediction methods to the analysis of competition policy outcomes: supervised machine learning techniques. In particular, we implement the causal forest algorithm proposed by Athey and Imbens (2016). This step allows a more flexible approach to model the heterogeneity in merger control decisions. Specifically, the association between structural indicators and the Commission's decisions is made a function of all other covariates. Especially after the reform of 2004, a so-called effects-based approach centered on a clearly stated theory of harm was made a cornerstone of EU merger control. In such an approach, the reliance on structural parameters was expected to decrease, leaving space for the use of counterfactual analysis where the interactions of different elements might play a crucial role to substantiate the theory of harm. Using this model, we find that the importance of market share and concentration measures has declined over time while the importance of barriers to entry and the risk of foreclosure has increased in DG Comp's decision making. Yet, the impact of structural indicators appears to be much less volatile than in the simple linear probability model. Thus, the arguments put forward by the EC to substantiate its decisions appear to be more consistently applied once the process underlying these decisions is modelled in a flexible way.

The remainder of the study is structured as follows. In Section 2, we discuss the institutional details of European merger control and review recent studies that empirically investigate the determinants of merger intervention. In Section 3, we describe the data set used in estimation. We present the parametric model as well as estimation results for the determinants of EC merger interventions in Section 4, while Section 5 presents the model and results for non-parametric estimation of heterogeneous correlations between merger characteristics and intervention by the EC. We conclude in Section 6. 


\section{Literature \& Institutional Details}

\subsection{Institutional Details}

The European Communities Merger Regulation (ECMR) was passed in 1989 and came into force in September $1990 .^{2}$ It specifies the scope of intervention and juridical competence of the European Commission in merger cases with a "community dimension." In article 1.2 of regulation $4064 / 89$, a combination is defined to have community dimension by meeting the following conditions:

(a) the aggregate worldwide turnover of all the undertakings concerned is more than $\mathrm{ECU}^{3} 5000$ million, and

(b) the aggregate Community-wide turnover of each of at least two of the undertakings concerned is more than ECU 250 million, unless each of the undertakings concerned achieves more than two-thirds of its aggregate Community-wide turnover within one and the same Member State.

That means that from 1990 onwards, all major combinations affecting EU markets have been scrutinized by the EC, whereas national competition authorities have been focusing solely on mergers affecting one single Member State. In 1997, the above definition was significantly widened by the passing of regulation 1310/97, which made the definition of a community dimension less stringent. ${ }^{4}$

Notice that these definitions also include companies that are located, produce, and sell outside of Europe, as long as their sales to European markets are sufficiently high. Thus, a merger can be subject to the jurisdiction of more than one competition authority. This resulted in diplomatic strife, for instance, when the merger of the two US companies General Electric and Honeywell was ratified by American authorities, but prohibited by the European Commission.

Once it is established that a combination is subject to EC jurisdiction, the merging parties are required to notify the Commission prior to the implementation of the concentration. On receipt of the notification, the Commission publishes a note in the Official Journal of the European Communities, where third parties can comment on the proposed transaction.

After the notification of the Commission (and the receipt of all necessary information), phase- 1 proceedings are initiated. The EC then has 25 working days (which can be extended to a maximum of 35 working days) for an initial assessment of the merger. Based on this initial assessment the EC can clear the proposed merger (phase-1 clearance), clear it subject to remedies proposed by the merging parties (phase-1 remedy), or initiate a more in-depth investigation (phase-2 investigation) depending on whether the proposed transaction raises competitive concerns and depending on whether these can be addressed by initial remedies

\footnotetext{
${ }^{2}$ Council Regulation (EEC) No 4064/89 of 21 December 1989 on the control of concentrations between undertakings [Official Journal L 395 of 30 December 1989].

${ }^{3}$ ECU was replaced by Euro in 1998.

${ }^{4}$ Council Regulation (EC) No 1310/97 of 30 June 1997 [Official Journal L 180 of 9 July 1997] defines a community dimension when i) the combined aggregate worldwide turnover of all the undertakings concerned is more than EUR 2500 million; ii) in each of at least three Member States, the combined aggregate turnover of all the undertakings concerned is more than EUR 100 million; iii) in each of at least three Member States included for the purpose of point (b), the aggregate turnover of each of at least two of the undertakings concerned is more than EUR 25 million; and iv) the aggregate Community-wide turnover of each of at least two of the undertakings concerned is more than EUR 100 million, unless each of the undertakings concerned achieves more than two-thirds of its aggregate Community-wide turnover within one and the same Member State.
} 
or not. Furthermore, the merging parties can also withdraw the proposed merger during phase-1 (phase-1 withdrawal).

If the EC initiates an in-depth investigation, the phase-2 investigation may take up to 90 working days. Following this second investigation phase, the EC can again unconditionally clear the merger (phase-2 clearance), clear the merger subject to commitments by the merging parties (phase-2 remedy) or prohibit the merger (phase-2 prohibition). Again, the merging parties can also withdraw the proposed merger in phase-2 (phase-2 withdrawal). It is argued that withdrawing a merger in phase-2 of the investigation process is virtually equivalent to a prohibition as parties often withdraw a merger before an actual prohibition by the EC can take place (Bergman et al., 2005). Hence, both a prohibition as well as a phase- 2 withdrawal suggest that the EC and the notifying parties were unable to find suitable remedies to address the anti-competitive concerns of the proposed transaction. Thus, we thus consider prohibitions, phase-2 remedies, phase- 2 withdrawals, and phase-1 remedies as an intervention in our empirical analysis.

Significant changes to European merger control were introduced in 2004 through an amendment to ECMR with the aim of bringing merger control closer to economic principles: the concept of an efficiency defense was introduced, a chief economist was appointed, the timetable for remedies was improved and horizontal merger guidelines were issued. The reception of the new merger regulation was generally favorable (Lyons, 2004). One of the most significant changes was the change from the "dominance test" for market power in favor of a "significant impediment of effective competition test" (SIEC).

The pre-2004 dominance test required the creation or strengthening of a dominant position as a necessary condition for the prohibition of a merger. It is argued that the dominance test was deficient in cases of collective dominance and tacit collusion, and that the "substantial lessening of competition" test employed by the United States' Federal Trade Commission (FTC) would be preferable. After the 2004 reform, the test used by the European Commission can be most accurately described as a significant impediment of effective competition (SIEC) test, which is more closely aligned with US practice (Bergman et al., 2007; Szücs, 2012).

\subsection{Previous Literature}

Mergers are studied extensively, with a large body of both theoretical and empirical literature on questions such as firms' incentives to merge and merger policy effectiveness. In the present paper, we evaluate the time dynamics of the EC's decision procedures and how the importance of structural market parameters in motivating a particular merger decision evolved over time. Thus, this paper most closely relates to the literature that empirically studies the determinants of merger policy intervention decisions by competition authorities.

Most of the related literature - with the prominent exceptions of Bradford et al. (2018) and Mini (2018) - investigate the determinants of merger intervention decisions at the merger level and for a sample of merger cases only. The scope and depth of our data (see Section 3) allow us to go beyond the existing literature by, firstly, not relying on a sample of decisions but instead reporting patterns for the entire population of merger cases examined by DG Comp and, secondly, allowing for heterogeneity within merger cases by examining the individual product and geographic markets concerned. Furthermore, all of the existing literature uses

parametric models to empirically study the determinants of merger intervention decisions. We instead go one step further and use flexible, non-parametric machine learning techniques to study the heterogeneity in 
the association between the structural market parameters and the intervention decision.

Bergman et al. (2005) are the first to study the determinants of EU merger control. They employ a logit model for a sample of $96 \mathrm{EU}$ merger cases to estimate the likelihood of going to phase- 2 or prohibition decisions as a function of market-relevant and political variables. They find that decisions of the European Commission are only influenced by variables that directly affect welfare. In both estimated models (likelihood of phase-2 and likelihood of prohibition), the probability of intervention increases with the market share of the companies involved in the merger. Dummy variables indicating the possibility of post-merger joint dominance and the existence of entry barriers are also relevant determinants of the intervention decision while political/institutional variables are not significant. Bergman et al. (2010) examine instead similarities between EU and US merger decisions using a sample of horizontal phase-2 mergers between 1990-2004 for both the EU (109 cases) and the US (166 cases). They estimate a probit model for each regime to evaluate enforcement policy, where the dependent variable is an indicator for intervention (one for prohibition, approval subject to substantial remedies or withdrawal by the parties at least one month into the phase- 2 investigation). They find that market shares, the Herfindahl-Hirschman-Index (HHI), ${ }^{5}$ and entry barriers matter for the intervention decision. In a second step, they then apply the model of the EU authority to the US case sample and vice versa to predict the challenge probabilities for dominant firm unilateral effect cases if the other regime had decided the case. For dominance mergers, the study finds that the EU is tougher than the US on average, in particular for mergers with moderate market shares of the notifying parties. The US, on the other hand, seem to be more aggressive for coordinated interaction and non-dominance unilateral effects cases. In the most recent study, Bergman et al. (2016) update the dataset of Bergman et al. (2010) by adding observations both to the EU as well as the US dataset for the time period after the $2004 \mathrm{EU}$ merger policy reform. The final dataset, covering 1993-2013, used in the analysis contains a sample of 151 EU phase-2 cases and 260 US cases. Separate logit models on an intervention indicator variable are estimated for the EU cases (distinguishing pre- and post-reform) and US cases. Market shares and entry barriers are found to have a significant positive effect on the probability of intervention. As the EU merger reform increases the likelihood that the EC challenges a merger under a coordinated effects theory of harm and reduces the likelihood that a merger case will raise concerns under the dominance standard, it should affect the difference between EU and US policy. Predictions of interventions using the model of respectively the other jurisdiction (and distinguishing preand post-reform cases) show evidence of convergence between US and EU case decisions in unilateral effects mergers, where EU policy seems to be less aggressive post-reform.

Similar to this study, Szücs (2012) investigates the convergence between US and EU merger policy following the $2004 \mathrm{EU}$ merger policy reform. In particular, he uses a sample of $309 \mathrm{EU}$ and 286 US merger cases scrutinized by DG Comp and the FTC, respectively, between 1991 and 2008. For each of the pre-reform EU, post-reform EU and US merger samples, he estimates a logit model on the decision to intervene and then uses the estimated models to predict the probability of intervention for each merger case from the point of view of both competition authorities. Based on the decreasing differences in the predicted intervention probabilities between the EU and the US authorities over time, he concludes that EU and US merger policy are converging in the era following the 2004 EU merger policy reform. Both pre- and post-reform, barriers to entry as well as the existence of a dominant player in the market increase the likelihood of intervention. Post-reform, also the HHI has a positive and significant effect on intervention.

\footnotetext{
${ }^{5}$ The HHI is defined as the sum of squared market shares of all firms active in the market.
} 
Duso et al. (2013) evaluate European merger policy effectiveness along three dimensions: the predictability, correctness, and deterrence effects of a decision. Regarding predictability of European merger policy, Duso et al. (2013) estimate two probit models (one pre-reform, one post-reform) for a sample of $368 \mathrm{EU}$ merger cases where the intervention decision of DG Comp (remedies or prohibition) is a function of ex ante observable merger characteristics. Unlike the existing literature, they do not use characteristics derived from the decision itself but constructed by matching the merger data to firm-level data from Datastream and Compustat. Prior to the 2004 merger policy reform full mergers, conglomerate mergers, and mergers, where the parties have high market value, increase the probability of intervention while mergers involving US firms are less likely to be challenged. Post-reform, mergers between US firms, full mergers, and cross-border mergers, decrease the probability of intervention while conglomerate mergers are more likely to be challenged.

Mai (2016) studies the effect of the EU merger policy reform on the probability of a merger being challenged by DG Comp based on a sample of 341 phase- 1 and phase-2 horizontal mergers between 1990 and 2012. The probability of a challenge in a probit model pooling pre- and post-reform cases is driven by the market shares of the merging parties, entry barriers, and some other factors. Political factors, measured as the country of the merging firms, are found to be insignificant. The merger reform reduces the probability of challenge by between 8 and 16 percentage points. Mai (2016) also estimates separate pre- and post-reform models and applies the methodology used by Bergman et al. (2010), Szücs (2012), and Bergman et al. (2016) by predicting the probability of challenge for pre-reform mergers using the post-reform model and vice versa. The author finds that the EU merger policy seems to have slightly softened post-reform and that market shares and entry barriers are important predictors of challenge both pre- and post-reform. However, the importance of market shares is lower post-reform.

Two recent papers differentiate from the previous literature by significantly expanding the sample of mergers analyzed. Bradford et al. (2018) empirically investigate whether European merger control is used for protectionism. Similar to our data, they collect information on all merger cases scrutinized by DG Comp between 1990 and 2014. However, their analysis is still conducted at the level of the merger rather than the concerned product and geographic market. Furthermore, they do not collect information on the structural parameters of market shares, concentration, likelihood of entry, and foreclosure from the case documents. While the authors use control variables measuring relative market size and market concentration, both $\mathrm{HHI}$ as well as market size are based on European-wide industry sales data ${ }^{6}$ rather than on the market shares of merging parties and competitors as reported in the case documents. The authors find that DG Comp did not intervene more frequently or extensively in transactions involving non-EU or US-based firms. While transaction value, HHI, hostile takeovers, and whether the merger is horizontal increase the likelihood of intervention, mergers involving a financial sponsor, taking place in large markets, and being stock acquisitions are less likely to be challenged.

The paper that is most closely related to this study in terms of data is the study by Mini (2018). Similar to this paper and unlike all other studies, Mini (2018) also collected information on the universe of EU merger decisions from the publicly available case documents between 1990 and 2013, recording each market concerned by the transaction as a separate observation. Thus, for each merger, he records potentially many

\footnotetext{
${ }^{6} \mathrm{The} \mathrm{HHI}$ and market size variables are constructed based on European-wide sales at the two-digit NACE code industry level from the Amadeus data base. Clearly, these measures are quite different from those calculated by the Commission itself in well-defined product and geographic markets.
} 
observations and collects similar merger and market level characteristics from the case documents as we do. He then estimates probit models at this concerned market level for horizontal overlap markets, interacting all explanatory variables with a post-reform indicator variable. In the first model, the main variables of interest are the merging parties' market shares and the change in market shares, while in the second he focuses on post-merger HHI as well as the change in HHI due to the merger. Similarly to Bergman et al. (2010), Szücs (2012), Bergman et al. (2016) and Mai (2016), he uses the models to predict how the estimated pre-reform model would have handled post-reform cases, decomposing observed differences into policy and case mix effects. He concludes that while the EC changed neither its stance towards mergers to quasi-monopoly or monopoly nor towards mergers in unconcentrated markets, it has challenged fewer mergers due to unilateral concerns for mid ranges of market shares and HHI post-reform. Unlike previous studies (and also the present data), rather than using the midpoints of the market share ranges reported in the case documents, Mini (2018) constructs the expected market shares and expected HHI from the reported market share ranges. Thus, the author highlights the issue of measurement error in market shares and HHI and how to explicitly account for it in estimation.

Thus, Mini (2018) is the only paper that studies the determinants of merger policy interventions at the relevant product and geographic market level based on the population of European merger decisions as we do. However, we focus on a different aspect in our analysis by studying the heterogeneity in the association between structural market parameters and other merger and market characteristics and the intervention decision by DG Comp. To this end, we use flexible, non-parametric machine learning techniques and, in particular, show how the association between structural market parameters and the intervention decision has evolved over time. Unlike the existing literature, we let the data determine time patterns rather than imposing different pre- and post-reform models.

\section{Data and Descriptives}

The data contain almost the entire population of DG Comp's merger decisions, both in the dimension of time and with regard to the scope of the decisions encompassed. The data were obtained from the publicly accessible cases published by DG Comp on the EC's webpage. ${ }^{7}$ We started data collection with the very first year of common European merger control, 1990, and included all years up to 2014. This amounts to data on the first 25 years of European merger control.

Rather than taking a particular merger case as the level of observation, we collected data at a more fine-grained level and defined an observation as a particular product and geographic market combination concerned by a merger.

For the analysis in this study, we dropped cases that were referred back to member states as well as phase- 1 withdrawals. ${ }^{8}$ The final dataset used in the estimation contains 5,109 DG Comp merger decisions, where each decision includes a number of observations equal to the number of product/geographic markets affected in the specific transaction. The dataset contains a total of 30,995 market level observations. For

\footnotetext{
${ }^{7}$ The types of notified mergers, decisions taken and reports for each of the EC's decisions can be downloaded from: http://ec. europa.eu/competition/mergers/cases/ and http://ec.europa.eu/competition/mergers/legislation/simplified_procedure. html.

${ }^{8}$ We only have information on two phase- 1 withdrawals in the data.
} 
further details on the merger database as well as the data collection procedure, we refer the reader to the data documentation (Affeldt et al., 2018).

The data set contains information on the name and country of the merging parties (acquirer and target), the date of the notification, the date of the decision ${ }^{9}$ and the type of decision eventually taken by DG Comp (clearance, remedy, and prohibition) or whether the proposing parties withdrew the notification. The data also allow us to distinguish between a policy action taking place in the initial (phase-1) or second phase (phase-2) of the merger review process.

Figure 1 shows the number of yearly merger notifications, phase- 1 merger cases, mergers cleared subject to remedies (phase-1 and phase-2) and prohibitions between 1990 and 2014. Overall, merger notifications show an increasing trend with a big drop around 2002. Most of the notified mergers are decided in phase-1: Phase-1 mergers track the number of notifications very closely. The number of mergers cleared subject to remedies increased dramatically after 1996 and oscillates between 10 and 25 per year in more recent years. The number of prohibitions varies between zero and three prohibitions per year.

The dataset further contains information on the nature of mergers. Variables for full mergers and joint ventures indicate whether DG Comp considered the case to be a full merger ( $55 \%$ of the notified mergers) and/or a joint venture (37\% of the mergers); these are reported in Table 1.

Further indicator variables for vertical and conglomerate transactions indicate whether a product/geographic market is vertically affected by the merger ( $26 \%$ of the concerned markets) and whether the merger is conglomerate in nature in the particular concerned market ( $2 \%$ of the concerned markets), see Table 2.

Table 1: Summary Statistics Indicator Variables at Merger Level, 1990-2014

\begin{tabular}{lcccc}
\hline & 0 & 1 & mean & sd \\
\hline Intervention & 4,742 & 367 & 0.07 & 0.258 \\
Full merger & 2,293 & 2,816 & 0.55 & 0.497 \\
Joint Venture & 3,228 & 1,881 & 0.37 & 0.482 \\
\hline
\end{tabular}

Furthermore, the dataset contains information on the geographic market definition adopted in each market by DG Comp. In about $58 \%$ of the concerned markets the geographic market is defined as national, in about $20 \%$ it is considered to be EU wide, in only $10 \%$ it is defined as a worldwide market while in about $12 \%$ of the cases the geographic market definition is left open (see Table 2).

We also observe which markets DG Comp considered to be problematic. The variable concern indicates the geographic and product markets affected by the merger, in which competitive concerns arose. This is the case in about $11 \%$ of markets. Further indicator variables record whether DG Comp considered barriers to entry to exist and whether DG Comp raised concerns that the merger would foreclose other firms in a particular market. As Table 2 shows, DG Comp considered entry barriers to exist in about $12 \%$ of the concerned markets, while risk of foreclosure was present in about $3 \%$ of markets.

The database also contains a count of the number of competitors in the concerned market and an indicator variable equal to one if no information on competitors is available. Merging parties face, on average,

\footnotetext{
${ }^{9}$ Note that the notification of a merger and the decision do not necessarily take place in the same year. We calculate the number of notifications based on the notification year and the number of decisions of a certain type based on the decision year.
} 
Figure 1: Enforcement History of DG Comp Merger Cases, 1990-2014

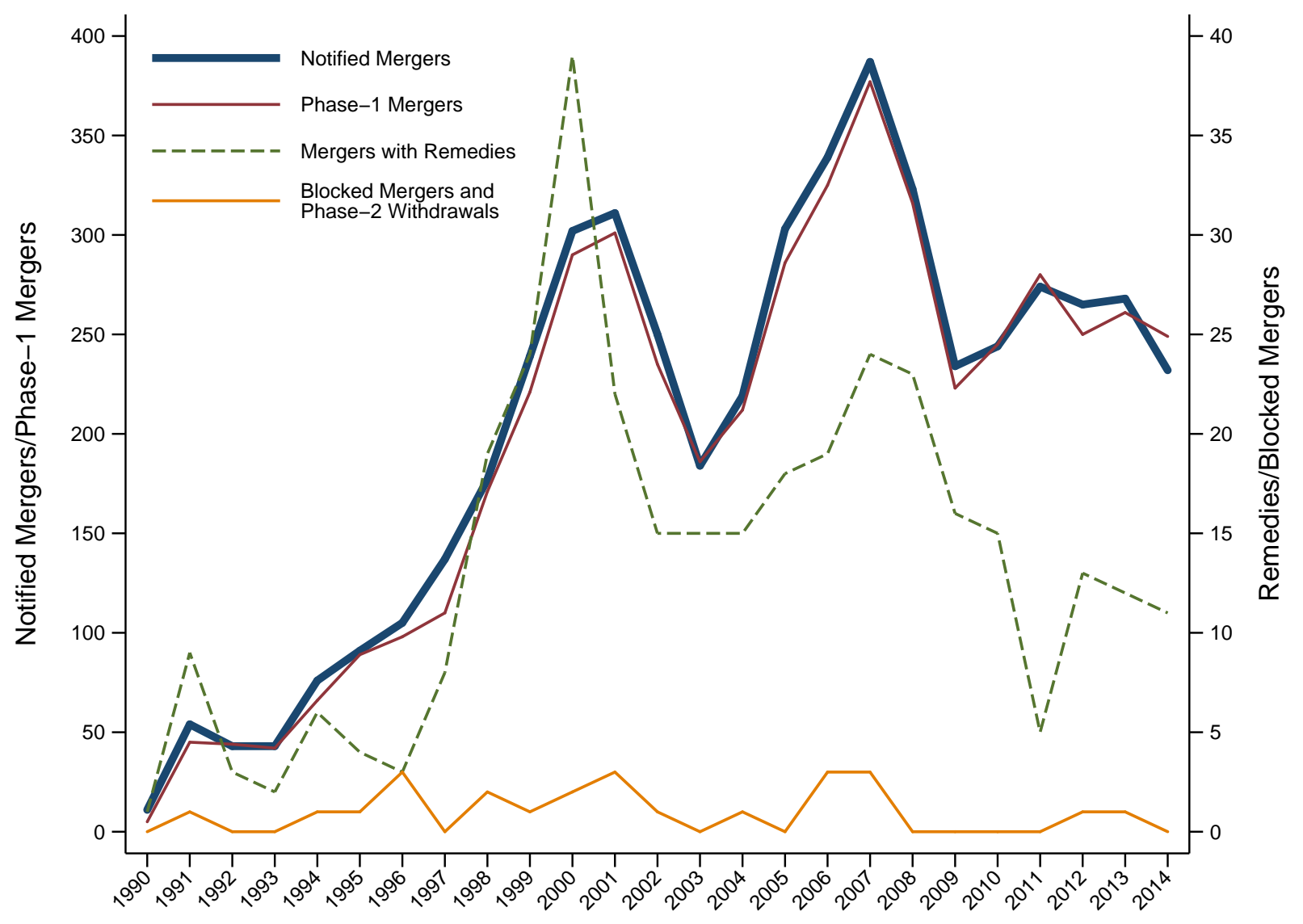

We report notified cases per notification year and phase- 1 cases per decision year (left axis) as well as remedies (phase- 1 and phase-2) and prohibitions per decision year (right axis). We exclude phase- 1 withdrawals from the count of phase-1 mergers and include phase-2 withdrawals in the count of prohibitions. We exclude all cases where the decision type is "other."

1.6 competitors, with the number of competitors varying between 0 and 34 . However, information on competitors is missing in about $56 \%$ of the markets - these are mainly mergers that were cleared in phase- 1 . We also include a variable indicating the complexity of a particular merger case, measured as the count of product/geographic markets concerned by the merger. A merger affects on average 6 geographic/product markets, ranging between one and 245 concerned markets.

Where available, data on the market shares of the merging parties were collected from DG Comp's competitive assessment in the decision document. Data availability is thus constrained by the extent of DG Comp's analysis. Market share information is collected at the level of the relevant product/geographic market combination. This information allows the calculation of the merging parties' combined market shares, the $\mathrm{HHI}$ and the change in HHI. ${ }^{10}$

\footnotetext{
${ }^{10}$ Since DG Comp generally reports only a range of market shares in the publicly available documents, we defined the market shares to be equal to the central value of the interval. If for example the market share range indicated is [0-10] percent, we record a market share of
} 
Table 2: Summary Statistics Indicator Variables at Market Level, 1990-2014

\begin{tabular}{lcccc}
\hline & 0 & 1 & mean & sd \\
\hline Concerns & 27,675 & 3,320 & 0.11 & 0.309 \\
Vertical merger & 22,802 & 8,193 & 0.26 & 0.441 \\
Conglomerate merger & 30,472 & 523 & 0.02 & 0.129 \\
National market & 12,990 & 18,005 & 0.58 & 0.493 \\
EU wide market & 24,741 & 6,254 & 0.20 & 0.401 \\
Worldwide market & 28,037 & 2,958 & 0.10 & 0.294 \\
Left open market & 27,218 & 3,777 & 0.12 & 0.327 \\
Entry barriers & 27,423 & 3,572 & 0.12 & 0.319 \\
Risk of foreclosure & 30,184 & 811 & 0.03 & 0.160 \\
No competitor information & 13,733 & 17,262 & 0.56 & 0.497 \\
\hline
\end{tabular}

Table 3 shows summary statistics for the market share related variables. The merging parties' average joint market share is 33\%, with average post-merger HHI between 2,148 and 5,639 depending on the calculation method. ${ }^{11}$ The mean change in HHI due to the merger is about 445 , ranging from 0 to 8,450 . As Table 3 shows, market share information is not available for all observations: while joint market share and HHI information is available for about 23,000 out of the 31,000 observations, the change in HHI due to the merger can be calculated for only about 13,000 observations.

Table 3: Summary Statistics Continuous Variables at Market Level

\begin{tabular}{lccccc}
\hline & mean & sd & min & max & observations \\
\hline Joint market share & 32.5 & 23.6 & 0 & 100 & 22,812 \\
Post-merger HHI (low) & 2147.7 & 2368.3 & 0 & 10,000 & 22,812 \\
Post-merger HHI (high) & 5639.0 & 2251.1 & 650 & 10,000 & 22,812 \\
Delta HHI & 444.7 & 779.1 & 0 & 8,450 & 12,875 \\
Number of Competitors & 1.6 & 2.3 & 0 & 34 & 30,995 \\
\hline
\end{tabular}

Lastly, the data include information on the main industry in which a merger took place. The industry is identified by NACE codes, which is the industry classification system used by the European Union to classify different economic activities. For the empirical analysis, we group the industries into 25 groups, as shown in Table 4, where some NACE codes are grouped together but, primarily, the manufacturing industry has been

5 percent. If however the interval given in the decision is only 5 percentage points wide, we report the conservative lower market share bound. If for example the market share interval is [15-20] percent, we report 15 percent market share. Therefore, we cannot avoid that market shares contain measurement error; however this is an issue that this study shares with the existing literature. To our knowledge, Mini (2018) is the only one who, rather than using the midpoints of the market share ranges reported in the case documents, constructs the expected market shares and expected HHI from the reported market share ranges. Thus, he highlights the issue of measurement error in market shares and HHI, explicitly accounting for it in estimation.

${ }^{11}$ We calculate two different HHI measures. The variable Post-merger HHI (low) is a lower bound of the post-merger HHI: it is calculated as the square of the merging parties' joint market share plus the sum of squared market shares of competitors, whenever information on competitors' market shares is available. This assumes that competitors are very small whenever market share information of competitors is not available but market shares do not add up to $100 \%$. The variable Post-merger HHI (high), on the other hand, is an upper bound for the post-merger HHI: it adds the square of all missing market shares (100\% minus all available market share information) to Postmerger HHI (low). This hence treats all missing market share information as one missing competitor. In our empirical analysis, we use Post-merger HHI (high). 
further divided into smaller subgroups. In 150 merger cases, the industry code was missing. For these cases, we went back to the decision documents and manually classified the mergers into the 25 industry groups according to our best judgement.

Table 4: Industry Groups, 1990-2014

\begin{tabular}{|c|c|c|}
\hline Industry Group & obs & cases \\
\hline accomodation and food service & 192 & 64 \\
\hline agriculture, forestry, fishing, mining & 1,106 & 173 \\
\hline arts, other services, households as employers & 392 & 55 \\
\hline electricity, gas, steam & 1,381 & 280 \\
\hline financial service activities & 960 & 249 \\
\hline information and communication & 1,304 & 259 \\
\hline insurance and pensions & 925 & 237 \\
\hline manufacturing (coke, petroleum, chemicals) & 3,827 & 401 \\
\hline manufacturing (computer, electronics, optical products) & 1,702 & 247 \\
\hline manufacturing (food, beverages, tobacco) & 1,845 & 230 \\
\hline manufacturing (furnitures, other manufacturing) & 669 & 52 \\
\hline manufacturing (machinery and equipment) & 865 & 173 \\
\hline manufacturing (metals and metallic products) & 1,113 & 219 \\
\hline manufacturing (motor vehicles, trailers, transport equipment) & 1,539 & 302 \\
\hline manufacturing (pharmaceuticals) & 2,068 & 106 \\
\hline manufacturing (rubber, plastic, non-metallic) & 1,086 & 165 \\
\hline manufacturing (textiles, clothes, leather) & 169 & 31 \\
\hline manufacturing (wood, paper, printing) & 1,031 & 152 \\
\hline public administration, education, human health, social work & 169 & 47 \\
\hline real estate, professional activities, administrative service activities & 1,162 & 254 \\
\hline repair, installation of machinery and equipment & 1,046 & 200 \\
\hline telecommuications & 1,090 & 224 \\
\hline transporting and storage & 2,729 & 329 \\
\hline water supply, waste management, construction & 520 & 152 \\
\hline wholesale and retail trade & 2,105 & 508 \\
\hline Total & 30,995 & 5,109 \\
\hline
\end{tabular}

Note that all of these merger and market characteristics are characteristics, as stated in DG Comp's decision documents. As such, they reflect, to some extent, the assessment, subjective views, and potential mistakes of DG Comp. However, this issue is present in all papers in the empirical literature on the determinants of merger decisions.

The final merger sample contains information on 5,109 merger cases concerning 30,995 markets. For the analysis at the merger level, we take the mean value across concerned markets for those variables that vary at the market level.

\section{Linear probability model}

In this section, we explore the association between merger characteristics and the intervention decision by DG Comp within a parametric approach. We first replicate the results of the existing literature, which explain a competition authority's decision as a function of merger characteristics at the merger level. In contrast 
to previous studies, we explicitly estimate different models in various sub-samples to assess the issue of sample selection, which could arise because some important indicators - prominently market share and concentration measures - are only observable for ca. $60 \%$ of the mergers. Second, as a merger often affects many different markets, while its characteristics and effects on competition can be heterogeneous across these affected markets, we investigate in a second step the correlation between merger characteristics and DG Comp's intervention decision at the market level. Lastly, in order to allow for heterogeneity in the correlation between merger characteristics and intervention decisions, we look at the evolution of these relationships over time.

\subsection{Methodology}

We employ a linear probability model to estimate the relationship between merger characteristics and the intervention decisions of DG Comp. ${ }^{12}$

The dependent variable is an indicator variable for whether DG Comp intervened following a merger notification. We define the indicator variable intervention to be equal to one if DG Comp prohibited the merger, cleared the merger subject to remedies in phase-1, cleared the merger subject to remedies in phase-2, or the merging parties withdrew the merger proposal in phase-2. As Table 1 shows, DG Comp intervened in 367 out of the 5,109 merger cases in the estimation dataset (i.e. $7 \%$ of mergers).

The estimation equation for the probability of intervention at the merger level is:

$$
P_{j}\left(Y_{j}=1 \mid X_{j}, \bar{X}_{i j}, \eta_{m_{j}}, \eta_{t_{j}}\right)=\beta_{0}+\beta_{1} X_{j}+\beta_{2} \bar{X}_{i j}+\eta_{m_{j}}+\eta_{t_{j}}+\epsilon_{j}
$$

where $i$ refers to a particular concerned market, $j$ refers to a merger, $m_{j}$ refers to an industry group, and $t_{j}$ refers to the year when merger $j$ took place. The merger characteristics $X_{j}$ vary at the merger level, while $X_{i j}$ are market-specific characteristics within merger $j$. In the merger-level regressions, we use the average of market-level variables $\left(\bar{X}_{i j}\right)$.

This approach naturally extends to the level of the individual markets. Thus, in a second step, we estimate the correlation between market and merger characteristics and DG Comp's assessment at the level of the concerned product/geographic market. Instead of estimating the overall probability of intervention, the dependent variable used in the estimation at the market level is concern, which is a dummy variable indicating that a specific product/geographic market $i$ affected by merger $j$ raised competitive concerns according to DG Comp. As Table 2 shows, DG Comp raised competitive concerns in about $11 \%$ of the concerned markets.

The estimation equation for the probability of competitive concerns at the market level is:

$$
P_{i j}\left(Y_{i j}=1 \mid X_{j}, X_{i j}, \eta_{m_{j}}, \eta_{t_{j}}\right)=\beta_{0}+\beta_{1} X_{j}+\beta_{2} X_{i j}+\eta_{m_{j}}+\eta_{t_{j}}+\epsilon_{i j}
$$

where the unit of observation is now the concerned market $i$ in merger $j$ rather than the merger $j$ itself, $X_{j}$ are the characteristics varying at the merger level, while $X_{i j}$ are the characteristics varying at the market level.

\footnotetext{
${ }^{12}$ We decided to use a linear probability model rather than a probit or logit specification for easy interpretability of the estimated coefficients as well as the possibility to include industry fixed effects.
} 
Lastly, we explore the heterogeneity in the correlation between merger characteristics and competitive concerns by DG Comp over time. We run separate OLS regressions at the market level dividing the dataset into sub-samples based on the notification year.

The explanatory variables of primary interest are four determinants of competitive concerns that are expected to drive DG Comp's intervention decision. The so called structural market parameters - market shares, concentration, the likelihood of entry, and the likelihood of foreclosure - are measured as follows:

- Indicator variable for high post-merger concentration: equal to one if post-merger HHI is above 2000 and the change in HHI is larger than $150 .{ }^{13}$

- Indicator variable for joint market share: equal to one if the merging firms' joint market share is above $50 \%$ in the concerned market. ${ }^{14}$

- Indicator variable barriers to entry: equal to one if DG Comp considered barriers to entry to exist in the concerned market.

- Indicator variable risk of foreclosure: equal to one if DG Comp raised concerns that the merger would foreclose other firms in a particular market.

In addition to these four determinants of competitive concerns of a merger, we control for further merger characteristics. We include the market definition indicator variables for national, EU wide, and worldwide geographic markets as well as all information on the type of merger available in the data. Specifically, we use indicator variables for vertical mergers, conglomerate mergers, full mergers, and joint ventures; the count of the number of competitors in concerned markets; an indicator variable for whether information on competitors is missing in the data as well as a measure of the complexity of the merger measured by a count of the concerned markets.

Lastly, we include different industry and year fixed effects, depending on the specification. Industry dummy variables are defined for the 25 different industry groups as presented in Table 4 . For the OLS regressions at the merger and market level, we include a set of industry-year fixed effects, controlling for unobserved time-varying industry specific factors. ${ }^{15}$ For the regressions that explore the heterogeneity in the correlation between merger characteristics and competitive concerns over time, we regrouped the years 1990-1994 into one group for the sample splits, as there are relatively few merger cases in these early years of European merger control. In each of the year-specific OLS regressions, we include industry fixed effects. We corrected the error term by clustering standard errors at the industry group level.

\footnotetext{
${ }^{13}$ We used the variable Post-merger HHI (high) for the construction of the indicator variable. Results obtained with Post-merger HHI (low) are qualitatively similar.

${ }^{14}$ We also run models where we use the level of the market shares rather than the dummy variable for high market shares. Results are similar. We decided to use the dummy for comparability with the approach based on machine learning discussed in Section 5.

${ }^{15}$ As a robustness check, we use industry and year fixed effects separately and include a set of time-varying control variables at the industry based on Worldscope data (e.g., mean size, mean total assets, mean Tobit's q, mean R\&D...) as suggested by Clougherty and Seldeslachts (2013) and Clougherty et al. (2016). However, this does not qualitatively change the results.
} 


\subsection{Estimation Results}

\subsubsection{Determinants of Intervention - Merger Level}

We present four specifications run at both the merger and market levels. Specification 1 is run on the full dataset without including the market share variables. Hence, this specification basically includes all mergers decided by DG Comp. Market share and concentration information is not available for all cases. If we include the market share variables in the regression, the sample size decreases significantly. However, the change in the estimated coefficients could be driven by selection (market share information is most frequently missing for phase-1 clearances) rather than just by the inclusion of the additional explanatory variables. Hence, specifications 2 and 3 present the results for the same specification as 1 split into those cases without information on market shares (specification 2) and those with information on market shares (specification 3 ). Lastly, specification 4 adds the indicator variables for joint market share above $50 \%$ and high concentration to specification 3 .

Table 5 contains the regressions at the merger level. Reassuringly, we find that the EC's decision determinants are rather similar across all four sub-samples considered: the share of markets where entry barriers exist, the number of markets rising concerns, as well as the total number of markets affected by the merger increase the probability of a challenge. While the size of the effects is relatively constant for the number of markets affected, the impact of barriers to entry is almost $50 \%$ larger in cases where no market share information was gathered.

Neither merger characteristics (full mergers and joint ventures) nor the variables indicating alternative theories of harm (foreclosure concerns, vertical mergers, conglomerate mergers) significantly affect the Commission's decisions. Interestingly, the size of the concerned markets (national, EU wide, worldwide) also has no effect. In the full sample (column 1), we find some evidence for more challenges after the 2004 reform, but the coefficient is not precisely estimated in the other samples. Finally, in the sample including market share information (column 4), the indicator for a joint market share above $50 \%$ has no effect whereas the indicator pertaining to HHIs strongly and significantly increases the probability of challenge. Mergers in markets with HHIs above 2000 that entail an HHI increase of at least 150 are almost $9 \%$ more likely to be remedied or blocked.

\subsubsection{Determinants of Concern - Market Level}

Table 6 contains the same sets of regressions at the concerned market level. In general, more covariates appear to be significantly associated with competitive concerns at the market level than what is observed at the merger level. While this might be a statistical results due to the larger number of observations in these regressions, it is likely that the aggregation to the merger level hides some of the EC's more fine-grained considerations concerning specific markets.

In line with the merger level regressions, we find that barriers to entry increase the likelihood of competitive concerns at the market level as well. In addition, the risk of foreclosure also has a positive and significant, though smaller, effect. Joint ventures appear to be treated more leniently. Market size now plays a more decisive role, with national markets increasing the probability of concerns in all specifications except (2). While the total number of competitors (across all markets) was insignificant at the merger level, the number of 
Table 5: Linear Probability Model for Intervention (Merger Level)

\begin{tabular}{|c|c|c|c|c|}
\hline & $\begin{array}{c}(1) \\
\text { Full sample } \\
\text { no market shares }\end{array}$ & $\begin{array}{c}(2) \\
\text { Selected sample } \\
\text { no market share info }\end{array}$ & $\begin{array}{c}(3) \\
\text { Selected sample } \\
\text { market share info }\end{array}$ & $\begin{array}{c}(4) \\
\text { Selected sample } \\
\text { market share info }\end{array}$ \\
\hline $\begin{array}{l}\text { mean barriers to } \\
\text { entry }\end{array}$ & $\begin{array}{c}0.2673^{* * *} \\
(0.0560)\end{array}$ & $\begin{array}{c}0.3793^{* * *} \\
(0.0786)\end{array}$ & $\begin{array}{l}0.2278^{* *} \\
(0.0899)\end{array}$ & $\begin{array}{c}0.2127^{* *} \\
(0.0857)\end{array}$ \\
\hline $\begin{array}{l}\text { mean risk of } \\
\text { foreclosure }\end{array}$ & $\begin{array}{c}0.0145 \\
(0.0691)\end{array}$ & $\begin{array}{l}-0.0289 \\
(0.0878)\end{array}$ & $\begin{array}{c}0.0016 \\
(0.1115)\end{array}$ & $\begin{array}{c}0.0040 \\
(0.1087)\end{array}$ \\
\hline fullmerger & $\begin{array}{l}-0.0019 \\
(0.0194)\end{array}$ & $\begin{array}{c}0.0170 \\
(0.0116)\end{array}$ & $\begin{array}{l}-0.0079 \\
(0.0483)\end{array}$ & $\begin{array}{l}-0.0044 \\
(0.0472)\end{array}$ \\
\hline joint venture & $\begin{array}{l}-0.0150 \\
(0.0159)\end{array}$ & $\begin{array}{c}0.0147 \\
(0.0105)\end{array}$ & $\begin{array}{l}-0.0321 \\
(0.0464)\end{array}$ & $\begin{array}{l}-0.0283 \\
(0.0449)\end{array}$ \\
\hline $\begin{array}{l}\text { mean } \\
\text { conglomerate merger }\end{array}$ & $\begin{array}{l}-0.0051 \\
(0.0471)\end{array}$ & $\begin{array}{c}0.0404 \\
(0.0770)\end{array}$ & $\begin{array}{l}-0.0222 \\
(0.0735)\end{array}$ & $\begin{array}{l}-0.0238 \\
(0.0740)\end{array}$ \\
\hline $\begin{array}{l}\text { mean vertical } \\
\text { merger }\end{array}$ & $\begin{array}{l}-0.0024 \\
(0.0107)\end{array}$ & $\begin{array}{c}0.0155 \\
(0.0145)\end{array}$ & $\begin{array}{l}-0.0269 \\
(0.0240)\end{array}$ & $\begin{array}{l}-0.0067 \\
(0.0241)\end{array}$ \\
\hline $\begin{array}{l}\text { mean market } \\
\text { definition national }\end{array}$ & $\begin{array}{c}0.0103 \\
(0.0075)\end{array}$ & $\begin{array}{l}-0.0059 \\
(0.0047)\end{array}$ & $\begin{array}{c}0.0171 \\
(0.0646)\end{array}$ & $\begin{array}{c}0.0143 \\
(0.0621)\end{array}$ \\
\hline $\begin{array}{l}\text { mean market } \\
\text { definition EU wide }\end{array}$ & $\begin{array}{c}0.0202 \\
(0.0137)\end{array}$ & $\begin{array}{c}0.0079 \\
(0.0111)\end{array}$ & $\begin{array}{c}0.0068 \\
(0.0589)\end{array}$ & $\begin{array}{c}0.0066 \\
(0.0578)\end{array}$ \\
\hline $\begin{array}{l}\text { mean market } \\
\text { definition worldwide }\end{array}$ & $\begin{array}{l}-0.0158 \\
(0.0120)\end{array}$ & $\begin{array}{l}-0.0069 \\
(0.0113)\end{array}$ & $\begin{array}{c}-0.0343 \\
(0.0781)\end{array}$ & $\begin{array}{l}-0.0382 \\
(0.0767)\end{array}$ \\
\hline $\begin{array}{l}\text { number of } \\
\text { concerned markets }\end{array}$ & $\begin{array}{c}0.0036^{* * *} \\
(0.0005)\end{array}$ & $\begin{array}{c}0.0030^{* * *} \\
(0.0011)\end{array}$ & $\begin{array}{c}0.0030^{* * *} \\
(0.0009)\end{array}$ & $\begin{array}{c}0.0031^{* * *} \\
(0.0008)\end{array}$ \\
\hline $\begin{array}{l}\text { percentage of } \\
\text { markets with concerns }\end{array}$ & $\begin{array}{c}0.9375^{* * *} \\
(0.0623)\end{array}$ & $\begin{array}{c}0.7312^{* * *} \\
(0.1094)\end{array}$ & $\begin{array}{c}0.9681^{* * *} \\
(0.1107)\end{array}$ & $\begin{array}{c}0.9340^{* * *} \\
(0.1117)\end{array}$ \\
\hline $\begin{array}{l}\text { total number of } \\
\text { competitors in all product markets }\end{array}$ & $\begin{array}{c}0.0004 \\
(0.0004)\end{array}$ & $\begin{array}{c}0.0003 \\
(0.0008)\end{array}$ & $\begin{array}{c}0.0008 \\
(0.0005)\end{array}$ & $\begin{array}{c}0.0006 \\
(0.0005)\end{array}$ \\
\hline $\begin{array}{l}\text { Post reform } \\
\text { indicator }\end{array}$ & $\begin{array}{l}0.0333^{* *} \\
(0.0147)\end{array}$ & $\begin{array}{c}0.0042 \\
(0.0069)\end{array}$ & $\begin{array}{c}0.1169 \\
(0.0824)\end{array}$ & $\begin{array}{l}0.1384^{*} \\
(0.0768)\end{array}$ \\
\hline $\begin{array}{l}\text { joint market } \\
\text { share above } 50 \%\end{array}$ & & & & $\begin{array}{l}-0.0009 \\
(0.0481)\end{array}$ \\
\hline $\begin{array}{l}\mathrm{HHI} \geq 2000 \\
\& \text { delta HHI } \geq 150\end{array}$ & & & & $\begin{array}{c}0.0881^{* * *} \\
(0.0169)\end{array}$ \\
\hline Constant & $\begin{array}{c}-0.0541^{* * *} \\
(0.0177)\end{array}$ & $\begin{array}{c}-0.0211^{* *} \\
(0.0090)\end{array}$ & $\begin{array}{l}-0.1110 \\
(0.0913)\end{array}$ & $\begin{array}{c}-0.2210^{* *} \\
(0.0924)\end{array}$ \\
\hline $\begin{array}{l}\text { Industry Group Year FE } \\
\text { R2 }\end{array}$ & $\begin{array}{c}\text { Yes } \\
0.609\end{array}$ & $\begin{array}{c}\text { Yes } \\
0.557\end{array}$ & $\begin{array}{c}\text { Yes } \\
0.682\end{array}$ & $\begin{array}{c}\text { Yes } \\
0.689\end{array}$ \\
\hline Observations & 5,109 & 3,665 & 1,444 & 1,444 \\
\hline
\end{tabular}

We report heteroskedasticity robust standard errors clustered at the industry group level.

Significance at the $1 \%, 5 \%$, and $10 \%$ levels is represented by ***** and * respectively. 
competitors in a specific market decreases the probability of competitive concerns in all four specifications. When the EC does not collect information on competitors, i.e. it does not spend too much time and effort to define the relevant market, the likelihood of concerns is expectedly lower.

Finally, in the sub-sample with market share information, both market power indicators now significantly raise the chance of concerns: a joint market share in excess of $50 \%$ increases it by almost a quarter, while the HHI indicator increases it by $10 \%$.

\subsubsection{Determinants of Concern - Market Level - Split Sample over Time}

We explore the heterogeneity in the correlation between merger characteristics and competitive concerns by DG Comp over time by running separate OLS regressions splitting the market-level dataset over years (regrouping notification years 1990-1994). ${ }^{16}$ For each of the sub-samples, we run specification 4 of the previous regressions - hence, the indicator variables for high concentration and joint market share above $50 \%$ are included as explanatory variables in all regressions. Although this decreases the sample size, we consider market share and concentration to be important determinants of merger decisions, thus these are included in the analysis. As discussed in the previous section, while the estimated coefficients might differ across samples, the relevant determinants of intervention or competitive concerns are the same across the different subsamples.

In this section, we only present regression coefficient plots for our four main explanatory variables of interest. The underlying regression results are found in Appendix A.1. Note that we have relatively few observations from 2014 that include market share information. For this subsample, the barriers to entry indicator perfectly predicts the outcome variable of competitive concerns. We therefore show coefficient plots only up to and including the year 2013.

Figure 2 shows the impact of the HHI indicator. With few exceptions, coefficient estimates are positive but only significantly during the years 1999-2001, as well as in 2003, 2005, and 2007. Thus, in the last six years of the data, 2008 - 2013, high concentration was not a significant determinant of competitive concerns.

In Figure 3, we repeat the exercise focusing on the time dynamics of the joint market share of the merging parties. The impact of market share on competitive concerns was - with the exception of 2006 - consistently significant and positive from 1996 to 2009. The coefficient estimates are roughly twice the size of those associated with the concentration indicator presented above, suggesting that a high market share of the merging parties carries more weight in DG Comp's assessment than overall high concentration. However, similarly to the concentration measure, the importance of market shares seems to have declined after 2009.

\footnotetext{
${ }^{16}$ We also explore whether the correlation between the main variables of interest and concerns identified by DG Comp differs across industries. We ran analogous specifications splitting the sample over industries rather than time. OLS regression results, as well as coefficient plots equivalent to the ones shown here, are found in Appendix A.2.
} 
Table 6: Linear Probability Model for Concern (Market Level)

\begin{tabular}{|c|c|c|c|c|}
\hline & $\begin{array}{c}(1) \\
\text { Full sample } \\
\text { no market shares }\end{array}$ & $\begin{array}{c}\text { (2) } \\
\text { Selected sample } \\
\text { no market share info }\end{array}$ & $\begin{array}{c}\text { (3) } \\
\text { Selected sample } \\
\text { market share info }\end{array}$ & $\begin{array}{c}(4) \\
\text { Selected sample } \\
\text { market share info }\end{array}$ \\
\hline $\begin{array}{l}\text { barriers to } \\
\text { entry in submarket }\end{array}$ & $\begin{array}{c}0.3856^{* * *} \\
(0.0558)\end{array}$ & $\begin{array}{c}0.3408^{* * *} \\
(0.0856)\end{array}$ & $\begin{array}{c}0.4067^{* * *} \\
(0.0485)\end{array}$ & $\begin{array}{c}0.3160^{* * *} \\
(0.0406)\end{array}$ \\
\hline $\begin{array}{l}\text { risk of } \\
\text { foreclosure in submarket }\end{array}$ & $\begin{array}{l}0.2066^{* *} \\
(0.0956)\end{array}$ & $\begin{array}{c}0.2958^{* *} \\
(0.1248)\end{array}$ & $\begin{array}{l}0.1849^{*} \\
(0.0921)\end{array}$ & $\begin{array}{l}0.1777^{*} \\
(0.0951)\end{array}$ \\
\hline fullmerger & $\begin{array}{l}-0.0375 \\
(0.0250)\end{array}$ & $\begin{array}{l}-0.0071 \\
(0.0263)\end{array}$ & $\begin{array}{l}-0.0615 \\
(0.0373)\end{array}$ & $\begin{array}{l}-0.0586 \\
(0.0347)\end{array}$ \\
\hline joint venture & $\begin{array}{c}-0.0656^{* *} \\
(0.0244)\end{array}$ & $\begin{array}{l}-0.0218 \\
(0.0285)\end{array}$ & $\begin{array}{c}-0.1192^{* * *} \\
(0.0323)\end{array}$ & $\begin{array}{c}-0.1061^{* * *} \\
(0.0301)\end{array}$ \\
\hline $\begin{array}{l}\text { conglomerate } \\
\text { merger in submarket }\end{array}$ & $\begin{array}{c}0.0201 \\
(0.0372)\end{array}$ & $\begin{array}{c}0.0302 \\
(0.0469)\end{array}$ & $\begin{array}{c}0.0259 \\
(0.0355)\end{array}$ & $\begin{array}{c}0.0140 \\
(0.0353)\end{array}$ \\
\hline $\begin{array}{l}\text { vertical merger } \\
\text { in submarket }\end{array}$ & $\begin{array}{l}-0.0024 \\
(0.0100)\end{array}$ & $\begin{array}{c}0.0240 \\
(0.0180)\end{array}$ & $\begin{array}{c}-0.0410^{* * *} \\
(0.0128)\end{array}$ & $\begin{array}{l}-0.0135 \\
(0.0125)\end{array}$ \\
\hline $\begin{array}{l}\text { market } \\
\text { definition national }\end{array}$ & $\begin{array}{c}0.0182^{* * *} \\
(0.0049)\end{array}$ & $\begin{array}{c}0.0042 \\
(0.0076)\end{array}$ & $\begin{array}{c}0.0690^{* * *} \\
(0.0239)\end{array}$ & $\begin{array}{c}0.0634^{* * *} \\
(0.0213)\end{array}$ \\
\hline $\begin{array}{l}\text { market } \\
\text { definition EU wide }\end{array}$ & $\begin{array}{l}-0.0108 \\
(0.0087)\end{array}$ & $\begin{array}{c}0.0007 \\
(0.0129)\end{array}$ & $\begin{array}{c}0.0039 \\
(0.0246)\end{array}$ & $\begin{array}{c}0.0264 \\
(0.0248)\end{array}$ \\
\hline $\begin{array}{l}\text { market } \\
\text { definition worldwide }\end{array}$ & $\begin{array}{c}0.0076 \\
(0.0163)\end{array}$ & $\begin{array}{c}0.0176 \\
(0.0224)\end{array}$ & $\begin{array}{c}0.0245 \\
(0.0252)\end{array}$ & $\begin{array}{c}0.0496^{* *} \\
(0.0224)\end{array}$ \\
\hline $\begin{array}{l}\text { number of } \\
\text { concerned markets }\end{array}$ & $\begin{array}{c}0.0001 \\
(0.0003)\end{array}$ & $\begin{array}{l}-0.0001 \\
(0.0005)\end{array}$ & $\begin{array}{c}0.0002 \\
(0.0004)\end{array}$ & $\begin{array}{c}0.0000 \\
(0.0003)\end{array}$ \\
\hline $\begin{array}{l}\text { number of } \\
\text { competitors }\end{array}$ & $\begin{array}{c}-0.0099^{* * *} \\
(0.0030)\end{array}$ & $\begin{array}{c}-0.0066^{* * *} \\
(0.0020)\end{array}$ & $\begin{array}{c}-0.0116^{* * *} \\
(0.0040)\end{array}$ & $\begin{array}{c}-0.0080^{* *} \\
(0.0036)\end{array}$ \\
\hline $\begin{array}{l}\text { indicator no } \\
\text { info on competitors }\end{array}$ & $\begin{array}{c}-0.0652^{* * *} \\
(0.0152)\end{array}$ & $\begin{array}{c}-0.0358^{* * *} \\
(0.0124)\end{array}$ & $\begin{array}{c}-0.0792^{* * *} \\
(0.0230)\end{array}$ & $\begin{array}{c}-0.0502^{* *} \\
(0.0202)\end{array}$ \\
\hline $\begin{array}{l}\text { Post reform } \\
\text { indicator }\end{array}$ & $\begin{array}{l}-0.1916 \\
(0.1300)\end{array}$ & $\begin{array}{l}-0.0332 \\
(0.0305)\end{array}$ & $\begin{array}{l}-0.3779 \\
(0.2222)\end{array}$ & $\begin{array}{l}-0.3113 \\
(0.2339)\end{array}$ \\
\hline $\begin{array}{l}\text { joint market } \\
\text { share above } 50 \%\end{array}$ & & & & $\begin{array}{c}0.2313^{* * *} \\
(0.0226)\end{array}$ \\
\hline $\begin{array}{l}\mathrm{HHI} \geq 2000 \\
\& \text { delta } \mathrm{HHI} \geq 150\end{array}$ & & & & $\begin{array}{c}0.1043^{* * *} \\
(0.0134)\end{array}$ \\
\hline Constant & $\begin{array}{l}0.2355^{*} \\
(0.1360)\end{array}$ & $\begin{array}{c}0.0640^{* *} \\
(0.0279)\end{array}$ & $\begin{array}{l}0.4508^{*} \\
(0.2417)\end{array}$ & $\begin{array}{c}0.2658 \\
(0.2557)\end{array}$ \\
\hline $\begin{array}{l}\text { Industry Group Year FE } \\
\text { R2 } \\
\text { Observations }\end{array}$ & $\begin{array}{c}\text { Yes } \\
0.377 \\
30,995\end{array}$ & $\begin{array}{c}\text { Yes } \\
0.410 \\
18,185\end{array}$ & $\begin{array}{c}\text { Yes } \\
0.401 \\
12,810\end{array}$ & $\begin{array}{c}\text { Yes } \\
0.473 \\
12,810\end{array}$ \\
\hline
\end{tabular}

We report heteroskedasticity robust standard errors clustered at the industry group level.

Significance at the $1 \%, 5 \%$, and $10 \%$ levels is represented by $* * * * *$ and ${ }^{*}$ respectively. 
Figure 2: OLS Regression Coefficient on High Concentration over Time

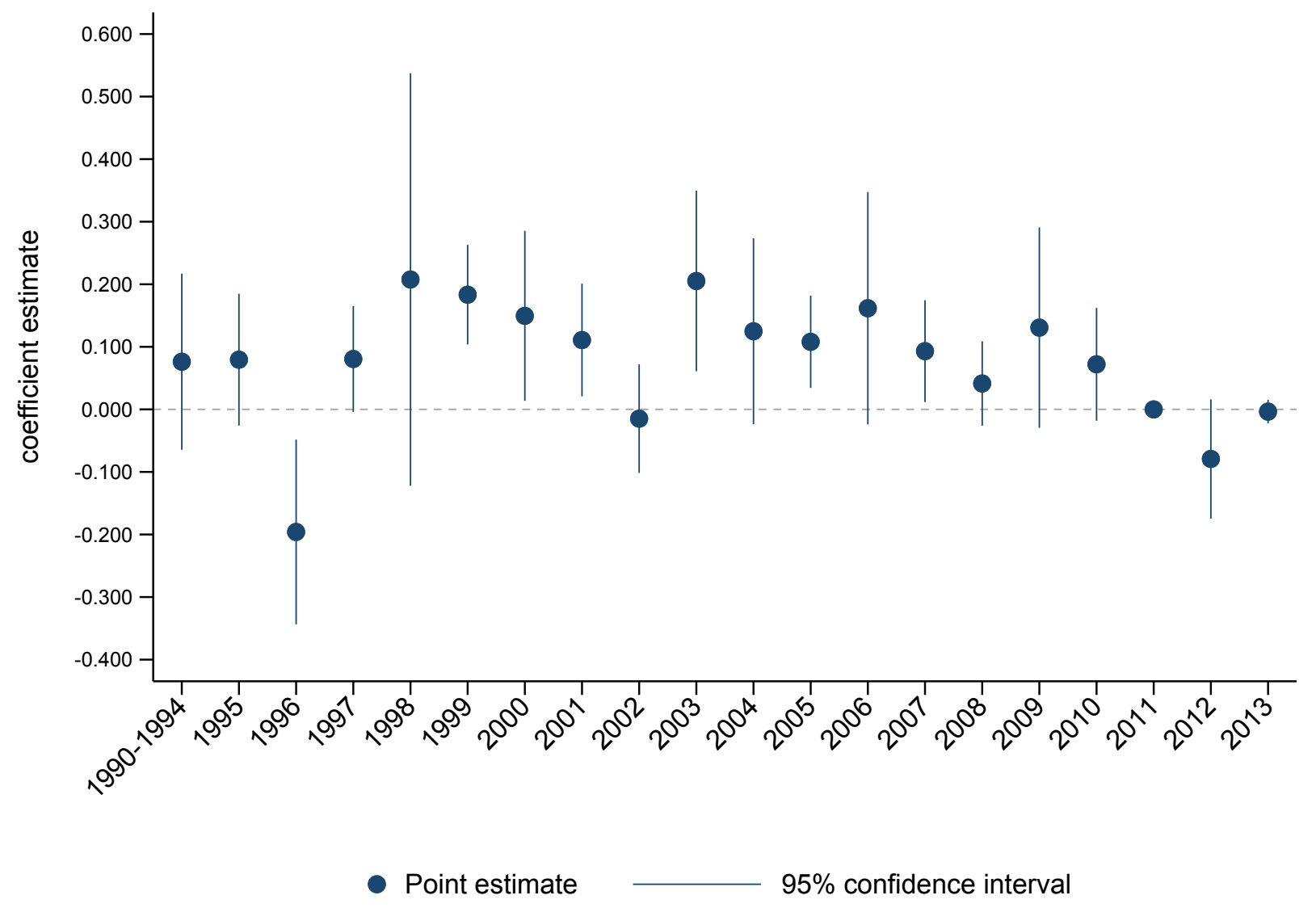

Regression coefficient on indicator variable for post-merger HHI above 2000 and change in HHI due to the merger larger than 150 in OLS regression on concerns. Each reported coefficient stems from a separate regression for the respective time period. Confidence intervals are based on heteroskedasticity robust standard errors clustered at the industry group level.

Figure 4 reports the coefficient estimates for barriers to entry in different time periods. Similar to market shares, barriers to entry were consistently associated with a higher probability of intervention for a long period of time (1998 to 2009, with the exception of 2007). The size of the effect is, on average, even larger than that of market shares. As with market shares and high concentration, the importance of barriers to entry seems to have declined in the last years of the data. 
Figure 3: OLS Regression Coefficient on Joint Market Share over Time

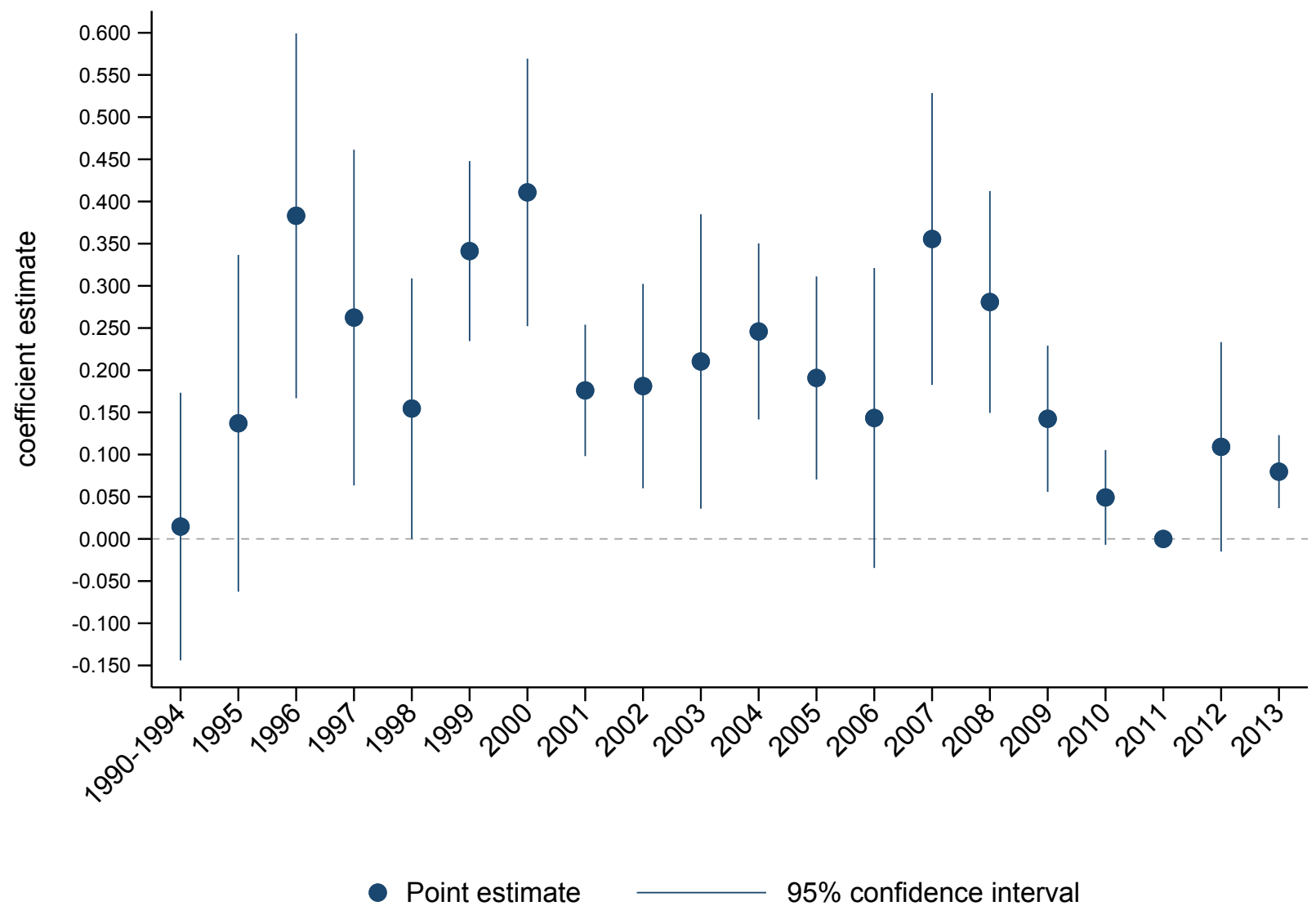

\begin{abstract}
Regression coefficient on indicator variable for joint market share above 50\% in OLS regression on concerns. Each reported coefficient stems from a separate regression for the respective time period. Confidence intervals are based on heteroskedasticity robust standard errors clustered at the industry group level.
\end{abstract}

Finally, in Figure 5 we report the period-specific coefficients associated with foreclosure concerns. While the coefficients are positive and, in a few periods, significant, no clear pattern seems to emerge. Note that the coefficients reported as zero without confidence intervals indicate years, in which no cases with foreclosure concerns were handled. 
Figure 4: OLS Regression Coefficient on Barriers to Entry over Time

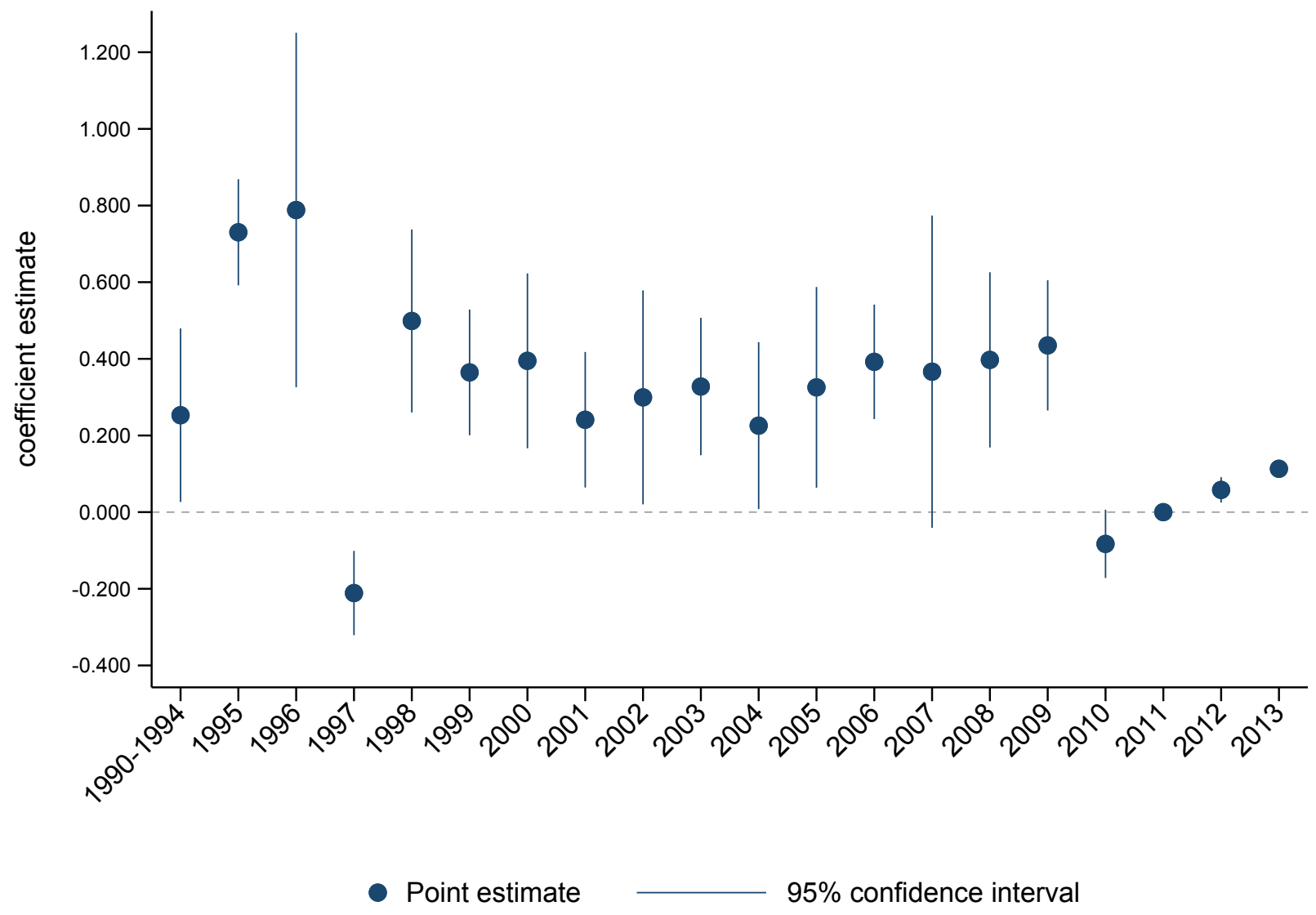

Regression coefficient on barriers to entry in OLS regression on concerns. Each reported coefficient stems from a separate regression for the respective time period. Confidence intervals are based on heteroskedasticity robust standard errors clustered at the industry group level.

\section{Machine Learning/Causal Forests}

In Section 4, we explore the association between concentration, market shares, entry barriers, and the risk of foreclosure with the intervention decision by DG Comp parametrically. However, the correlation between these variables might differ for different types of mergers. We try to investigate this heterogeneity by running separate regressions over time and industries. In this section, we take the idea of heterogeneous effects one step further by employing machine learning techniques. Specifically, we use the causal forest algorithm developed by Athey and Imbens (2016), Wager and Athey (2017), and Athey et al. (2017) to explore the heterogeneity in these correlations non-parametrically. Causal forests are a flexible tool to uncover heterogeneous effects, in particular when there are many covariates and potentially complex interactions between them. They allow getting the richest possible specification supported by the data. This has three main advantages.

First, this approach allows a much better modelling of the process that leads to a particular decision 
Figure 5: OLS Regression Coefficient on Risk of Foreclosure over Time

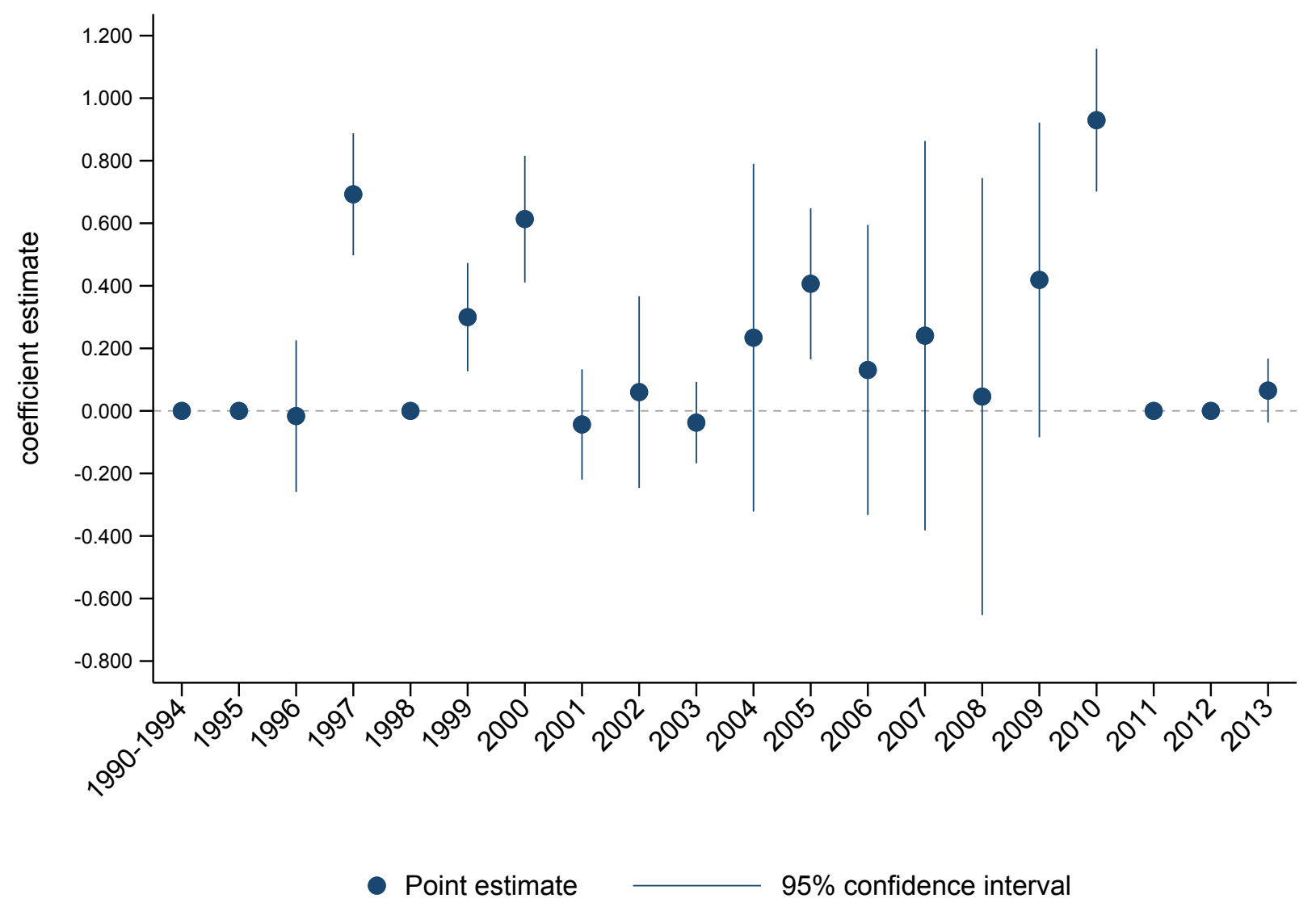

\footnotetext{
Regression coefficient on risk of foreclosure in OLS regression on concerns. Each reported coefficient stems from a separate regression for the respective time period. Confidence intervals are based on heteroskedasticity robust standard errors clustered at the industry group level.
}

by taking into account the specificities of each merger. As an example, consider that we want to measure the impact of high market shares on the likelihood that a market is considered problematic. In a factsbased approach, the Commission would surely consider that high market shares have a different impact if the market is narrowly defined or whether it is global in nature. Further, it is likely that industry specific information might also play a role: in national telecom markets, the role of high market shares is likely to be different than in a global manufacturing market. The strength of machine learning tools is that they allow determining the relevant interactions among covariates based on the observed data.

Second, by generating a more "saturated" model through the many interactions, this approach makes omitted variable bias less relevant than in the standard simple additive linear probability model discussed in the previous sections and used in the literature. While we still should be careful to interpret the coefficient estimates in a causal way, the potential bias in the coefficient estimates should be reduced. Put differently, the correlations that we retrieve are less spurious than in the OLS model. 
Third, this approach makes the exact definition of the considered variables less relevant. When building the database, we face the trade-off between defining simple and general variables comparable across thousands of different mergers and the need to better measure single aspects of a decision. Therefore, some of our key concepts are measured by means of simple dichotomous dummy variables rather than more complex metrics. While this might be more problematic in the model discussed in the previous sections, it is less relevant in the context of this model, where the covariates become complex interactions among all indicator variables.

\subsection{Methodology}

\subsubsection{Background on Heterogeneous Treatment Effects}

The main goal of our analysis is to understand how the effect of one explanatory variable (in the present application, concentration, market shares, entry barriers, and risk of foreclosure) on an outcome variable (in this application, the competitive concerns raised by DG Comp) varies with the nature of the merger, where the nature of the merger is described by all other merger and market characteristics included in the dataset. Hence, we want to explore the heterogeneity in the effect of a key parameter of interest. This question relates to the literature on heterogeneous treatment effects, where one major problem is the fear that researchers might iteratively search for subgroups with high treatment effects and only report results for these subgroups. The reported heterogeneity in treatment effects might then be purely spurious.

The causal tree and causal forest algorithms address this problem as they non-parametrically identify subgroups that have different treatment effects. The methodology lets the data discover the relevant subgroups without invalidating the confidence intervals constructed on the treatment effects within the subgroups (Athey and Imbens, 2016).

In the context of heterogeneous treatment effect estimation, the model to be estimated is:

$$
Y_{i j}=\tau\left(X_{i j}\right) W_{i j}+\mu\left(X_{i j}\right)+\epsilon_{i j}
$$

where $Y_{i j}$ is the outcome variable (binary in the present case) for market $i$ in merger $j, W_{i j}$ is a binary treatment variable (i.e. our structural indicators), $\tau\left(X_{i j}\right)$ is the effect of $W_{i j}$ on $Y_{i j}$ at point $X_{i j}$ in covariate space, and $\epsilon_{i j}$ is an error term that may be correlated with $W_{i j}$. Using the notation of the potential outcomes framework by Rubin (1974), the treatment effect can be written as:

$$
\tau(x)=\mathbf{E}\left[Y_{i j}^{1}-Y_{i j}^{0} \mid X_{i j}=x\right]
$$

where $Y_{i j}^{1}$ is the potential outcome for unit $i j$ under treatment -i.e. whether the EC identifies a concern when market shares are high - and $Y_{i j}^{0}$ is the potential outcome for unit $i j$ absent treatment -i.e. whether the EC identifies a concern when market shares are low - where one of the two is not observed. The aim is to estimate how the function $\tau(x)$ varies with the covariates $X$. As Athey et al. (2017) highlight, this is different from estimating a single parameter such as an average treatment effect while controlling for a large set of covariates, $X$.

The so-called unconfoundedness assumption implies that the treatment assignment $W_{i j}$ is independent 
of potential outcomes $Y_{i j}$ conditional on $X_{i j}$. This means that observations that are "close" in $X$-space can be treated as having come from a randomized experiment. Untreated observations that are close to the treated observation $i$ under consideration can then be used to predict the outcome $Y_{i j}^{0}$ absent the treatment. In these instances, methods such as nearest-neighbor matching or other local methods allow for consistently estimating $\tau(x)$.

Notice that this is essentially the same identification assumption used in the OLS model discussed above. Thus, exactly as in that model, the causal interpretation of $\tau(x)$ should be careful, as the structural indicators could be correlated to the error term because of omitted factors. However, as discussed above, the causal forest model might be expected to outperform the simple OLS model since it contains a larger sets of covariates. Nonetheless, we cannot claim that we estimate any causal effect of these variables on DG Comp's intervention decision. We rather estimate the correlation between these treatment variables $W_{i j}$ and the intervention decision $Y_{i j}$ and how this correlation varies with merger characteristics $X_{i j}$.

\subsubsection{Estimation using Causal Forests}

We use the causal forest algorithm by Athey et al. (2017) implemented in the generalized random forest (grf) package in $\mathrm{R}$ to investigate how the correlation between the treatment variables and DG Comp's intervention decision varies with merger characteristics. Causal forests are based on the random forest methodology by Breiman (2001). They were developed by Athey and co-authors in a series of papers (see Athey and Imbens (2016), Wager and Athey (2017), and Athey et al. (2017)), extending the regression tree and random forest algorithms so as to estimate average treatment effects for different subgroups, rather than predicting outcomes as is the case for regression trees and random forests.

In a standard regression tree, the aim is to predict individual outcomes $Y_{i j}$ using the mean outcome $Y$ of observations that are "close" in $X$-space. To determine which observations are "close," the algorithm starts to recursively split the covariate space (binary splits) until it is partitioned into a set of so-called leaves $L$ that contain only a few observations. The algorithm automatically decides on the splitting variables and split points based on an in-sample goodness-of-fit criterion such as a mean squared error (i.e. how close the predicted outcomes are to the actual outcomes). The outcome $Y_{i j}$ for observation $i j$ is then predicted by identifying the leaf containing observation $i j$ based on its characteristics $X_{i j}$ and setting the prediction to the mean outcome within that leaf. A random forest is essentially an ensemble of trees, where the predictions of outcomes $Y_{i j}$ are averaged across all trees in the forest to reduce variance and produce more robust predictions.

In case of a causal forest, we are not interested in predicting individual outcomes $Y_{i j}$ but individual treatment effects $Y_{i j}^{1}-Y_{i j}^{0}$ to study how treatment effects vary by subgroup. This implies that standard fit measures used in regression trees and random forests, such as the mean squared error, are not available since one of the potential outcomes and hence the actual treatment effect is never observed. However, the causal forest methodology builds on regression tree methods in that it also applies a "goodness-of-fit" criterion in treatment effects to decide on splits. Athey and Imbens (2016) show that the mean squared error function of a causal tree can be estimated and is a function of the variance of the estimated treatment effect. Basically, the goodness-of-fit measure to be minimized rewards a partition of the data for finding strong heterogeneity in treatment effects and penalizes a partition for high variance in leaf estimates. Minimizing the expected 
mean squared error of predicted treatment effects (rather than the infeasible mean squared error), is shown to be equivalent to maximizing the variance of the predicted treatment effects across leaves with a penalty for within-leaf variance (variance of treatment and control group mean outcomes within leaves).

Within a causal tree, the conditional average treatment effects are then simply estimated as the difference of mean outcomes between treated and control observations within a leaf. Thus, causal trees are similar to nearest-neighbor methods as they also rely on the unconfoundedness assumption and use "close" observations to predict treatment effects. However, rather than defining closeness based on some pre-specified distance measure (such as Euclidean distance in $k$-nearest-neighbor matching), closeness is defined with respect to a decision tree and the closest control observations to $i j$ are those that fall in the same leaf.

A causal forest, is then essentially an ensemble of causal trees, which only uses a random subset of the full dataset to grow each individual causal tree. The causal forest algorithm by Athey et al. (2017) then weights nearby control observations according to the fraction of trees in which a control observation appears in the same leaf as the treated observation $i j$ (Athey et al., 2017). This implies that for each observation an individual treatment effect $\tau_{i j}$ can be estimated while in a causal tree all units assigned to a given leaf have the same estimated treatment effect (Wager and Athey, 2017).

Athey and Imbens (2016) further introduce so-called "honesty" in causal trees to ensure correct inference: the data is divided in half, where one-half of the data is used to build the tree (i.e. determine the splits in covariate space) and the other half is used to predict treatment effects. Wager and Athey (2017) extend this idea to causal forests and develop theory for inference in causal forests. Thus, the causal forest algorithm by Athey et al. (2017) does not only allow for predicting treatment effects but also for predicting confidence intervals.

The big advantage of causal trees and forests is that they allow the data to determine the relevant subgroups in a flexible, data-driven way without invalidating confidence intervals. This is particularly important in applications with many covariates and potentially complex interactions between these covariates that matter for measuring the effects. Wager and Athey (2017) also highlight that an advantage of trees is that the leaves can be narrower along some dimensions and wider along others, depending on how fast the signal is changing. For further technical background on the causal forest methodology and the implementation using the grf package, see Appendix A.3.

As for the regressions presented in Section 4, we run the causal forests at the market $(i j)$ rather than merger level $(j)$. The outcome variable is therefore the concern dummy variable that indicates which specific product/geographic market affected by the merger raised competitive concerns according to DG Comp. We run four different causal forests, each including one of the four determinants of competitive concerns that should influence DG Comp's intervention decision (the treatment variable in causal forest terminology). These are the same four indicator variables as those used in the previous regressions: high post-merger concentration, joint market share above $50 \%$, barriers to entry, and risk of foreclosure.

In addition to the treatment variable, each of the causal forests includes a set of covariates $X$ over which the correlation between the variable of interest and the outcome is allowed to vary. These are essentially the same as in the regression analyses of Section 4. Different from the regression analyses, we include the notification year as a continuous variable from 1990 to 2014 rather than year fixed effects, which allows the algorithm to determine the relevant binary splits over time. We include the market definition indicator variables for national, EU wide, and worldwide geographic markets as well as all information on the type of 
merger available in the data - vertical mergers, conglomerate mergers, full mergers, joint ventures, a count of the number of competitors in the concerned market as well as an indicator variable for whether information on competitors is missing in the data, and the complexity of the merger measured by a count of the concerned markets. Lastly, we include a set of industry fixed effects which are industry dummy variables for the 25 different industry groups defined as presented in Table 4.

Each of the causal forests is grown with a minimum node size of 10 and consists of 5000 trees. ${ }^{17}$ Also note that the dataset used for the estimation of the causal forests for barriers to entry and risk of foreclosure differs from the dataset used for the estimation of the causal forests for the high concentration and joint market share measures. The dataset where the treatment variable is based on market share information has fewer observations because market shares are not available for all mergers. See the discussion of the issue in Section 4.2.1.

\subsection{Estimation Results}

In this section, we present the results of the correlation analysis between the four main variables of interest and the competitive concerns by DG Comp using causal forests. While a causal forest allows for predicting conditional average treatment effects, we are not primarily interested in the average correlation between a variable of interest and the outcome variable, rather, we want to explore and visualize how this correlation varies over the covariate space $X$. We look in particular at how the correlation between high concentration, market shares, entry barriers, risk of foreclosure, and concerns identified by DG Comp varies over time and industry. We only show and discuss results for the variation over time here, predicted correlations across industries are shown in Appendix A.5 as variation across industries is relatively small.

In order to explore how the correlation between the treatment variable and the outcome varies with one dimension included in the covariates $X$, we need to hold all other variables included in $X$ constant and vary only the covariate of interest. ${ }^{18}$

The prediction plots below are obtained as follows: We generate a prediction dataset that contains the range of one $X$ variable of interest (here notification year), for which we want to explore the heterogeneity in the association between the treatment variable and the outcome variable. We set all the other covariates included in $X$ to their mean respectively median sample value. ${ }^{19}$ We then predict the treatment effects at the data points of this prediction dataset using the causal forest grown and plot the treatment effect along with the point-wise $95 \%$ confidence intervals. In short, we take the mean/median merger in terms of all covariates, except time, and look at how the predicted correlation between for example the presence of entry barriers and competitive concerns varies if that mean merger had been notified in different years. ${ }^{20}$

\footnotetext{
${ }^{17}$ The term "minimum node size" is a bit misleading. The minimum node size in a causal forest is rather the minimum number of observations that must be part of a node in order for a split to be attempted. We ran causal forests for the entry barrier treatment using minimum node sizes of 5, 10, 15, 20,30, and 40 . The estimated conditional average treatment effect did not change much using these different node sizes.

${ }^{18}$ See also the example of the effect of child rearing on labor-force participation provided in Athey et al. (2017), where the mother's age at first birth and the father's income are varied while all other covariates are set to their median values.

${ }^{19}$ This also implies that indicator variables are set to their mean sample value; for example, the mean value of an industry dummy variable. This also explains the sometimes large difference in predictions setting all other covariates to mean or median values, since the median of a dummy variable will be either zero or one.

${ }^{20}$ Rather than taking the mean merger over the entire sample, we also created a prediction dataset based on the mean merger for which we have information on the market shares and concentration variables. We then used this prediction dataset to create alternative predictions based on the causal forests for high concentration and joint market share. As the predicted "treatment" effects did not change
} 
Once again, given that our treatment variables might be correlated with the error term, we interpret the predicted treatment as the correlation between this variable and the probability that DG Comp found competitive concerns in the affected market. Further, we discuss how this correlation varies over time.

\subsubsection{Treatment - High Concentration}

Figure 6 shows the predicted correlation between the high concentration indicator variable and competitive concerns of DG Comp over time setting all other covariates to their mean (dark blue), respectively median (light blue), value. The conditional average treatment effect predicted by the causal forest is 0.14 , which is slightly higher than the coefficient on the high concentration indicator in specification 4 in Table 6 . Compared to the patterns obtained based on the OLS estimates reported in Figure 2, the estimated effect of high concentration obtained with the causal forest is much smoother over time. This indicates that, once we use a richer model that better describes the process behind DG Comp's decisions, the impact of this structural indicator is less volatile and much more consistent over time.

Nonetheless, the importance of concentration appears to follow a downward trend over the years. The correlation between concentration and concerns is positive and mostly significant up to 2001, it seems to decrease since then and becomes insignificant in 2011. For the predicted correlation setting all other covariates to median rather than mean values, the drop in correlation in 2001/2002 is even more pronounced and insignificant as of 2001.

\subsubsection{Treatment - Joint Market Share above 50\%}

Figure 7 shows the predicted correlation between the indicator variable for merging parties' market shares above $50 \%$ and competitive concerns of DG Comp over time, as before setting all other covariates to their mean (dark blue), respectively median (light blue), value. The conditional average treatment effect predicted by the causal forest is 0.22 , which is similar to the coefficient on the joint market share indicator in specification 4 in Table 6.

Again, we find considerable heterogeneity in the predicted correlation between the market share indicator and concerns over time. While the predicted correlation is positive and significant up until 2010 (at least setting all other covariates to their mean), market shares seem to become a less important intervention decision criterion since the early 2000s and even become insignificant as of 2011. For the predicted correlation setting all other covariates to median rather than mean values, the predicted correlation is even lower and mostly insignificant since 2002. Notice again that, as for concentration, the correlations estimated by means of the causal forest seem to be much less volatile and more consistent over time than those estimated based on the simple linear probability model.

Putting the developments of the correlation between concentration and market share measures with the intervention decision by DG Comp together highlights the shift away from evaluating mergers based on structural indicators towards a more economics based approach.

by much, we only report the predictions based on the mean merger over the entire sample. 
Figure 6: Effect of High Concentration on Concerns over Time

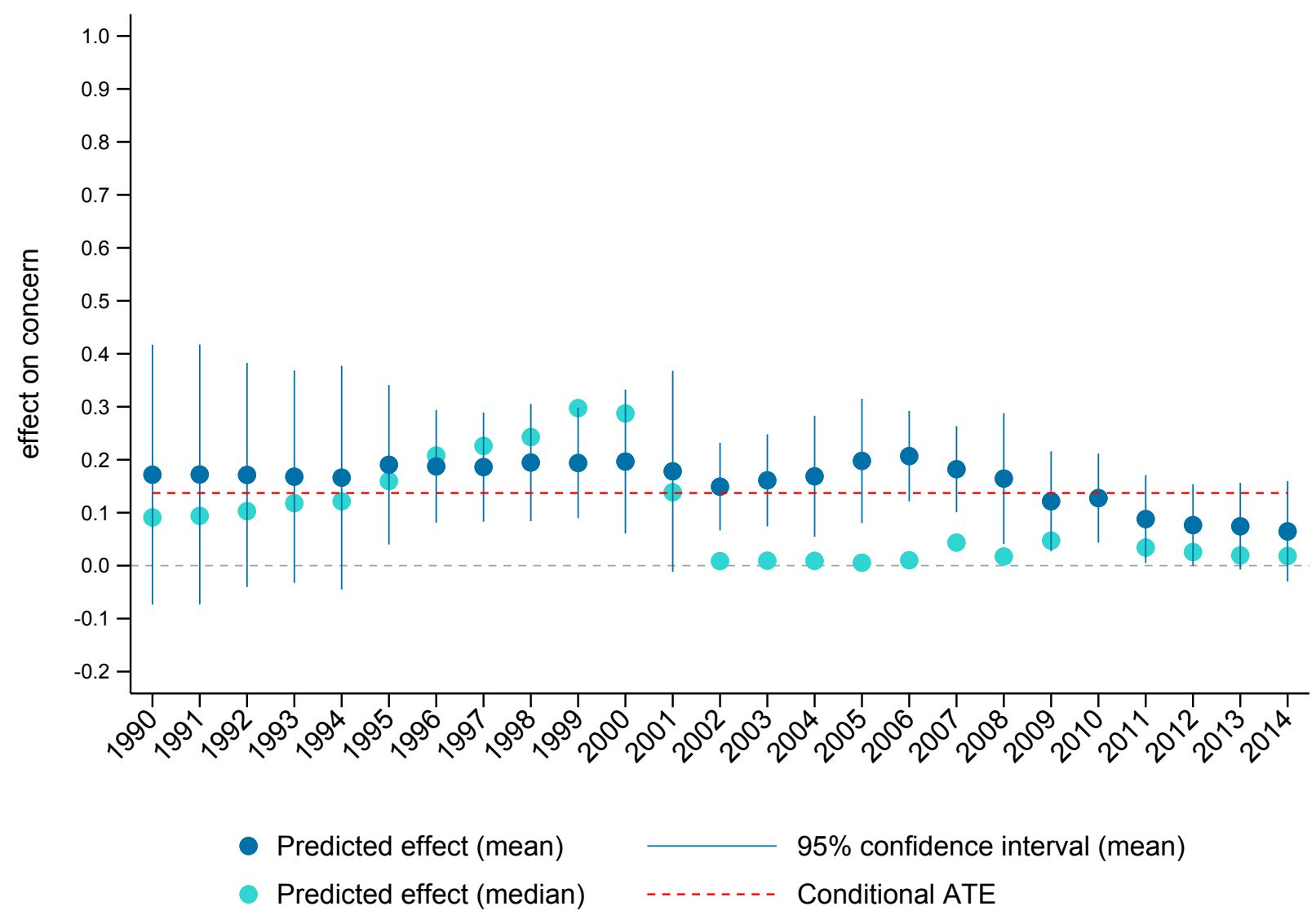

Predicted effect of indicator variable for post-merger HHI above 2000 and change in HHI larger than 150 on concerns over time, setting all other included explanatory variables equal to the sample mean/median.

\subsubsection{Treatment - Barriers to Entry}

Figure 8 shows the predicted correlation between the presence of entry barriers in the concerned market and competitive concerns of DG Comp over time, again setting all other covariates to their mean (dark blue), respectively median (light blue), value. The conditional average treatment effect predicted by the causal forest is 0.46 , which is higher than the coefficient on the entry barrier indicator in any specification in Table 6 .

Furthermore, there is considerable heterogeneity in the predicted correlation between the existence of entry barriers and competitive concerns over time. While the predicted correlation with concerns was essentially zero up to 1997, it becomes positive, significant, and of increasing importance since 1998. This development is also in line with the shift of DG Comp's merger policy toward a more economics based approach. 
Figure 7: Effect of Joint Market Share on Concerns over Time

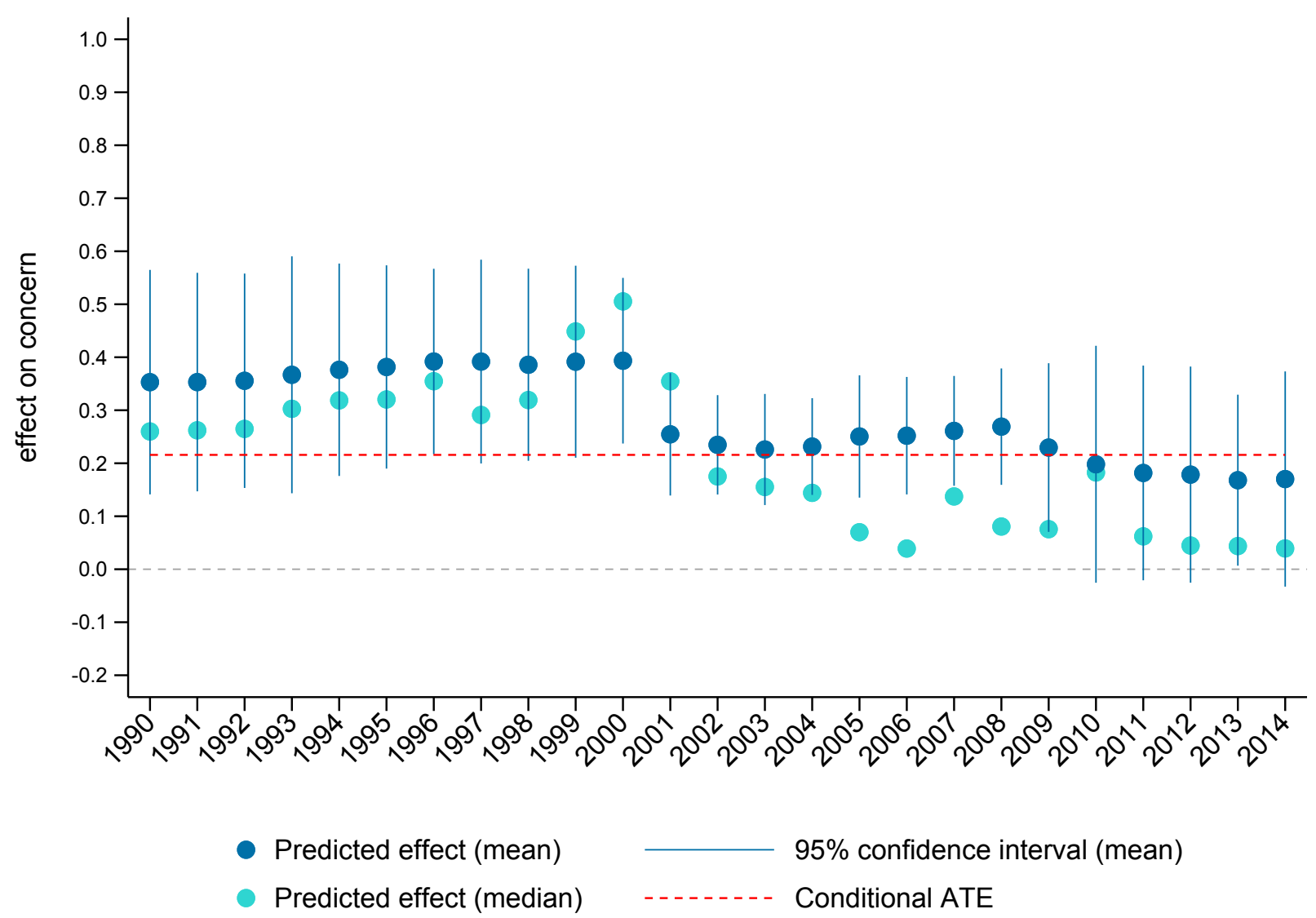

Predicted effect of indicator variable for joint market share above $50 \%$ on concerns over time, setting all other included explanatory variables equal to the sample mean/median.

\subsubsection{Treatment - Risk of Foreclosure}

Lastly, Figure 9 shows the predicted correlation between the indicator variable for risk of foreclosure in the concerned market and competitive concerns of DG Comp over time, setting all other covariates to their mean (dark blue), respectively median (light blue), value. The conditional average treatment effect predicted by the causal forest is 0.51 , which is more than the double of the coefficient on the foreclosure indicator in the specifications in Table 6.

However, as shown in Table 2, DG Comp considered risk of foreclosure to exist in only about $3 \%$ of the concerned markets. Consequently, the confidence intervals for the predicted correlation are very wide, especially in the early years with fewer merger cases, and no clear pattern for the relationship between risk of foreclosure and competitive concerns emerges. However, there is a positive and mostly significant correlation that, if anything, seems to become more important over time. 
Figure 8: Effect of Barriers to Entry on Concerns over Time

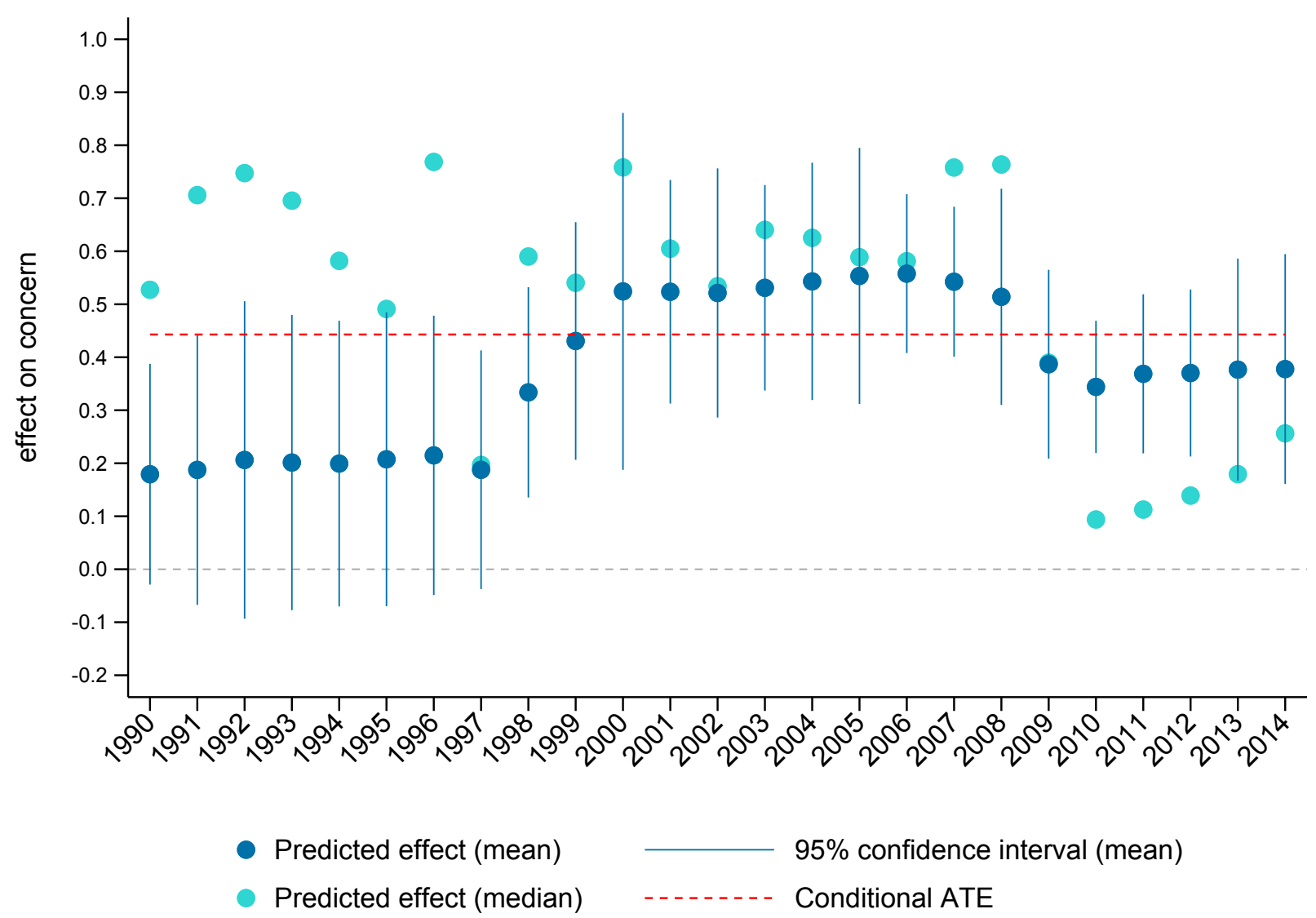

Predicted effect of barriers to entry on concerns over time, setting all other included explanatory variables equal to the sample mean/median.

\section{Conclusion}

In this paper, we study the time-dynamics of the EC's merger decision procedure over the first 25 years of European merger control using a new dataset containing all merger cases with an official decision documented by DG Comp (more than 5000 individual decisions). Specifically, we evaluate how consistently different arguments related to the structural market parameters - market shares, concentration, likelihood of entry, and foreclosure - are put forward to motivate a particular decision over time.

In a first step, and in line with the existing literature, we start by estimating the probability of intervention as a function of merger characteristics at the merger level. We find that the existence of barriers to entry, the increase of concentration measures and, in particular, the share of product markets with competitive concerns increase the likelihood of an intervention.

In order to obtain a more fine-grained picture of the decision determinants, we extend our analysis to the specific product and geographic markets concerned by a merger. Instead of estimating the overall prob- 
Figure 9: Effect of Risk of Foreclosure on Concerns over Time

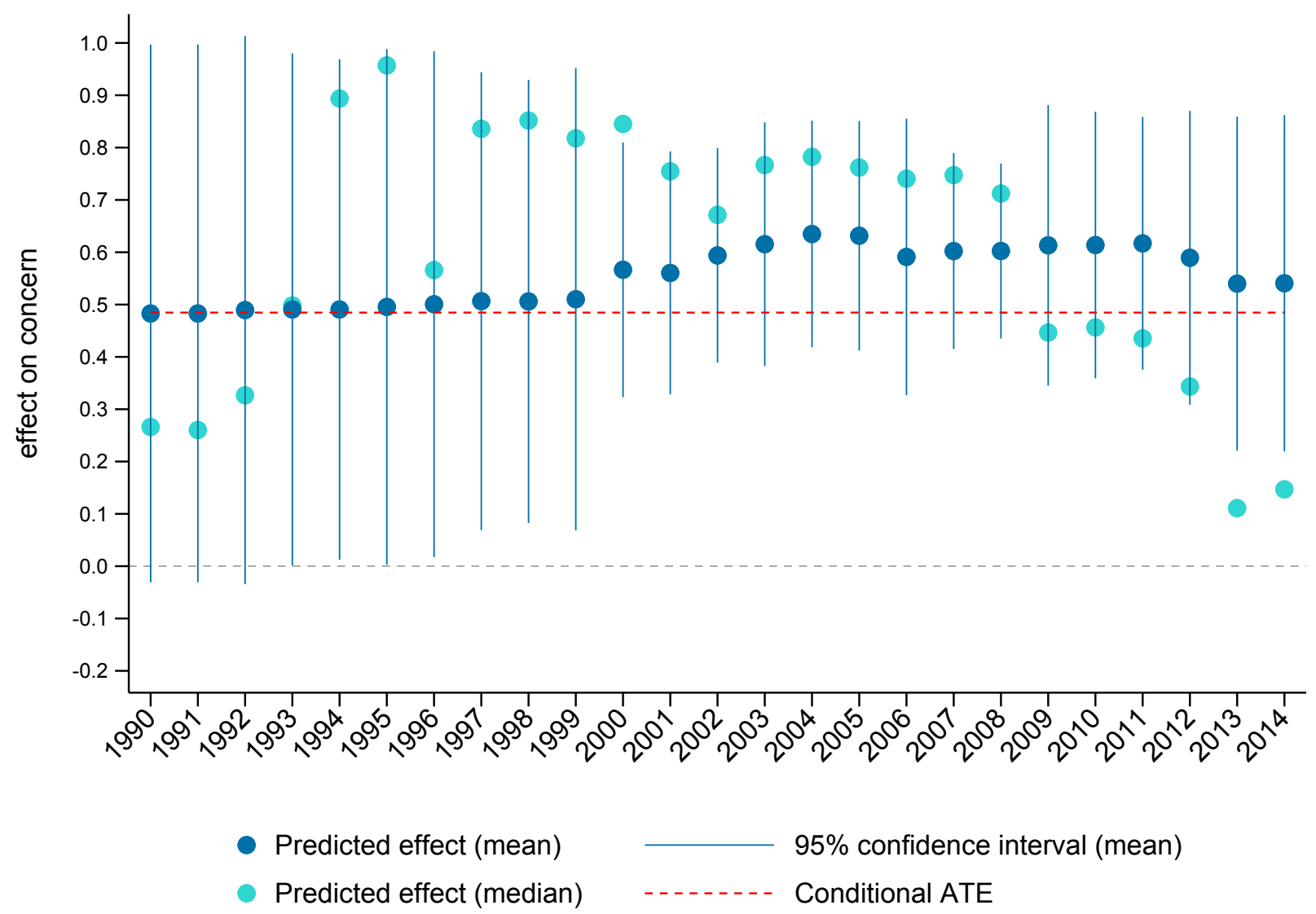

Predicted effect of risk of foreclosure on concerns over time, setting all other included explanatory variables equal to the sample mean/median.

ability of an intervention, we estimate the likelihood that competitive concerns are found in that specific product/geographical market (our data contain more than 30,000 affected markets). This step is particularly important because larger mergers typically affect many different product markets in many different geographic regions. Therefore, by analyzing individual markets we not only get more statistical power but we are also able to conduct a more disaggregate analysis. We find that more determinants significantly affect the Commission's competitive concerns at the market level than seen at the merger level. Thus, the aggregation to - and the analysis at - the merger level hides some of the EC's more fine-grained considerations concerning specific markets. We find that, again, barriers to entry, but also the risk of foreclosure play an important role for the competitive analysis. Moreover, while tightly defined (national) markets increase the probability of concerns, the number of active competitors decreases it. Finally, structural indicators of market shares and concentration have the expected effects, which are however more relevant than in the merger-level analysis.

After this static analysis, we assess how the impact of these key determinants changes over time. We 
generally find that the importance of market shares and concentration seems to have declined over time. However, the parametric estimations are quite volatile and do not allow for uncovering clear patterns over time.

In the final step, we use non-parametric prediction methods, in particular the causal forest algorithm proposed by Athey and Imbens (2016), to more precisely explore how the correlation between the structural market parameters and competitive concerns varies with all other merger and market characteristics. Predicting the relationship between one structural market parameter and competitive concerns over time using the trained causal forests and holding all other merger and market characteristics constant, allows us to uncover clearer patterns over time. In particular, we find that concentration as well as the merging parties' market shares have become less important decision determinants over time and are even insignificant in most recent years. On the other hand, the importance of barriers to entry as well as the risk of foreclosure have increased in DG Comp's merger assessment since the early 2000s. This is in line with the goals of the 2004 merger policy reform, which aimed at adopting a more economics based approach of merger assessment and, consequently, putting less weight on simple structural indicators, such as $\mathrm{HHI}$ and market share. 


\section{References}

Affeldt, P., T. Duso, and F. Szücs, "EU Merger Control Database: 1990-2014," DIW Berlin Data Documentation 95, 2018.

Athey, Susan and Guido Imbens, "Recursive partitioning for heterogeneous causal effects," Proceedings of the National Academy of Sciences of the United States of America, 2016, 113 (27), 7353-7360.

_ , Julie Tibshirani, and Stefan Wager, “Generalized Random Forests,” Mimeographed July 2017.

Bergman, Mats A, Malcolm B Coate, Maria Jakobsson, and Shawn W Ulrick, "Comparing Merger Policies: The European Union versus the United States," Potomac Papers in Law and Economics, 2007, (07-01).

Bergman, Mats A., Malcolm B. Coate, Maria Jakobsson, and Shawn W. Ulrick, "Comparing Merger Policies in the European Union and the United States," Review of Industrial Organization, 2010, 36 (4), 305-331.

Bergman, Mats A, Maria Jakobsson, and Carlos Razo, "An econometric analysis of the European Commission's merger decisions," International Journal of Industrial Organization, 2005, 23 (9-10), 717-737.

Bergman, Mats, Malcolm B. Coate, Anh Mai, and Shawn W. Ulrick, "Does Merger Policy Converge after the 2004 European Union Reforms?," Mimeographed September 2016.

Bradford, Anu, Robert J. Jackson, and Jonathan Zytnick, "Is E.U. Merger Control Used for Protectionism? An Empirical Analysis," Journal of Empirical Legal Studies, 2018, 15 (1), 165-191.

Breiman, Leo, “Random Forests," Machine Learning, 2001, 45 (1), 5-32.

Clougherty, Joseph and Jo Seldeslachts, "The Deterrence Effects of US Merger Policy Instruments," Journal of Law, Economics and Organization, 2013, 29, 1114-1144.

_ , Tomaso Duso, Miyu Lee, and Jo Seldeslachts, "Effective European Antitrust: Does EC Merger Policy Generate Deterrence?," Economic Inquiry, 2016, 54, 1884-1903.

Duso, Tomaso, Klaus Gugler, and Florian Szücs, "An Empirical Assessment of the 2004 EU Merger Policy Reform," Economic Journal, November 2013, 123, F596-F619.

Gutiérrez, Germán and Thomas Philippon, "How EU Markets Became More Competitive Than US Markets: A Study of Institutional Drift," NBER Working Paper No. 24700, 2018.

Hastie, Trevor, Robert Tibshirani, and Jerome Friedman, The Elements of Statistical Learning - Data Mining, Inference, and Prediction Springer Series in Statistics, Springer New York Inc., 2008.

Lyons, Bruce R, “Reform of European Merger Policy," Review of International Economics, 2004, 12 (2), 246-261.

Mai, Anh Thi Van, “Is EU Merger Policy Less Stringent After Its 2004 Reform?,” Mimeographed 2016.

Mini, Federico, "Fifty is the New Forty: EU Merger Policy Permits Higher Market Shares After the 2004 Reform," Review of Industrial Organization, 2018, pp. 1-27.

Rubin, Donald B., "Estimating Causal Effects of Treatments in Randomized and Nonrandomized Studies," Journal of Educational Psychology, 1974, 66 (5), 688-701.

Szücs, Florian, "Investigating transatlantic merger policy convergence," International Journal of Industrial Organization, 2012, 30 (6), 654-662.

Wager, Stefan and Susan Athey, "Estimation and Inference of Heterogeneous Treatment Effects using Random Forests," Mimeographed July 2017. 


\section{A Appendix}

\section{A.1 Regression Results OLS Concern over Time}

Table 7: Linear Probability Model for Concern by Notification Year

\begin{tabular}{|c|c|c|c|c|c|c|c|c|c|c|}
\hline & 1990-1994 & 1995 & 1996 & 1997 & 1998 & 1999 & 2000 & 2001 & 2002 & 2003 \\
\hline $\begin{array}{l}\text { risk of } \\
\text { foreclosure in submarket }\end{array}$ & & & $\begin{array}{l}-0.017 \\
(0.111)\end{array}$ & $\begin{array}{c}0.693^{* * *} \\
(0.091)\end{array}$ & & $\begin{array}{c}0.300^{* * *} \\
(0.083)\end{array}$ & $\begin{array}{c}0.613^{* * *} \\
(0.098)\end{array}$ & $\begin{array}{l}-0.043 \\
(0.085)\end{array}$ & $\begin{array}{c}0.060 \\
(0.147)\end{array}$ & $\begin{array}{l}-0.037 \\
(0.062)\end{array}$ \\
\hline $\begin{array}{l}\text { joint market } \\
\text { share above } 50 \%\end{array}$ & $\begin{array}{c}0.015 \\
(0.075)\end{array}$ & $\begin{array}{c}0.137 \\
(0.091)\end{array}$ & $\begin{array}{c}0.383^{* * *} \\
(0.099)\end{array}$ & $\begin{array}{l}0.262^{* *} \\
(0.093)\end{array}$ & $\begin{array}{l}0.155^{* *} \\
(0.072)\end{array}$ & $\begin{array}{c}0.341^{* * *} \\
(0.051)\end{array}$ & $\begin{array}{c}0.411^{* * *} \\
(0.077)\end{array}$ & $\begin{array}{c}0.176^{* * *} \\
(0.038)\end{array}$ & $\begin{array}{c}0.181^{* * *} \\
(0.058)\end{array}$ & $\begin{array}{l}0.210^{* *} \\
(0.084)\end{array}$ \\
\hline fullmerger & $\begin{array}{l}-0.062 \\
(0.122)\end{array}$ & $\begin{array}{c}0.070 \\
(0.074)\end{array}$ & $\begin{array}{c}0.261 \\
(0.185)\end{array}$ & $\begin{array}{c}-0.176^{* *} \\
(0.066)\end{array}$ & $\begin{array}{c}0.004 \\
(0.147)\end{array}$ & $\begin{array}{l}-0.067 \\
(0.129)\end{array}$ & $\begin{array}{l}-0.062 \\
(0.111)\end{array}$ & $\begin{array}{l}0.118^{*} \\
(0.063)\end{array}$ & $\begin{array}{l}-0.006 \\
(0.044)\end{array}$ & $\begin{array}{l}-0.181 \\
(0.115)\end{array}$ \\
\hline joint venture & $\begin{array}{c}-0.201^{* * *} \\
(0.067)\end{array}$ & $\begin{array}{c}0.046 \\
(0.067)\end{array}$ & $\begin{array}{c}0.096 \\
(0.119)\end{array}$ & $\begin{array}{c}-0.268^{* * *} \\
(0.055)\end{array}$ & $\begin{array}{c}0.042 \\
(0.160)\end{array}$ & $\begin{array}{l}-0.088 \\
(0.130)\end{array}$ & $\begin{array}{l}-0.152^{*} \\
(0.088)\end{array}$ & $\begin{array}{c}0.083 \\
(0.055)\end{array}$ & $\begin{array}{c}0.027 \\
(0.046)\end{array}$ & $\begin{array}{l}-0.151 \\
(0.156)\end{array}$ \\
\hline $\begin{array}{l}\text { market } \\
\text { definition national }\end{array}$ & $\begin{array}{l}0.100^{*} \\
(0.049)\end{array}$ & $\begin{array}{l}0.516^{*} \\
(0.270)\end{array}$ & $\begin{array}{c}0.160 \\
(0.196)\end{array}$ & $\begin{array}{c}0.019 \\
(0.065)\end{array}$ & $\begin{array}{l}0.261^{*} \\
(0.139)\end{array}$ & $\begin{array}{c}0.065 \\
(0.040)\end{array}$ & $\begin{array}{c}0.050 \\
(0.188)\end{array}$ & $\begin{array}{l}0.208^{* *} \\
(0.082)\end{array}$ & $\begin{array}{l}-0.188^{*} \\
(0.092)\end{array}$ & $\begin{array}{c}0.270 \\
(0.246)\end{array}$ \\
\hline $\begin{array}{l}\text { market } \\
\text { definition EU wide }\end{array}$ & $\begin{array}{l}0.026 \\
(0.067)\end{array}$ & $\begin{array}{l}0.501^{*} \\
(0.272)\end{array}$ & $\begin{array}{c}0.233 \\
(0.190)\end{array}$ & $\begin{array}{l}0.188^{* *} \\
(0.063)\end{array}$ & $\begin{array}{c}0.217 \\
(0.153)\end{array}$ & $\begin{array}{l}0.074^{* *} \\
(0.030)\end{array}$ & $\begin{array}{l}-0.015 \\
(0.195)\end{array}$ & $\begin{array}{l}0.129^{* *} \\
(0.049)\end{array}$ & $\begin{array}{c}-0.280^{* * *} \\
(0.094)\end{array}$ & $\begin{array}{c}0.226 \\
(0.241)\end{array}$ \\
\hline $\begin{array}{l}\text { market } \\
\text { definition worldwide }\end{array}$ & $\begin{array}{c}0.391 \\
(0.250)\end{array}$ & $\begin{array}{l}0.367^{*} \\
(0.201)\end{array}$ & $\begin{array}{c}0.160 \\
(0.196)\end{array}$ & $\begin{array}{c}0.138 \\
(0.126)\end{array}$ & $\begin{array}{l}0.430^{* *} \\
(0.171)\end{array}$ & $\begin{array}{c}0.060 \\
(0.068)\end{array}$ & $\begin{array}{c}0.075 \\
(0.191)\end{array}$ & $\begin{array}{l}0.299^{* *} \\
(0.133)\end{array}$ & $\begin{array}{l}-0.201^{*} \\
(0.116)\end{array}$ & $\begin{array}{c}0.321 \\
(0.220)\end{array}$ \\
\hline $\begin{array}{l}\text { number of } \\
\text { concerned markets }\end{array}$ & $\begin{array}{c}-0.012^{* *} \\
(0.005)\end{array}$ & $\begin{array}{l}-0.004 \\
(0.003)\end{array}$ & $\begin{array}{l}-0.009 \\
(0.010)\end{array}$ & $\begin{array}{c}0.002 \\
(0.004)\end{array}$ & $\begin{array}{l}-0.001 \\
(0.004)\end{array}$ & $\begin{array}{c}0.001 \\
(0.001)\end{array}$ & $\begin{array}{l}-0.001 \\
(0.001)\end{array}$ & $\begin{array}{c}0.001 \\
(0.001)\end{array}$ & $\begin{array}{l}-0.001 \\
(0.000)\end{array}$ & $\begin{array}{c}0.000 \\
(0.001)\end{array}$ \\
\hline $\mathrm{R} 2$ & 0.515 & 0.687 & 0.591 & 0.632 & 0.636 & 0.592 & 0.612 & 0.698 & 0.403 & 0.508 \\
\hline Observations & 205 & 137 & 155 & 242 & 204 & 520 & 887 & 774 & 569 & 494 \\
\hline
\end{tabular}

We report heteroskedasticity robust standard errors clustered at the industry group level.

Significance at the $1 \%, 5 \%$, and $10 \%$ levels is represented by ***** and * respectively. 
Table 8: Linear Probability Model for Concern by Notification Year (Continued)

\begin{tabular}{|c|c|c|c|c|c|c|c|c|c|c|c|}
\hline & 2004 & 2005 & 2006 & 2007 & 2008 & 2009 & 2010 & 2011 & 2012 & 2013 & 2014 \\
\hline $\begin{array}{l}\text { barriers to } \\
\text { entry in submarket }\end{array}$ & $\begin{array}{l}0.226^{* *} \\
(0.103)\end{array}$ & $\begin{array}{l}0.326^{* *} \\
(0.126)\end{array}$ & $\begin{array}{c}0.392^{* * *} \\
(0.072)\end{array}$ & $\begin{array}{l}0.366^{*} \\
(0.197)\end{array}$ & $\begin{array}{c}0.397^{* * *} \\
(0.110)\end{array}$ & $\begin{array}{c}0.435^{* * *} \\
(0.081)\end{array}$ & $\begin{array}{l}-0.083^{*} \\
(0.042)\end{array}$ & $\begin{array}{l}0.000 \\
(.)\end{array}$ & $\begin{array}{c}0.058^{* * *} \\
(0.016)\end{array}$ & $\begin{array}{c}0.113^{* * *} \\
(0.007)\end{array}$ & $\begin{array}{c}1.000^{* * *} \\
(0.000)\end{array}$ \\
\hline $\begin{array}{l}\text { risk of } \\
\text { foreclosure in submarket }\end{array}$ & $\begin{array}{c}0.234 \\
(0.264)\end{array}$ & $\begin{array}{c}0.406^{* * *} \\
(0.116)\end{array}$ & $\begin{array}{c}0.131 \\
(0.224)\end{array}$ & $\begin{array}{c}0.241 \\
(0.301)\end{array}$ & $\begin{array}{c}0.046 \\
(0.335)\end{array}$ & $\begin{array}{l}0.419^{*} \\
(0.239)\end{array}$ & $\begin{array}{c}0.930^{* * *} \\
(0.108)\end{array}$ & & & $\begin{array}{c}0.065 \\
(0.048)\end{array}$ & \\
\hline $\begin{array}{l}\text { joint market } \\
\text { share above } 50 \%\end{array}$ & $\begin{array}{c}0.246^{* * *} \\
(0.049)\end{array}$ & $\begin{array}{c}0.191^{* * *} \\
(0.058)\end{array}$ & $\begin{array}{c}0.143 \\
(0.086)\end{array}$ & $\begin{array}{c}0.356^{* * *} \\
(0.084)\end{array}$ & $\begin{array}{c}0.281^{* * *} \\
(0.063)\end{array}$ & $\begin{array}{c}0.142^{* * *} \\
(0.041)\end{array}$ & $\begin{array}{l}0.049^{*} \\
(0.026)\end{array}$ & $\begin{array}{l}0.000 \\
(.)\end{array}$ & $\begin{array}{l}0.109^{*} \\
(0.059)\end{array}$ & $\begin{array}{c}0.080^{* * *} \\
(0.021)\end{array}$ & $\begin{array}{c}0.000 \\
(0.000)\end{array}$ \\
\hline $\begin{array}{l}\mathrm{HHI} \geq 2000 \\
\& \text { delta } \mathrm{HHI} \geq 150\end{array}$ & $\begin{array}{l}0.125^{*} \\
(0.070)\end{array}$ & $\begin{array}{c}0.108^{* * *} \\
(0.036)\end{array}$ & $\begin{array}{l}0.162^{*} \\
(0.090)\end{array}$ & $\begin{array}{l}0.093^{* *} \\
(0.039)\end{array}$ & $\begin{array}{c}0.041 \\
(0.032)\end{array}$ & $\begin{array}{c}0.131 \\
(0.076)\end{array}$ & $\begin{array}{c}0.072 \\
(0.043)\end{array}$ & $\begin{array}{l}0.000 \\
(.)\end{array}$ & $\begin{array}{l}-0.079^{*} \\
(0.045)\end{array}$ & $\begin{array}{l}-0.004 \\
(0.009)\end{array}$ & $\begin{array}{c}0.000 \\
(0.000)\end{array}$ \\
\hline fullmerger & $\begin{array}{l}0.190^{* *} \\
(0.089)\end{array}$ & $\begin{array}{c}-0.173^{* *} \\
(0.069)\end{array}$ & $\begin{array}{c}-0.141^{* *} \\
(0.054)\end{array}$ & $\begin{array}{l}-0.105 \\
(0.064)\end{array}$ & $\begin{array}{c}0.041 \\
(0.101)\end{array}$ & $\begin{array}{c}0.014 \\
(0.031)\end{array}$ & $\begin{array}{c}0.050^{* * *} \\
(0.014)\end{array}$ & $\begin{array}{l}0.000 \\
(.)\end{array}$ & $\begin{array}{c}0.044 \\
(0.038)\end{array}$ & $\begin{array}{l}-0.039 \\
(0.036)\end{array}$ & $\begin{array}{c}0.000 \\
(0.000)\end{array}$ \\
\hline joint venture & $\begin{array}{l}0.445^{*} \\
(0.219)\end{array}$ & $\begin{array}{c}-0.208^{* *} \\
(0.075)\end{array}$ & $\begin{array}{c}-0.231^{* *} \\
(0.104)\end{array}$ & $\begin{array}{c}-0.127^{* *} \\
(0.050)\end{array}$ & $\begin{array}{l}-0.038 \\
(0.110)\end{array}$ & $\begin{array}{c}0.024 \\
(0.051)\end{array}$ & $\begin{array}{l}-0.025 \\
(0.034)\end{array}$ & $\begin{array}{l}0.000 \\
(.)\end{array}$ & $\begin{array}{l}0.088^{*} \\
(0.048)\end{array}$ & $\begin{array}{c}0.004 \\
(0.005)\end{array}$ & \\
\hline $\begin{array}{l}\text { conglomerate } \\
\text { merger in submarket }\end{array}$ & $\begin{array}{c}-0.393^{* * *} \\
(0.072)\end{array}$ & & $\begin{array}{l}-0.001 \\
(0.098)\end{array}$ & $\begin{array}{l}-0.119 \\
(0.079)\end{array}$ & $\begin{array}{c}0.052 \\
(0.130)\end{array}$ & $\begin{array}{l}-0.453^{*} \\
(0.225)\end{array}$ & & & & & \\
\hline $\begin{array}{l}\text { vertical merger } \\
\text { in submarket }\end{array}$ & $\begin{array}{c}-0.226^{* * *} \\
(0.074)\end{array}$ & $\begin{array}{l}-0.075^{*} \\
(0.039)\end{array}$ & $\begin{array}{l}0.227^{* *} \\
(0.086)\end{array}$ & $\begin{array}{l}-0.020 \\
(0.053)\end{array}$ & $\begin{array}{l}-0.009 \\
(0.031)\end{array}$ & $\begin{array}{l}-0.026 \\
(0.096)\end{array}$ & $\begin{array}{l}-0.115 \\
(0.071)\end{array}$ & $\begin{array}{l}0.000 \\
(.)\end{array}$ & $\begin{array}{c}0.060 \\
(0.060)\end{array}$ & $\begin{array}{l}-0.008 \\
(0.007)\end{array}$ & $\begin{array}{l}-0.000 \\
(0.000)\end{array}$ \\
\hline $\begin{array}{l}\text { market } \\
\text { definition national }\end{array}$ & $\begin{array}{c}0.032 \\
(0.069)\end{array}$ & $\begin{array}{l}-0.043 \\
(0.091)\end{array}$ & $\begin{array}{c}0.024 \\
(0.112)\end{array}$ & $\begin{array}{l}-0.007 \\
(0.104)\end{array}$ & $\begin{array}{c}0.154^{* * *} \\
(0.046)\end{array}$ & $\begin{array}{c}0.042 \\
(0.049)\end{array}$ & $\begin{array}{c}0.331^{* * *} \\
(0.038)\end{array}$ & $\begin{array}{l}0.000 \\
(.)\end{array}$ & $\begin{array}{c}0.001 \\
(0.006)\end{array}$ & $\begin{array}{l}-0.010 \\
(0.009)\end{array}$ & $\begin{array}{c}0.000 \\
(0.000)\end{array}$ \\
\hline $\begin{array}{l}\text { market } \\
\text { definition EU wide }\end{array}$ & $\begin{array}{l}-0.090 \\
(0.065)\end{array}$ & $\begin{array}{c}0.049 \\
(0.078)\end{array}$ & $\begin{array}{l}-0.066 \\
(0.118)\end{array}$ & $\begin{array}{c}0.011 \\
(0.100)\end{array}$ & $\begin{array}{c}0.014 \\
(0.046)\end{array}$ & $\begin{array}{l}0.115^{* *} \\
(0.041)\end{array}$ & $\begin{array}{c}0.250^{* * *} \\
(0.084)\end{array}$ & $\begin{array}{l}0.000 \\
(.)\end{array}$ & $\begin{array}{l}-0.201 \\
(0.117)\end{array}$ & $\begin{array}{c}0.003 \\
(0.013)\end{array}$ & $\begin{array}{c}0.000 \\
(0.000)\end{array}$ \\
\hline $\begin{array}{l}\text { market } \\
\text { definition worldwide }\end{array}$ & & $\begin{array}{c}0.093 \\
(0.089)\end{array}$ & $\begin{array}{l}-0.003 \\
(0.115)\end{array}$ & $\begin{array}{l}-0.051 \\
(0.088)\end{array}$ & $\begin{array}{l}-0.045 \\
(0.032)\end{array}$ & $\begin{array}{l}0.092^{*} \\
(0.050)\end{array}$ & $\begin{array}{l}0.196^{* *} \\
(0.072)\end{array}$ & $\begin{array}{l}0.000 \\
(.)\end{array}$ & $\begin{array}{l}-0.088 \\
(0.064)\end{array}$ & & \\
\hline $\begin{array}{l}\text { number of } \\
\text { concerned markets }\end{array}$ & $\begin{array}{l}-0.004 \\
(0.002)\end{array}$ & $\begin{array}{c}0.002 \\
(0.002)\end{array}$ & $\begin{array}{c}0.000 \\
(0.000)\end{array}$ & $\begin{array}{l}-0.000 \\
(0.000)\end{array}$ & $\begin{array}{l}-0.001 \\
(0.001)\end{array}$ & $\begin{array}{c}0.001 \\
(0.000)\end{array}$ & $\begin{array}{c}0.001 \\
(0.001)\end{array}$ & $\begin{array}{l}0.000 \\
(.)\end{array}$ & $\begin{array}{c}0.002^{* * *} \\
(0.000)\end{array}$ & $\begin{array}{c}0.000 \\
(0.000)\end{array}$ & $\begin{array}{l}-0.000 \\
(0.000)\end{array}$ \\
\hline $\begin{array}{l}\text { number of } \\
\text { competitors }\end{array}$ & $\begin{array}{c}-0.052^{* *} \\
(0.021)\end{array}$ & $\begin{array}{l}-0.012 \\
(0.010)\end{array}$ & $\begin{array}{l}-0.009 \\
(0.014)\end{array}$ & $\begin{array}{l}-0.009 \\
(0.006)\end{array}$ & $\begin{array}{l}-0.008 \\
(0.007)\end{array}$ & $\begin{array}{l}-0.004 \\
(0.010)\end{array}$ & $\begin{array}{c}0.003 \\
(0.003)\end{array}$ & $\begin{array}{l}0.000 \\
(.)\end{array}$ & $\begin{array}{l}-0.013 \\
(0.012)\end{array}$ & $\begin{array}{c}0.003 \\
(0.002)\end{array}$ & $\begin{array}{c}0.000 \\
(0.000)\end{array}$ \\
\hline $\begin{array}{l}\text { indicator no } \\
\text { info on competitors }\end{array}$ & $\begin{array}{c}-0.363^{* * *} \\
(0.093)\end{array}$ & $\begin{array}{c}0.020 \\
(0.047)\end{array}$ & $\begin{array}{r}-0.131^{*} \\
(0.064)\end{array}$ & $\begin{array}{c}0.013 \\
(0.045)\end{array}$ & $\begin{array}{l}-0.003 \\
(0.038)\end{array}$ & $\begin{array}{l}-0.091^{*} \\
(0.047)\end{array}$ & $\begin{array}{c}0.027 \\
(0.026)\end{array}$ & $\begin{array}{l}0.000 \\
(.)\end{array}$ & $\begin{array}{l}-0.099 \\
(0.083)\end{array}$ & $\begin{array}{c}0.002 \\
(0.006)\end{array}$ & $\begin{array}{l}-0.000 \\
(0.000)\end{array}$ \\
\hline Constant & $\begin{array}{l}0.308^{*} \\
(0.152)\end{array}$ & $\begin{array}{c}0.039 \\
(0.121)\end{array}$ & $\begin{array}{c}0.051 \\
(0.150)\end{array}$ & $\begin{array}{c}0.040 \\
(0.120)\end{array}$ & $\begin{array}{l}0.274^{* *} \\
(0.103)\end{array}$ & $\begin{array}{c}0.014 \\
(0.099)\end{array}$ & $\begin{array}{c}0.044 \\
(0.079)\end{array}$ & $\begin{array}{l}0.000 \\
(.)\end{array}$ & $\begin{array}{c}0.011 \\
(0.063)\end{array}$ & $\begin{array}{l}-0.010 \\
(0.014)\end{array}$ & $\begin{array}{l}-0.000 \\
(0.000)\end{array}$ \\
\hline Industry Group FE & Yes & Yes & Yes & Yes & Yes & Yes & Yes & Yes & Yes & Yes & Yes \\
\hline $\begin{array}{l}\mathrm{R} 2 \\
\text { Observations }\end{array}$ & $\begin{array}{c}0.483 \\
546 \\
\end{array}$ & $\begin{array}{l}0.446 \\
1,209 \\
\end{array}$ & $\begin{array}{l}0.547 \\
1,408 \\
\end{array}$ & $\begin{array}{l}0.445 \\
1,423 \\
\end{array}$ & $\begin{array}{l}0.496 \\
1,534 \\
\end{array}$ & $\begin{array}{c}0.415 \\
761 \\
\end{array}$ & $\begin{array}{c}0.542 \\
411 \\
\end{array}$ & 179 & $\begin{array}{c}0.468 \\
519\end{array}$ & $\begin{array}{c}0.122 \\
595\end{array}$ & $\begin{array}{c}1.000 \\
38\end{array}$ \\
\hline
\end{tabular}

We report heteroskedasticity robust standard errors clustered at the industry group level.

Significance at the $1 \%, 5 \%$, and $10 \%$ levels is represented by ***** and * respectively. 


\section{A.2 Determinants of Concern - Market Level - Split Sample over Industries}

Table 9: Linear Probability Model for Concern by Industry

\begin{tabular}{|c|c|c|c|c|c|c|c|c|c|}
\hline & Group 1 & Group 2 & Group 3 & Group 4 & Group 5 & Group 6 & Group 7 & Group 8 & Group 9 \\
\hline $\begin{array}{l}\text { barriers to } \\
\text { entry in submarket }\end{array}$ & $\begin{array}{c}0.412^{* * *} \\
(0.070)\end{array}$ & $\begin{array}{c}0.071 \\
(0.067)\end{array}$ & $\begin{array}{c}1.000^{* * *} \\
(0.000)\end{array}$ & $\begin{array}{c}0.637^{* * *} \\
(0.054)\end{array}$ & $\begin{array}{c}0.241^{* * * *} \\
(0.032)\end{array}$ & $\begin{array}{c}0.487^{* * *} \\
(0.038)\end{array}$ & $\begin{array}{c}0.403^{* * *} \\
(0.095)\end{array}$ & $\begin{array}{c}0.066 \\
(0.157)\end{array}$ & $\begin{array}{c}0.467^{* * *} \\
(0.057)\end{array}$ \\
\hline $\begin{array}{l}\text { risk of } \\
\text { foreclosure in submarket }\end{array}$ & $\begin{array}{c}0.326^{* * *} \\
(0.113)\end{array}$ & $\begin{array}{c}0.659^{* * *} \\
(0.147)\end{array}$ & & & $\begin{array}{c}0.469^{* * *} \\
(0.055)\end{array}$ & & $\begin{array}{l}-0.364 \\
(0.260)\end{array}$ & $\begin{array}{l}0.213^{*} \\
(0.118)\end{array}$ & $\begin{array}{c}0.502^{* * *} \\
(0.103)\end{array}$ \\
\hline $\begin{array}{l}\text { joint market } \\
\text { share above } 50 \%\end{array}$ & $\begin{array}{c}0.415^{* * *} \\
(0.047)\end{array}$ & $\begin{array}{c}0.329^{* * *} \\
(0.029)\end{array}$ & & $\begin{array}{c}0.217^{* * *} \\
(0.046)\end{array}$ & $\begin{array}{c}0.265^{* * *} \\
(0.022)\end{array}$ & $\begin{array}{c}0.301^{* * *} \\
(0.028)\end{array}$ & $\begin{array}{c}0.302^{* * *} \\
(0.061)\end{array}$ & $\begin{array}{c}0.215^{* * *} \\
(0.061)\end{array}$ & $\begin{array}{c}0.155^{* * *} \\
(0.036)\end{array}$ \\
\hline $\begin{array}{l}\mathrm{HHI} \geq 2000 \\
\text { \& delta HHI } \geq 150\end{array}$ & $\begin{array}{c}0.135^{* * *} \\
(0.029)\end{array}$ & $\begin{array}{c}0.079^{* * *} \\
(0.020)\end{array}$ & $\begin{array}{l}-0.000 \\
(0.000)\end{array}$ & $\begin{array}{l}0.066^{*} \\
(0.034)\end{array}$ & $\begin{array}{c}0.076^{* * *} \\
(0.017)\end{array}$ & $\begin{array}{c}0.177^{* * *} \\
(0.029)\end{array}$ & $\begin{array}{l}0.072^{* *} \\
(0.031)\end{array}$ & $\begin{array}{l}0.057^{* *} \\
(0.027)\end{array}$ & $\begin{array}{c}0.081^{* * *} \\
(0.019)\end{array}$ \\
\hline fullmerger & $\begin{array}{c}0.068 \\
(0.053)\end{array}$ & $\begin{array}{c}0.153^{* * *} \\
(0.026)\end{array}$ & $\begin{array}{c}0.000 \\
(0.000)\end{array}$ & $\begin{array}{c}-0.223^{* * *} \\
(0.051)\end{array}$ & $\begin{array}{c}-0.067^{* * *} \\
(0.025)\end{array}$ & $\begin{array}{c}0.121^{* * *} \\
(0.043)\end{array}$ & $\begin{array}{c}-0.228^{* * *} \\
(0.073)\end{array}$ & $\begin{array}{l}0.058 \\
(0.055)\end{array}$ & $\begin{array}{c}-0.200^{* * *} \\
(0.044)\end{array}$ \\
\hline joint venture & $\begin{array}{l}-0.006 \\
(0.054)\end{array}$ & $\begin{array}{l}0.060^{* *} \\
(0.030)\end{array}$ & & $\begin{array}{c}0.089 \\
(0.101)\end{array}$ & $\begin{array}{c}-0.150^{* * *} \\
(0.034)\end{array}$ & $\begin{array}{l}-0.093^{*} \\
(0.056)\end{array}$ & $\begin{array}{c}-0.280^{* * *} \\
(0.079)\end{array}$ & $\begin{array}{c}0.002 \\
(0.060)\end{array}$ & $\begin{array}{c}-0.218^{* * *} \\
(0.056)\end{array}$ \\
\hline $\begin{array}{l}\text { conglomerate } \\
\text { merger in submarket }\end{array}$ & & $\begin{array}{l}-0.087^{*} \\
(0.048)\end{array}$ & & & $\begin{array}{c}-0.185^{* * *} \\
(0.069)\end{array}$ & $\begin{array}{c}0.355^{* * *} \\
(0.075)\end{array}$ & & $\begin{array}{l}0.265^{*} \\
(0.143)\end{array}$ & $\begin{array}{c}-0.156^{* * *} \\
(0.057)\end{array}$ \\
\hline $\begin{array}{l}\text { vertical merger } \\
\text { in submarket }\end{array}$ & $\begin{array}{c}0.021 \\
(0.040)\end{array}$ & $\begin{array}{l}-0.042 \\
(0.026)\end{array}$ & $\begin{array}{l}-0.000 \\
(0.000)\end{array}$ & $\begin{array}{l}-0.009 \\
(0.055)\end{array}$ & $\begin{array}{l}-0.010 \\
(0.021)\end{array}$ & $\begin{array}{c}0.022 \\
(0.046)\end{array}$ & $\begin{array}{c}0.042 \\
(0.040)\end{array}$ & $\begin{array}{c}-0.080^{* * *} \\
(0.028)\end{array}$ & $\begin{array}{c}0.005 \\
(0.019)\end{array}$ \\
\hline $\begin{array}{l}\text { market } \\
\text { definition national }\end{array}$ & $\begin{array}{l}0.201^{* *} \\
(0.091)\end{array}$ & $\begin{array}{c}0.043 \\
(0.062)\end{array}$ & $\begin{array}{c}0.000 \\
(0.000)\end{array}$ & $\begin{array}{l}0.148^{* *} \\
(0.073)\end{array}$ & $\begin{array}{c}0.011 \\
(0.059)\end{array}$ & $\begin{array}{c}-0.244^{* * *} \\
(0.057)\end{array}$ & $\begin{array}{l}0.444^{* *} \\
(0.178)\end{array}$ & $\begin{array}{l}0.178^{*} \\
(0.094)\end{array}$ & $\begin{array}{c}0.025 \\
(0.105)\end{array}$ \\
\hline $\begin{array}{l}\text { market } \\
\text { definition EU wide }\end{array}$ & $\begin{array}{l}0.157^{*} \\
(0.089)\end{array}$ & $\begin{array}{l}0.045 \\
(0.066)\end{array}$ & & $\begin{array}{c}0.106 \\
(0.068)\end{array}$ & $\begin{array}{l}-0.047 \\
(0.057)\end{array}$ & $\begin{array}{c}-0.171^{* *} \\
(0.069)\end{array}$ & $\begin{array}{l}0.431^{* *} \\
(0.173)\end{array}$ & $\begin{array}{l}0.201^{* *} \\
(0.096)\end{array}$ & $\begin{array}{c}0.087 \\
(0.104)\end{array}$ \\
\hline $\begin{array}{l}\text { market } \\
\text { definition worldwide }\end{array}$ & $\begin{array}{l}0.157^{*} \\
(0.081)\end{array}$ & $\begin{array}{c}0.033 \\
(0.100)\end{array}$ & & $\begin{array}{c}0.219 \\
(0.207)\end{array}$ & $\begin{array}{l}-0.002 \\
(0.060)\end{array}$ & $\begin{array}{c}-0.198^{* * *} \\
(0.072)\end{array}$ & $\begin{array}{l}0.348^{*} \\
(0.196)\end{array}$ & $\begin{array}{l}0.242^{* *} \\
(0.095)\end{array}$ & $\begin{array}{c}0.062 \\
(0.103)\end{array}$ \\
\hline $\begin{array}{l}\text { number of } \\
\text { concerned markets }\end{array}$ & $\begin{array}{l}-0.000 \\
(0.001)\end{array}$ & $\begin{array}{c}0.000 \\
(0.000)\end{array}$ & $\begin{array}{l}-0.000 \\
(0.000)\end{array}$ & $\begin{array}{l}0.002^{*} \\
(0.001)\end{array}$ & $\begin{array}{c}-0.001^{* * *} \\
(0.000)\end{array}$ & $\begin{array}{l}-0.001 \\
(0.000)\end{array}$ & $\begin{array}{l}-0.000 \\
(0.000)\end{array}$ & $\begin{array}{c}-0.003^{* * *} \\
(0.001)\end{array}$ & $\begin{array}{c}0.005^{* * *} \\
(0.001)\end{array}$ \\
\hline $\begin{array}{l}\text { number of } \\
\text { competitors }\end{array}$ & $\begin{array}{l}-0.004 \\
(0.006)\end{array}$ & $\begin{array}{c}0.007 \\
(0.008)\end{array}$ & $\begin{array}{l}-0.000 \\
(0.000)\end{array}$ & $\begin{array}{c}0.003 \\
(0.011)\end{array}$ & $\begin{array}{l}-0.006 \\
(0.006)\end{array}$ & $\begin{array}{c}-0.021^{* * *} \\
(0.005)\end{array}$ & $\begin{array}{l}0.024^{*} \\
(0.013)\end{array}$ & $\begin{array}{c}0.002 \\
(0.006)\end{array}$ & $\begin{array}{c}-0.019^{* *} \\
(0.008)\end{array}$ \\
\hline $\begin{array}{l}\text { indicator no } \\
\text { info on competitors }\end{array}$ & $\begin{array}{l}-0.061 \\
(0.037)\end{array}$ & $\begin{array}{l}-0.026 \\
(0.033)\end{array}$ & & $\begin{array}{l}-0.123^{*} \\
(0.066)\end{array}$ & $\begin{array}{c}-0.089^{* * *} \\
(0.025)\end{array}$ & $\begin{array}{c}-0.061^{* *} \\
(0.027)\end{array}$ & $\begin{array}{l}0.114^{*} \\
(0.058)\end{array}$ & $\begin{array}{c}0.042 \\
(0.038)\end{array}$ & $\begin{array}{c}-0.145^{* * *} \\
(0.037)\end{array}$ \\
\hline $\begin{array}{l}\text { Post reform } \\
\text { indicator }\end{array}$ & $\begin{array}{c}0.093 \\
(0.085)\end{array}$ & $\begin{array}{c}0.052 \\
(0.052)\end{array}$ & $\begin{array}{c}0.000 \\
(0.000)\end{array}$ & $\begin{array}{c}-0.715^{* * *} \\
(0.179)\end{array}$ & $\begin{array}{c}-0.865^{* * *} \\
(0.037)\end{array}$ & $\begin{array}{l}-0.103 \\
(0.108)\end{array}$ & $\begin{array}{c}-0.067^{* *} \\
(0.033)\end{array}$ & $\begin{array}{c}0.101 \\
(0.091)\end{array}$ & $\begin{array}{c}-0.109^{* *} \\
(0.055)\end{array}$ \\
\hline Constant & $\begin{array}{l}-0.213^{*} \\
(0.123)\end{array}$ & $\begin{array}{c}-0.227^{* * *} \\
(0.087)\end{array}$ & $\begin{array}{c}0.000 \\
(0.000)\end{array}$ & $\begin{array}{l}0.485^{* *} \\
(0.198)\end{array}$ & $\begin{array}{c}1.010^{* * *} \\
(0.070)\end{array}$ & $\begin{array}{l}0.218^{*} \\
(0.129)\end{array}$ & $\begin{array}{l}-0.294 \\
(0.205)\end{array}$ & $\begin{array}{c}-0.331^{* * *} \\
(0.124)\end{array}$ & $\begin{array}{c}0.079 \\
(0.119)\end{array}$ \\
\hline Year FE & Yes & Yes & Yes & Yes & Yes & Yes & Yes & Yes & Yes \\
\hline R2 & 0.671 & 0.409 & 1.000 & 0.586 & 0.507 & 0.483 & 0.577 & 0.392 & 0.644 \\
\hline Observations & 455 & 1,022 & 39 & 435 & 1,919 & 1,035 & 339 & 369 & 621 \\
\hline
\end{tabular}

We report heteroskedasticity robust standard errors.

Significance at the $1 \%, 5 \%$, and $10 \%$ levels is represented by ***** and * respectively. 
Table 10: Linear Probability Model for Concern by Industry (Continued)

\begin{tabular}{|c|c|c|c|c|c|c|c|c|c|}
\hline & Group 10 & Group 11 & Group 12 & Group 13 & Group 14 & Group 15 & Group 16 & Group 17 & Group 18 \\
\hline $\begin{array}{l}\text { barriers to } \\
\text { entry in submarket }\end{array}$ & $\begin{array}{c}0.681^{* * *} \\
(0.072)\end{array}$ & $\begin{array}{c}0.268^{* * *} \\
(0.078)\end{array}$ & $\begin{array}{c}0.407^{* * *} \\
(0.055)\end{array}$ & $\begin{array}{c}0.328^{* * *} \\
(0.077)\end{array}$ & $\begin{array}{c}0.406^{* * *} \\
(0.069)\end{array}$ & $\begin{array}{c}0.000 \\
(.)\end{array}$ & $\begin{array}{c}0.346^{* * *} \\
(0.054)\end{array}$ & $\begin{array}{c}0.199^{* * *} \\
(0.028)\end{array}$ & \\
\hline $\begin{array}{l}\text { risk of } \\
\text { foreclosure in submarket }\end{array}$ & $\begin{array}{c}-0.322^{* *} \\
(0.125)\end{array}$ & $\begin{array}{c}0.510^{* * *} \\
(0.088)\end{array}$ & $\begin{array}{l}-0.047 \\
(0.044)\end{array}$ & $\begin{array}{c}0.408^{* * *} \\
(0.117)\end{array}$ & $\begin{array}{c}0.046 \\
(0.066)\end{array}$ & & $\begin{array}{c}0.269^{* * *} \\
(0.104)\end{array}$ & $\begin{array}{l}-0.027 \\
(0.040)\end{array}$ & \\
\hline $\begin{array}{l}\text { joint market } \\
\text { share above } 50 \%\end{array}$ & $\begin{array}{l}0.146^{* *} \\
(0.057)\end{array}$ & $\begin{array}{c}0.132^{* * *} \\
(0.031)\end{array}$ & $\begin{array}{c}0.171^{* * *} \\
(0.036)\end{array}$ & $\begin{array}{c}0.187^{* * *} \\
(0.050)\end{array}$ & $\begin{array}{c}0.253^{* * *} \\
(0.048)\end{array}$ & $\begin{array}{l}0.000 \\
(.)\end{array}$ & $\begin{array}{c}0.071 \\
(0.045)\end{array}$ & $\begin{array}{c}0.113^{* * *} \\
(0.020)\end{array}$ & $\begin{array}{l}0.000 \\
(.)\end{array}$ \\
\hline $\begin{array}{l}\mathrm{HHI} \geq 2000 \\
\text { \& delta HHI } \geq 150\end{array}$ & $\begin{array}{l}-0.016 \\
(0.020)\end{array}$ & $\begin{array}{c}0.106^{* * *} \\
(0.020)\end{array}$ & $\begin{array}{l}-0.037 \\
(0.035)\end{array}$ & $\begin{array}{c}0.028 \\
(0.018)\end{array}$ & $\begin{array}{c}0.205^{* * *} \\
(0.036)\end{array}$ & $\begin{array}{l}0.000 \\
(.)\end{array}$ & $\begin{array}{c}0.134^{* * *} \\
(0.020)\end{array}$ & $\begin{array}{c}0.197^{* * *} \\
(0.028)\end{array}$ & $\begin{array}{l}0.000 \\
(.)\end{array}$ \\
\hline fullmerger & $\begin{array}{l}-0.158^{* * *} \\
(0.052)\end{array}$ & $\begin{array}{c}-0.219^{* * *} \\
(0.036)\end{array}$ & $\begin{array}{c}-0.114^{* *} \\
(0.045)\end{array}$ & $\begin{array}{l}0.061^{*} \\
(0.032)\end{array}$ & $\begin{array}{c}-0.297^{* * *} \\
(0.064)\end{array}$ & $\begin{array}{c}0.000 \\
(.)\end{array}$ & $\begin{array}{c}-0.120^{* * *} \\
(0.036)\end{array}$ & $\begin{array}{l}-0.029 \\
(0.087)\end{array}$ & $\begin{array}{l}0.000 \\
(.)\end{array}$ \\
\hline joint venture & $\begin{array}{c}-0.126^{* *} \\
(0.057)\end{array}$ & $\begin{array}{c}-0.213^{* * *} \\
(0.035)\end{array}$ & & $\begin{array}{c}0.019 \\
(0.037)\end{array}$ & $\begin{array}{c}-0.372^{* * *} \\
(0.064)\end{array}$ & $\begin{array}{l}0.000 \\
(.)\end{array}$ & $\begin{array}{c}-0.084^{* *} \\
(0.036)\end{array}$ & $\begin{array}{c}0.003 \\
(0.093)\end{array}$ & $\begin{array}{l}0.000 \\
(.)\end{array}$ \\
\hline $\begin{array}{l}\text { conglomerate } \\
\text { merger in submarket }\end{array}$ & $\begin{array}{c}0.022 \\
(0.032)\end{array}$ & $\begin{array}{l}-0.131 \\
(0.096)\end{array}$ & $\begin{array}{l}-0.016 \\
(0.040)\end{array}$ & $\begin{array}{l}-0.059^{*} \\
(0.036)\end{array}$ & & $\begin{array}{l}0.000 \\
(.)\end{array}$ & $\begin{array}{l}-0.025 \\
(0.037)\end{array}$ & $\begin{array}{l}0.130^{* *} \\
(0.063)\end{array}$ & \\
\hline $\begin{array}{l}\text { vertical merger } \\
\text { in submarket }\end{array}$ & $\begin{array}{c}0.031 \\
(0.029)\end{array}$ & $\begin{array}{c}-0.039^{* *} \\
(0.016)\end{array}$ & $\begin{array}{l}-0.030 \\
(0.033)\end{array}$ & $\begin{array}{l}-0.050 \\
(0.031)\end{array}$ & $\begin{array}{c}0.047 \\
(0.038)\end{array}$ & $\begin{array}{l}0.000 \\
(.)\end{array}$ & $\begin{array}{l}0.006 \\
(0.015)\end{array}$ & $\begin{array}{c}0.037 \\
(0.028)\end{array}$ & $\begin{array}{l}0.000 \\
(.)\end{array}$ \\
\hline $\begin{array}{l}\text { market } \\
\text { definition national }\end{array}$ & $\begin{array}{c}0.294^{* * *} \\
(0.095)\end{array}$ & $\begin{array}{c}0.078 \\
(0.075)\end{array}$ & $\begin{array}{l}0.182^{* *} \\
(0.074)\end{array}$ & $\begin{array}{l}0.075^{*} \\
(0.043)\end{array}$ & $\begin{array}{c}0.004 \\
(0.061)\end{array}$ & $\begin{array}{l}0.000 \\
(.)\end{array}$ & $\begin{array}{l}-0.026 \\
(0.023)\end{array}$ & $\begin{array}{l}0.092^{*} \\
(0.048)\end{array}$ & \\
\hline $\begin{array}{l}\text { market } \\
\text { definition EU wide }\end{array}$ & $\begin{array}{l}0.132^{*} \\
(0.074)\end{array}$ & $\begin{array}{c}0.072 \\
(0.073)\end{array}$ & $\begin{array}{c}0.091 \\
(0.066)\end{array}$ & $\begin{array}{c}0.039 \\
(0.028)\end{array}$ & $\begin{array}{c}-0.166^{* *} \\
(0.078)\end{array}$ & $\begin{array}{l}0.000 \\
(.)\end{array}$ & $\begin{array}{c}0.014 \\
(0.024)\end{array}$ & $\begin{array}{c}0.062 \\
(0.059)\end{array}$ & \\
\hline $\begin{array}{l}\text { market } \\
\text { definition worldwide }\end{array}$ & $\begin{array}{c}0.079 \\
(0.081)\end{array}$ & $\begin{array}{l}0.149^{*} \\
(0.076)\end{array}$ & & $\begin{array}{c}0.068 \\
(0.051)\end{array}$ & & $\begin{array}{l}0.000 \\
(.)\end{array}$ & $\begin{array}{l}0.070^{*} \\
(0.036)\end{array}$ & $\begin{array}{c}0.052 \\
(0.055)\end{array}$ & \\
\hline $\begin{array}{l}\text { number of } \\
\text { concerned markets }\end{array}$ & $\begin{array}{c}-0.003^{* * *} \\
(0.001)\end{array}$ & $\begin{array}{c}0.001 \\
(0.001)\end{array}$ & $\begin{array}{c}-0.001^{* * *} \\
(0.000)\end{array}$ & $\begin{array}{c}0.001 \\
(0.001)\end{array}$ & $\begin{array}{l}-0.000 \\
(0.001)\end{array}$ & $\begin{array}{l}0.000 \\
(.)\end{array}$ & $\begin{array}{l}-0.001 \\
(0.001)\end{array}$ & $\begin{array}{c}0.000 \\
(0.000)\end{array}$ & $\begin{array}{l}0.000 \\
(.)\end{array}$ \\
\hline $\begin{array}{l}\text { number of } \\
\text { competitors }\end{array}$ & $\begin{array}{l}-0.005 \\
(0.005)\end{array}$ & $\begin{array}{c}0.003 \\
(0.005)\end{array}$ & $\begin{array}{l}-0.009 \\
(0.006)\end{array}$ & $\begin{array}{l}-0.004 \\
(0.008)\end{array}$ & $\begin{array}{c}0.002 \\
(0.006)\end{array}$ & $\begin{array}{l}0.000 \\
(.)\end{array}$ & $\begin{array}{l}0.006^{*} \\
(0.004)\end{array}$ & $\begin{array}{c}-0.028^{* * *} \\
(0.006)\end{array}$ & $\begin{array}{l}0.000 \\
(.)\end{array}$ \\
\hline $\begin{array}{l}\text { indicator no } \\
\text { info on competitors }\end{array}$ & $\begin{array}{c}-0.109^{* * *} \\
(0.040)\end{array}$ & $\begin{array}{l}0.052^{*} \\
(0.028)\end{array}$ & $\begin{array}{l}-0.007 \\
(0.055)\end{array}$ & $\begin{array}{l}-0.046 \\
(0.039)\end{array}$ & $\begin{array}{c}0.009 \\
(0.035)\end{array}$ & $\begin{array}{c}0.000 \\
(.)\end{array}$ & $\begin{array}{c}0.088^{* * *} \\
(0.022)\end{array}$ & $\begin{array}{c}-0.108^{* * *} \\
(0.034)\end{array}$ & $\begin{array}{c}0.000 \\
(.)\end{array}$ \\
\hline $\begin{array}{l}\text { Post reform } \\
\text { indicator }\end{array}$ & $\begin{array}{c}-0.351^{* * *} \\
(0.110)\end{array}$ & $\begin{array}{l}-0.021 \\
(0.026)\end{array}$ & $\begin{array}{c}0.632^{* * *} \\
(0.087)\end{array}$ & $\begin{array}{l}-0.028 \\
(0.023)\end{array}$ & $\begin{array}{l}0.106^{*} \\
(0.057)\end{array}$ & $\begin{array}{c}0.000 \\
(.)\end{array}$ & $\begin{array}{c}0.038^{* * *} \\
(0.012)\end{array}$ & $\begin{array}{l}-0.121 \\
(0.078)\end{array}$ & $\begin{array}{c}0.000 \\
(.)\end{array}$ \\
\hline Constant & $\begin{array}{l}0.240^{*} \\
(0.129)\end{array}$ & $\begin{array}{l}-0.109 \\
(0.082)\end{array}$ & $\begin{array}{c}0.053 \\
(0.042)\end{array}$ & $\begin{array}{l}-0.141^{*} \\
(0.079)\end{array}$ & $\begin{array}{l}0.212^{* *} \\
(0.097)\end{array}$ & $\begin{array}{c}0.000 \\
(.)\end{array}$ & $\begin{array}{l}-0.034 \\
(0.048)\end{array}$ & $\begin{array}{c}0.128 \\
(0.127)\end{array}$ & $\begin{array}{c}0.000 \\
(.)\end{array}$ \\
\hline Year FE & Yes & Yes & Yes & Yes & Yes & Yes & Yes & Yes & Yes \\
\hline $\mathrm{R} 2$ & 0.793 & 0.522 & 0.385 & 0.453 & 0.657 & . & 0.548 & 0.326 & . \\
\hline Observations & 339 & 632 & 443 & 435 & 547 & 85 & 680 & 1,398 & 60 \\
\hline
\end{tabular}

We report heteroskedasticity robust standard errors.

Significance at the $1 \%, 5 \%$, and $10 \%$ levels is represented by $* * * * *$ and * respectively. 
Table 11: Linear Probability Model for Concern by Industry (Continued)

\begin{tabular}{|c|c|c|c|c|c|c|c|}
\hline & Group 19 & Group 20 & Group 21 & Group 22 & Group 23 & Group 24 & Group 25 \\
\hline $\begin{array}{l}\text { barriers to } \\
\text { entry in submarket }\end{array}$ & $\begin{array}{c}0.581^{* * *} \\
(0.119)\end{array}$ & $\begin{array}{c}0.362^{* * *} \\
(0.062)\end{array}$ & $\begin{array}{c}0.974^{* * *} \\
(0.042)\end{array}$ & $\begin{array}{c}0.215 \\
(0.147)\end{array}$ & $\begin{array}{l}0.178^{* *} \\
(0.082)\end{array}$ & & $\begin{array}{c}0.751^{* * *} \\
(0.194)\end{array}$ \\
\hline $\begin{array}{l}\text { risk of } \\
\text { foreclosure in submarket }\end{array}$ & $\begin{array}{c}0.131 \\
(0.174)\end{array}$ & $\begin{array}{c}-0.283^{* * *} \\
(0.085)\end{array}$ & $\begin{array}{c}0.957^{* * *} \\
(0.044)\end{array}$ & & $\begin{array}{c}-0.274^{* *} \\
(0.123)\end{array}$ & & $\begin{array}{c}0.980^{* * *} \\
(0.044)\end{array}$ \\
\hline $\begin{array}{l}\text { joint market } \\
\text { share above } 50 \%\end{array}$ & $\begin{array}{c}0.221^{* * *} \\
(0.052)\end{array}$ & $\begin{array}{c}0.025 \\
(0.022)\end{array}$ & $\begin{array}{c}0.191 \\
(0.124)\end{array}$ & $\begin{array}{c}0.233^{* * *} \\
(0.078)\end{array}$ & $\begin{array}{c}0.268^{* * *} \\
(0.078)\end{array}$ & $\begin{array}{c}0.000 \\
(0.000)\end{array}$ & $\begin{array}{l}-0.021 \\
(0.038)\end{array}$ \\
\hline $\begin{array}{l}\mathrm{HHI} \geq 2000 \\
\& \text { delta HHI } \geq 150\end{array}$ & $\begin{array}{c}0.083^{* * *} \\
(0.027)\end{array}$ & $\begin{array}{c}0.076^{* * *} \\
(0.024)\end{array}$ & $\begin{array}{l}-0.008 \\
(0.012)\end{array}$ & $\begin{array}{c}0.026 \\
(0.052)\end{array}$ & $\begin{array}{c}0.204^{* * *} \\
(0.043)\end{array}$ & $\begin{array}{c}0.000 \\
(0.000)\end{array}$ & $\begin{array}{l}0.079^{*} \\
(0.041)\end{array}$ \\
\hline fullmerger & $\begin{array}{c}0.171 \\
(0.115)\end{array}$ & $\begin{array}{c}0.082^{* * *} \\
(0.027)\end{array}$ & $\begin{array}{l}-0.002 \\
(0.014)\end{array}$ & $\begin{array}{c}0.057 \\
(0.052)\end{array}$ & $\begin{array}{c}0.267 \\
(0.168)\end{array}$ & $\begin{array}{c}-1.000^{* * *} \\
(0.000)\end{array}$ & $\begin{array}{c}0.124 \\
(0.140)\end{array}$ \\
\hline joint venture & $\begin{array}{l}0.155^{* *} \\
(0.066)\end{array}$ & $\begin{array}{l}-0.083 \\
(0.063)\end{array}$ & $\begin{array}{l}-0.031 \\
(0.025)\end{array}$ & $\begin{array}{l}-0.022 \\
(0.067)\end{array}$ & $\begin{array}{l}0.302^{*} \\
(0.178)\end{array}$ & $\begin{array}{c}-1.000^{* * *} \\
(0.000)\end{array}$ & \\
\hline $\begin{array}{l}\text { conglomerate } \\
\text { merger in submarket }\end{array}$ & $\begin{array}{c}0.018 \\
(0.086)\end{array}$ & $\begin{array}{c}0.145 \\
(0.134)\end{array}$ & & $\begin{array}{l}-0.001 \\
(0.067)\end{array}$ & $\begin{array}{l}-0.141 \\
(0.132)\end{array}$ & & \\
\hline $\begin{array}{l}\text { vertical merger } \\
\text { in submarket }\end{array}$ & $\begin{array}{c}0.003 \\
(0.032)\end{array}$ & $\begin{array}{c}0.062 \\
(0.038)\end{array}$ & $\begin{array}{c}0.015 \\
(0.022)\end{array}$ & $\begin{array}{l}-0.097 \\
(0.114)\end{array}$ & $\begin{array}{l}0.103^{*} \\
(0.062)\end{array}$ & $\begin{array}{c}0.000 \\
(0.000)\end{array}$ & $\begin{array}{c}0.039 \\
(0.047)\end{array}$ \\
\hline $\begin{array}{l}\text { market } \\
\text { definition national }\end{array}$ & $\begin{array}{l}-0.004 \\
(0.177)\end{array}$ & $\begin{array}{l}-0.033 \\
(0.079)\end{array}$ & $\begin{array}{l}-0.042 \\
(0.032)\end{array}$ & $\begin{array}{c}-0.214^{* * *} \\
(0.072)\end{array}$ & $\begin{array}{c}-0.227^{* * *} \\
(0.047)\end{array}$ & $\begin{array}{l}-0.000 \\
(0.000)\end{array}$ & $\begin{array}{l}-0.158 \\
(0.124)\end{array}$ \\
\hline $\begin{array}{l}\text { market } \\
\text { definition EU wide }\end{array}$ & $\begin{array}{c}0.003 \\
(0.175)\end{array}$ & $\begin{array}{l}-0.022 \\
(0.088)\end{array}$ & $\begin{array}{l}-0.033 \\
(0.027)\end{array}$ & $\begin{array}{l}-0.075 \\
(0.112)\end{array}$ & $\begin{array}{c}-0.281^{* * *} \\
(0.075)\end{array}$ & $\begin{array}{l}-0.000 \\
(0.000)\end{array}$ & $\begin{array}{l}-0.054 \\
(0.073)\end{array}$ \\
\hline $\begin{array}{l}\text { market } \\
\text { definition worldwide }\end{array}$ & $\begin{array}{l}-0.045 \\
(0.166)\end{array}$ & $\begin{array}{l}-0.032 \\
(0.088)\end{array}$ & $\begin{array}{l}-0.027 \\
(0.023)\end{array}$ & $\begin{array}{c}-0.224^{* * *} \\
(0.083)\end{array}$ & $\begin{array}{l}-0.187 \\
(0.121)\end{array}$ & $\begin{array}{l}-0.000 \\
(0.000)\end{array}$ & $\begin{array}{l}-0.169 \\
(0.134)\end{array}$ \\
\hline $\begin{array}{l}\text { number of } \\
\text { concerned markets }\end{array}$ & $\begin{array}{l}-0.001 \\
(0.001)\end{array}$ & $\begin{array}{l}-0.003^{*} \\
(0.002)\end{array}$ & $\begin{array}{c}0.000 \\
(0.000)\end{array}$ & $\begin{array}{c}0.013^{* * *} \\
(0.004)\end{array}$ & $\begin{array}{c}-0.001 \\
(0.001)\end{array}$ & $\begin{array}{c}0.000 \\
(0.000)\end{array}$ & $\begin{array}{c}0.001 \\
(0.001)\end{array}$ \\
\hline $\begin{array}{l}\text { number of } \\
\text { competitors }\end{array}$ & $\begin{array}{c}0.025^{* * *} \\
(0.009)\end{array}$ & $\begin{array}{l}-0.004 \\
(0.003)\end{array}$ & $\begin{array}{l}-0.006 \\
(0.009)\end{array}$ & $\begin{array}{l}-0.026^{*} \\
(0.014)\end{array}$ & $\begin{array}{l}-0.011 \\
(0.011)\end{array}$ & $\begin{array}{l}0.000^{* *} \\
(0.000)\end{array}$ & $\begin{array}{l}-0.089 \\
(0.057)\end{array}$ \\
\hline $\begin{array}{l}\text { indicator no } \\
\text { info on competitors }\end{array}$ & $\begin{array}{l}0.076^{*} \\
(0.039)\end{array}$ & $\begin{array}{l}-0.002 \\
(0.024)\end{array}$ & $\begin{array}{l}-0.021 \\
(0.045)\end{array}$ & $\begin{array}{c}-0.275^{* * *} \\
(0.082)\end{array}$ & $\begin{array}{c}0.093 \\
(0.073)\end{array}$ & $\begin{array}{l}0.000^{* *} \\
(0.000)\end{array}$ & $\begin{array}{l}-0.356^{*} \\
(0.203)\end{array}$ \\
\hline $\begin{array}{l}\text { Post reform } \\
\text { indicator }\end{array}$ & $\begin{array}{l}-0.185 \\
(0.166)\end{array}$ & $\begin{array}{l}-0.044 \\
(0.090)\end{array}$ & $\begin{array}{l}-0.027 \\
(0.024)\end{array}$ & $\begin{array}{l}-0.135 \\
(0.143)\end{array}$ & $\begin{array}{c}0.137 \\
(0.181)\end{array}$ & $\begin{array}{l}-0.000 \\
(0.000)\end{array}$ & $\begin{array}{l}-0.099 \\
(0.094)\end{array}$ \\
\hline Constant & $\begin{array}{l}-0.319 \\
(0.207)\end{array}$ & $\begin{array}{c}0.055 \\
(0.181)\end{array}$ & $\begin{array}{c}0.091 \\
(0.083)\end{array}$ & $\begin{array}{l}0.389^{* *} \\
(0.171)\end{array}$ & $\begin{array}{c}0.020 \\
(0.184)\end{array}$ & $\begin{array}{c}1.000^{* * *} \\
(0.000) \\
\end{array}$ & $\begin{array}{l}0.355^{*} \\
(0.203)\end{array}$ \\
\hline Year FE & Yes & Yes & Yes & Yes & Yes & Yes & Yes \\
\hline R2 & 0.640 & 0.479 & 0.889 & 0.427 & 0.282 & 1.000 & 0.724 \\
\hline Observations & 420 & 442 & 251 & 244 & 434 & 50 & 116 \\
\hline
\end{tabular}

We report heteroskedasticity robust standard errors.

Significance at the $1 \%, 5 \%$, and $10 \%$ levels is represented by ${ }^{* * * * *}$ and * respectively. 
Figure 10: OLS Regression Coefficient on High Concentration over Industry

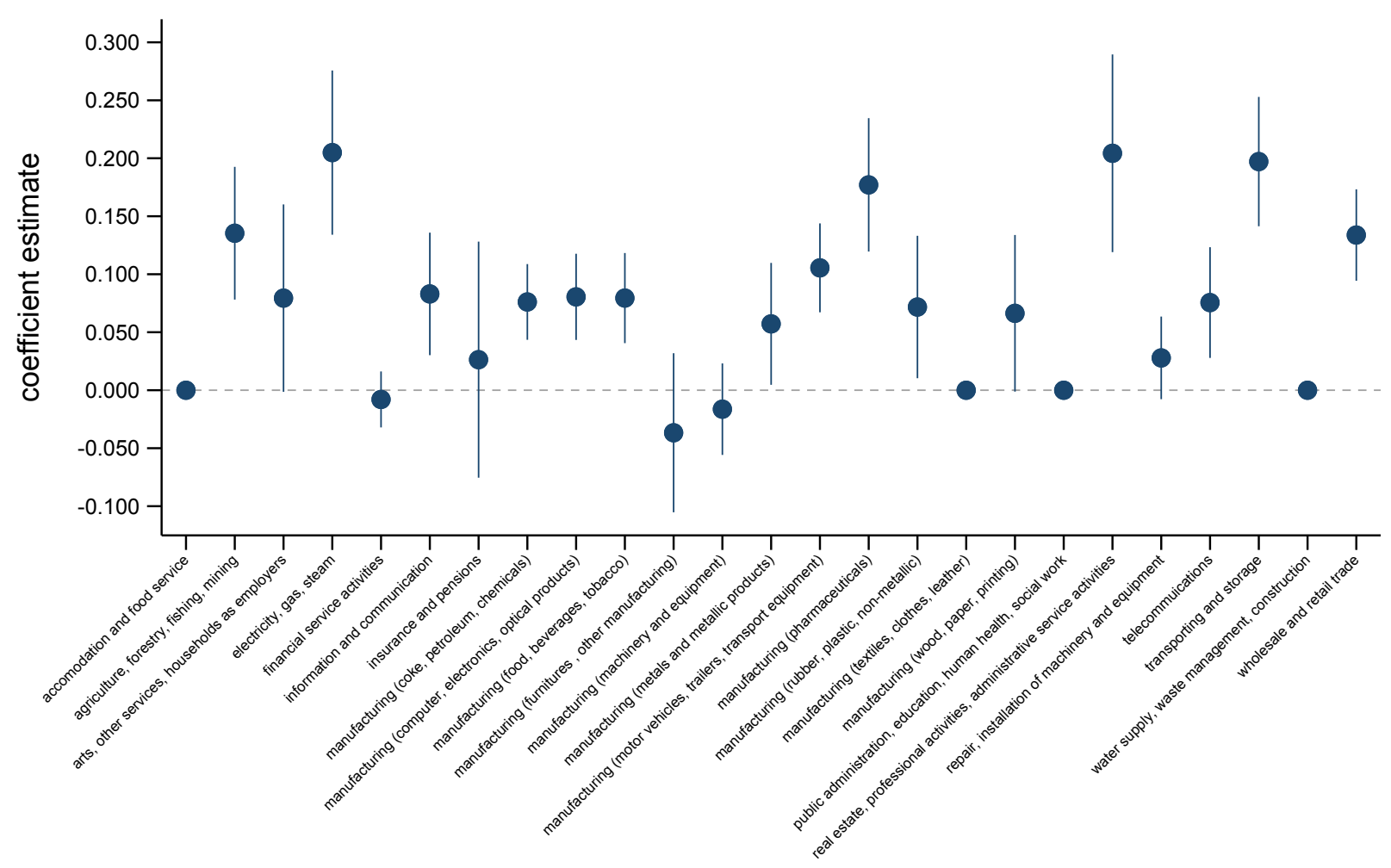

- Point estimate

$95 \%$ confidence interval

Regression coefficient on indicator variable for post-merger HHI above 2000 and change in HHI due to the merger larger than 150 in OLS regression on concerns. Each reported coefficient stems from a separate regression for the respective industry. Confidence intervals are based on heteroskedasticity robust standard errors. 
Figure 11: OLS Regression Coefficient on Joint Market Share over Industry

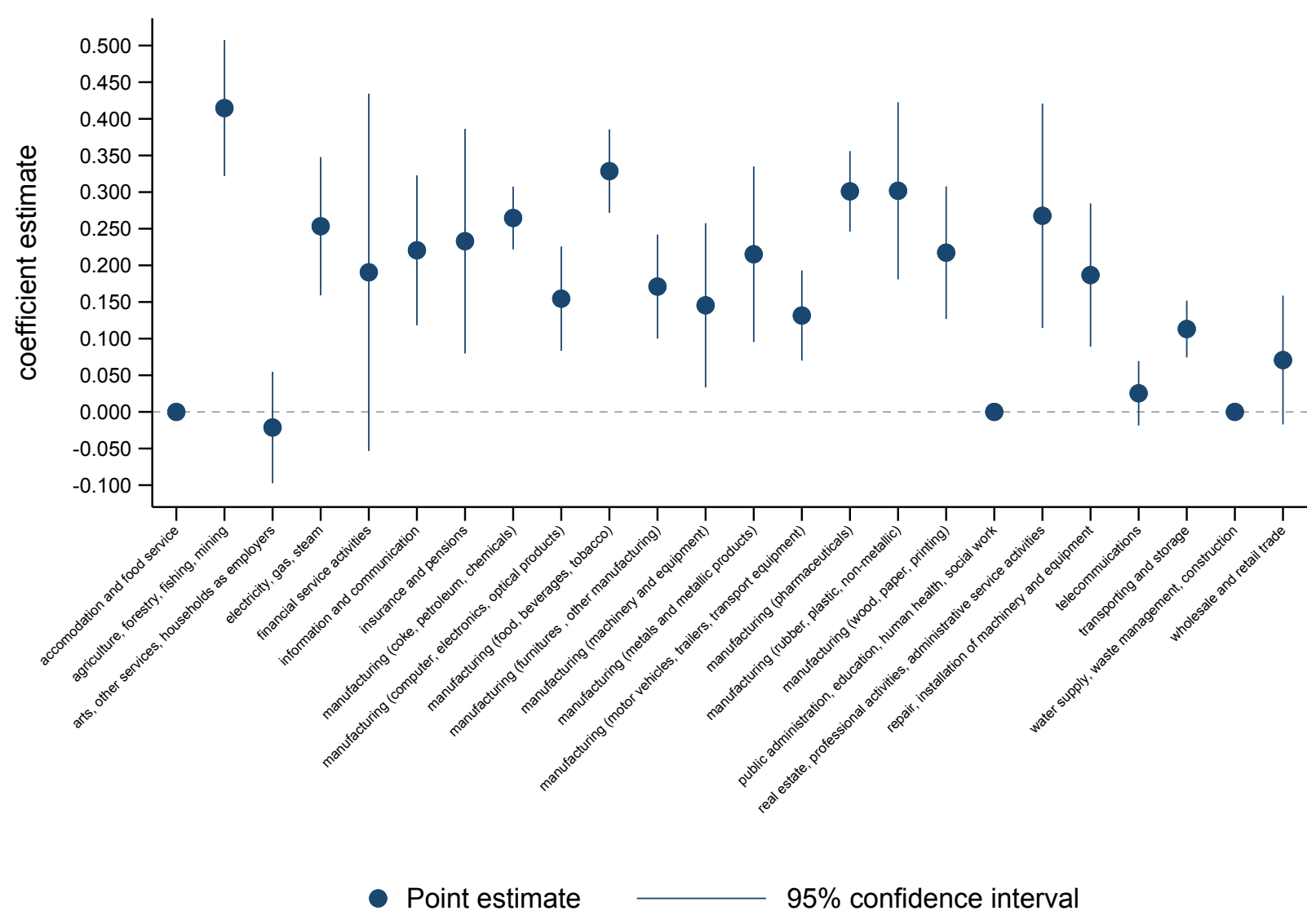

Regression coefficient on indicator variable for joint market share above 50\% in OLS regression on concerns. Each reported coefficient stems from a separate regression for the respective industry. Confidence intervals are based on heteroskedasticity robust standard errors. 
Figure 12: OLS Regression Coefficient on Barriers to Entry over Industry

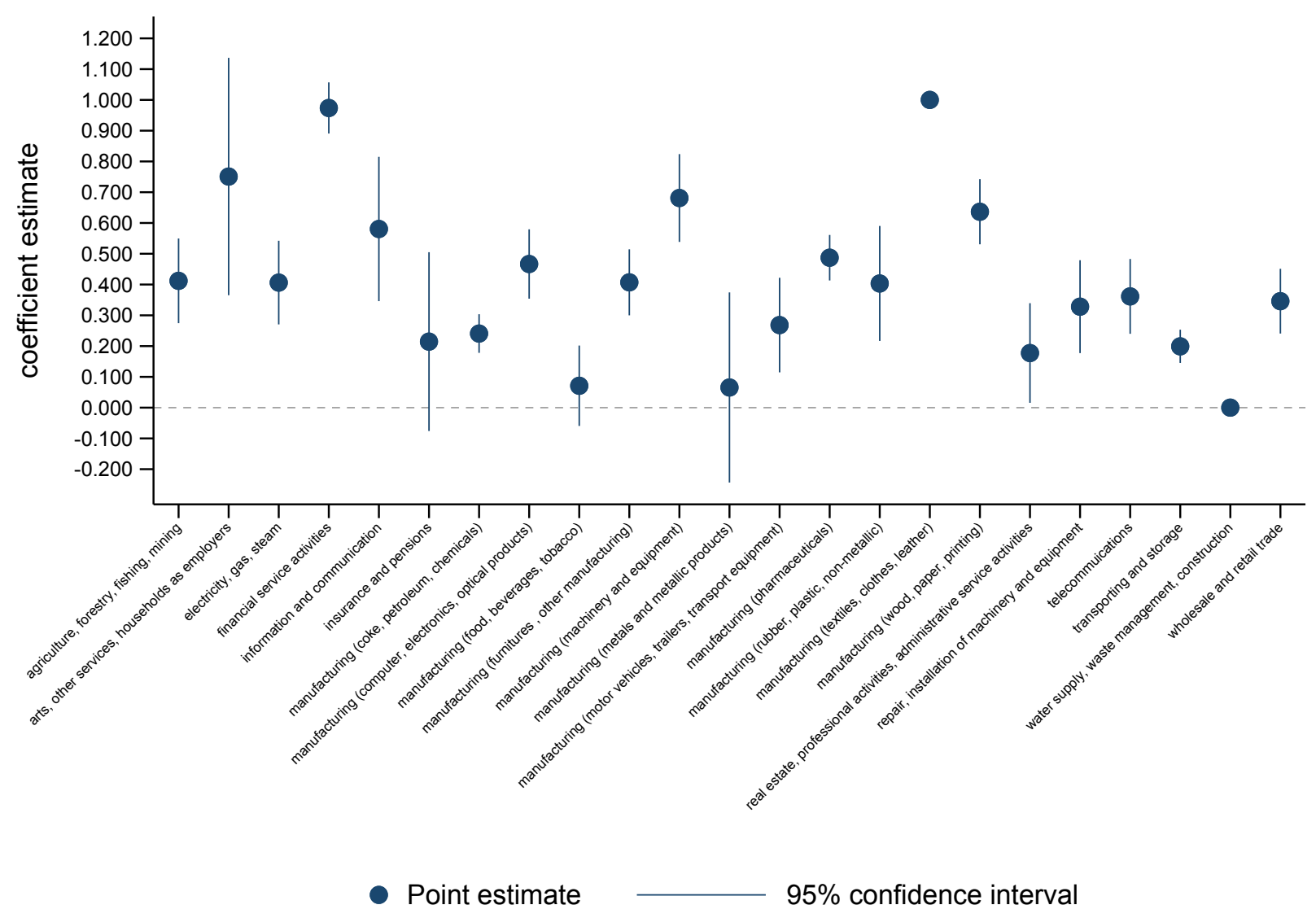

Regression coefficient on barriers to entry in OLS regression on concerns. Each reported coefficient stems from a separate regression for the respective industry. Confidence intervals are based on heteroskedasticity robust standard errors. 
Figure 13: OLS Regression Coefficient on Risk of Foreclosure over Industry

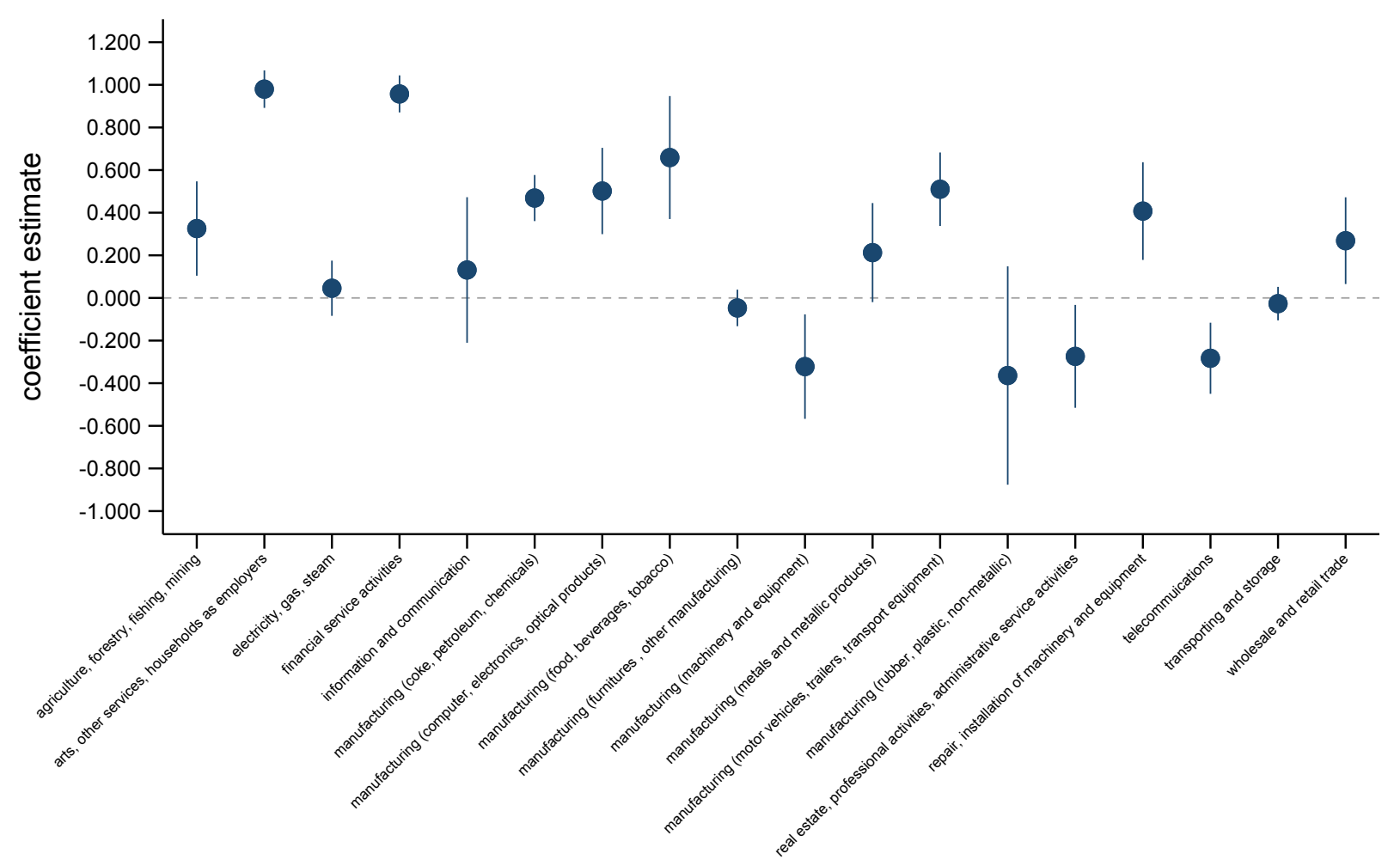

- Point estimate

$95 \%$ confidence interval

Regression coefficient on risk of foreclosure in OLS regression on concerns. Each reported coefficient stems from a separate regression for the respective industry. Confidence intervals are based on heteroskedasticity robust standard errors. 


\section{A.3 Technical Background on Causal Forests}

\section{A.3.1 Background on Causal Forests}

Causal forests are based on the random forest methodology by Breiman (2001). They have been developed by Athey and co-authors in a series of papers (see Athey and Imbens (2016), Wager and Athey (2017) and Athey et al. (2017)), extending the regression tree and random forest algorithms so as to estimate average treatment effects for different subgroups, rather than predicting outcomes as is the case for regression trees and random forests.

In a standard CART tree (Classification and Regression Tree), the goal is to predict individual outcomes $Y_{i}$ using the mean outcome $Y$ of observations that are "close" in $X$-space. To determine which observations are "close", the algorithm starts to recursively split the covariate space (binary splits) until it is partitioned into a set of so-called leaves $L$ that contain only a few training samples. The outcome $Y_{i}$ for observation $i$ is then predicted by identifying the leaf containing observation $i$ based on its characteristics $X_{i}$ and setting the prediction to the mean outcome within that leaf:

$$
\hat{\mu}(x)=\frac{1}{\left|\left\{i: X_{i} \in L(x)\right\}\right|} \sum_{\left\{i: X_{i} \in L(x)\right\}} Y_{i}
$$

The algorithm automatically decides on the splitting variables and split points. This is done based on an in sample goodness-of-fit criterion (so essentially how close the predicted outcomes are to the actual outcomes). For regression trees (continuous outcome variable $Y$ ) the goodness-of-fit criterion used is the mean squared error, for classification trees (categorical outcome variable $Y$ ) the goodness-of-fit criterion is a measure of classification error based on the empirical classification probabilities in the leaves. The algorithm then splits on the covariate at the cut-off value that leads to the greatest improvement in the goodness-of-fit criterion. Once the best split at a given point in the tree is found, the splitting process is repeated in each of the resulting two regions. For CART trees, the splitting process is usually stopped when a specified minimum node size is reached - by default this is a node size of 5 for regression and 1 for classification trees. The tree is then pruned based on some cost-complexity trade-off measure in order to avoid over-fitting (See Hastie et al. (2008, chapter 9) for further details).

A random forest is then an ensemble of regression or classification trees, where the predictions are averaged across trees (for classification problems, the random forest obtains a class vote from each tree and then classifies based on majority vote). Each individual tree in the forest is grown using a random sample with replacement from the training set. One third of the data is not used for training and can be used for testing (out-of-bag error). Differently from growing a single tree, splitting for each node in a tree in the forest is done based on only a subset of the covariates $X$ and each tree is grown to the largest extent possible without pruning. The idea behind random forests is to reduce variance and produce more robust predictions compared to a single tree. The splitting on only a subset of variables at each node reduces the correlation between the trees in the forest and the variance of the predictions further (See Breiman (2001) and Hastie et al. (2008, chapter 15) for further details).

In case of a causal forest, we are not interested in predicting individual outcomes $Y_{i}$ but individual treatment effects $Y_{i}^{1}-Y_{i}^{0}$ to study how treatment effects vary by subgroup. This implies that standard fit measures used in regression trees and random forests, such as the mean squared error, are not available since one of the potential outcomes and hence the actual treatment effect is never observed. However, the causal forest methodology builds on regression tree methods in that it also applies a "goodness-of-fit" criterion in treatment effects to decide on splits. Athey and Imbens (2016) show that the mean squared error function of a causal tree can be estimated and is a function of the variance of the estimated treatment effect. Basically, the goodness-of-fit measure to be minimized rewards a partition of the data for finding strong heterogeneity in treatment effects and penalizes a partition for high variance in leaf estimates. Minimizing the expected mean squared error of predicted treatment effects (rather than the infeasible mean squared error), is shown to be equivalent to maximizing the variance of the predicted treatment effects across leaves with a penalty for within-leaf variance (variance of means of treatment and control group outcomes within leaves). 
Causal trees are similar to nearest-neighbour methods as they also rely on the unconfoundedness assumption and use "close" observations to predict treatment effects. However, rather than defining closeness based on some pre-specified distance measure (such as Euclidean distance in $k$-nearest-neighbour matching), closeness is defined with respect to a decision tree and the closest control observations to $i$ are those that fall in the same leaf. Analogously to CART regression trees, the leaves in causal trees should be small enough so that the $\left(Y_{i}, W_{i}\right)$ pairs in a given leaf act as though they had come from a randomized experiment (Wager and Athey, 2017). The treatment effect for observation $i$ with covariates $X_{i}=x$ falling into leaf $L$ is then simply estimated as the difference of mean outcomes between treated and control observations within that leaf:

$$
\begin{aligned}
\hat{\tau}(x) & =\frac{1}{\left|\left\{i: W_{i}=1, X_{i} \in L\right\}\right|} \sum_{\left\{i: W_{i}=1, X_{i} \in L\right\}} Y_{i} \\
& -\frac{1}{\left|\left\{i: W_{i}=0, X_{i} \in L\right\}\right|} \sum_{\left\{i: W_{i}=0, X_{i} \in L\right\}} Y_{i}
\end{aligned}
$$

Given the procedure for generating a single causal tree, a causal forest then generates $B$ such trees, each of which delivers an estimate $\hat{\tau}_{b}(x)$. The causal forest as developed by Wager and Athey (2017) then aggregates the predictions of the single trees by averaging:

$$
\hat{\tau}(x)=\frac{1}{B} \sum_{b=1}^{B} \hat{\tau}_{b}(x)
$$

The causal forest algorithm by Athey et al. (2017) (the one we use here), predicts treatment effects slightly differently. For each observation $i$, the algorithm weights the nearby control observations according to the fraction of trees in which a control observation appears in the same leaf as the treated observation $i$. The treatment effect is then calculated as the difference between observation $i$ 's actual outcome and the weighted average outcome of its control observations. This implies that for each observation an individual treatment effect $\tau_{i}$ can be estimated.

As for CART trees and random forests, the advantage of a causal forest over a causal tree is that it is not always clear what the "best" causal tree is. The aggregation across trees helps to reduce variance, the estimates of the causal effects change more smoothly with covariates and individual treatment effects $\tau_{i}$ can be estimated while in a causal tree all individuals assigned to a given terminal leaf have the same estimated treatment effect (Wager and Athey, 2017).

Athey and Imbens (2016) further introduce so-called "honesty" in causal trees to ensure correct inference: the data is divided in half, where one half of the data is used to build the tree (so determine the splits in covariate space) and the other half is used to predict treatment effects. Wager and Athey (2017) extend this idea to causal forests and develop asymptotic theory for inference in causal forests. Thus, the causal forest algorithm by Athey et al. (2017) does not only allow to predict heterogeneous treatment effects in a very flexible way but also provides confidence intervals for these estimates.

\section{A.3.2 Background on grf package}

We use the generalized random forest (grf) $R$ package of Athey et al. (2017). The package allows, among others, to train a causal forest, obtain the conditional average treatment effect and predict treatment effects, either in-sample using out-of-bag training samples or out-of-sample using prediction datasets as we do in our application. As the package also predicts the variance of treatment effects, it is possible to compute point-wise confidence intervals for predicted treatment effects.

To build the trees in the forest, the package uses by default $50 \%$ of the data to grow each tree. When honesty is used, these sub-samples are further cut in half, where one half is used to place the splits within the tree and the other half is used to estimate treatment effects within the leaves. 
While the causal forest algorithm is based on the regression tree methodology, to our understanding, it can still be applied to a binary outcome variable $Y$ as is the case in our application. Athey et al. (2017) apply the causal forest methodology themselves in the example of the effect of child rearing on female labor-force participation where the outcome variable is an indicator variable for whether the mother did not work in the year preceding the census.

In case of a binary outcome variable, the causal forest function gives estimates of $\tau(x)=\mathbf{E}[Y(1)-Y(0) \mid X=x]$ and according to a forum discussion on the grf package by the authors, the provided confidence intervals are also formally justified for binary $Y$ as long as $Y(w)$ is not a deterministic function of $X$ (i.e. there is still some randomness in the outcome $Y$ given $X$ and $W$ ). For binary outcome $Y$, the prediction function for causal forests then returns the estimated change in the probability of $Y$ associated with the treatment $W$, which should be between -1 and 1 . 


\section{A.4 Variable Importance Plots of Causal Forests}

The variable importance measures the frequency with which the causal forest splits over a given covariate. It is based on the split frequencies function provided in the grf R package by Athey et al. (2017) that shows how often the forest chose to split on each covariate at different split depths. For the plots shown here, we take into account splits within trees up to a split depth of 4 . The variable importance function first counts the fraction of times the forest splits on each covariate at split levels 1, 2, 3 and 4 . To calculate the overall variable importance measure, splits on a given covariate are weighted differently depending on the split depth. In the variable importance plots below, we use a decay exponent of 2, implying weights for splits at depth 1,2,3 and 4 of $1,0.25,0.1111$ and 0.0625 respectively.

\section{A.4.1 Treatment - High Concentration}

Figure 14: Variable Importance Plot for Correlation between High Concentration and Concerns

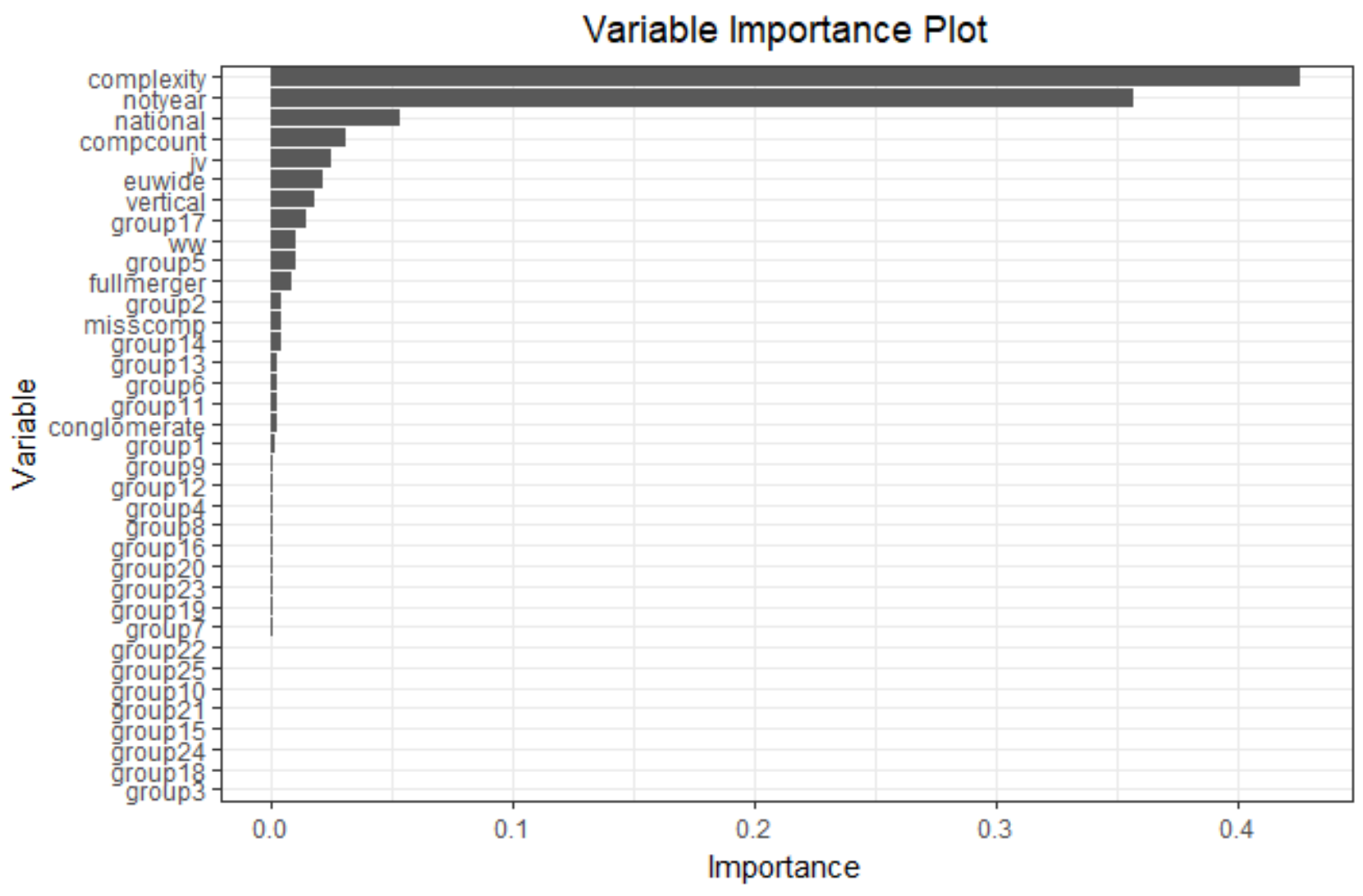




\section{A.4.2 Treatment - Joint Market Share above 50\%}

Figure 15: Variable Importance Plot for Correlation between Joint Market Share and Concerns

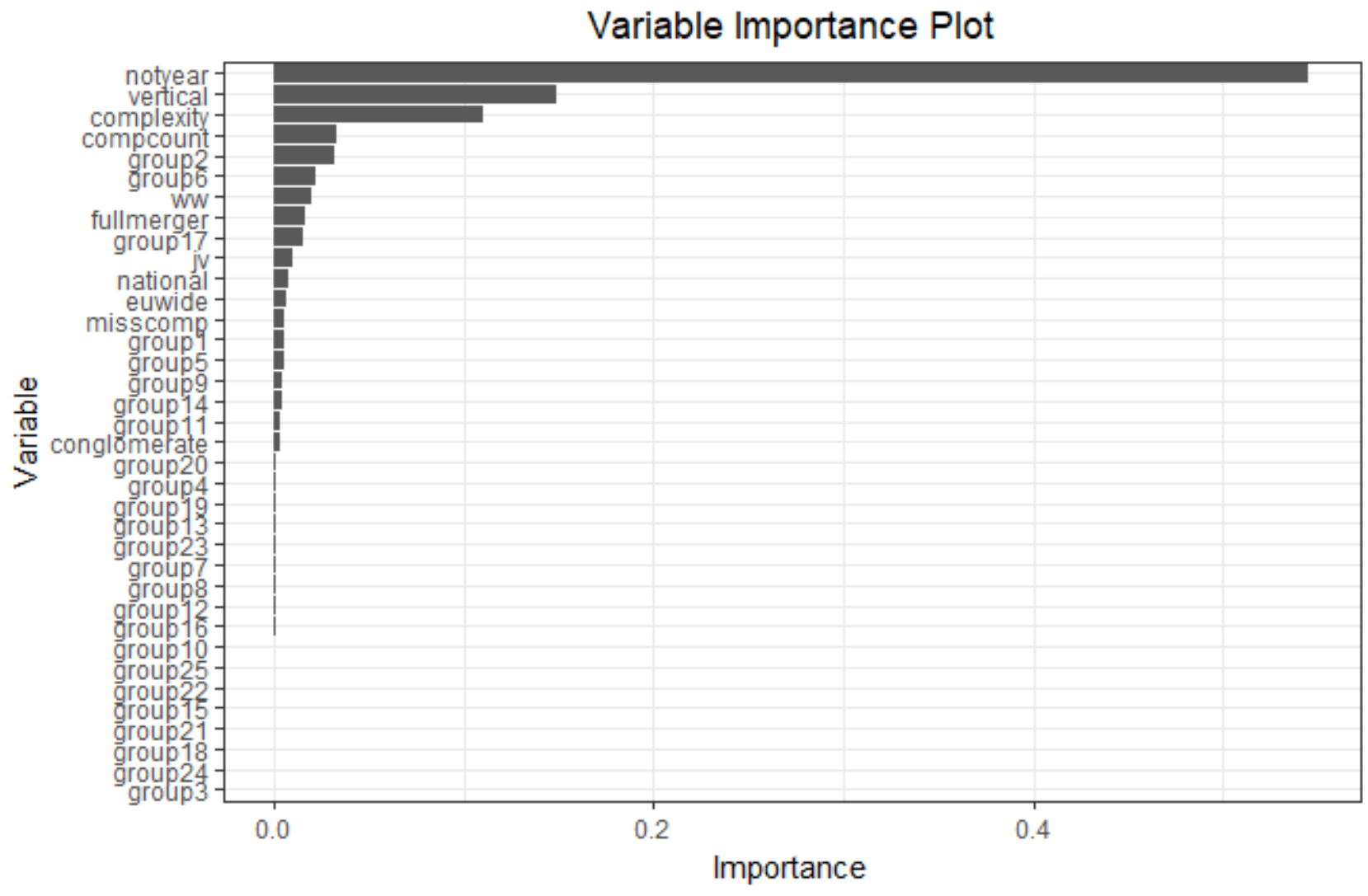




\section{A.4.3 Treatment - Barriers to Entry}

Figure 16: Variable Importance Plot for Correlation between Barriers to Entry and Concerns

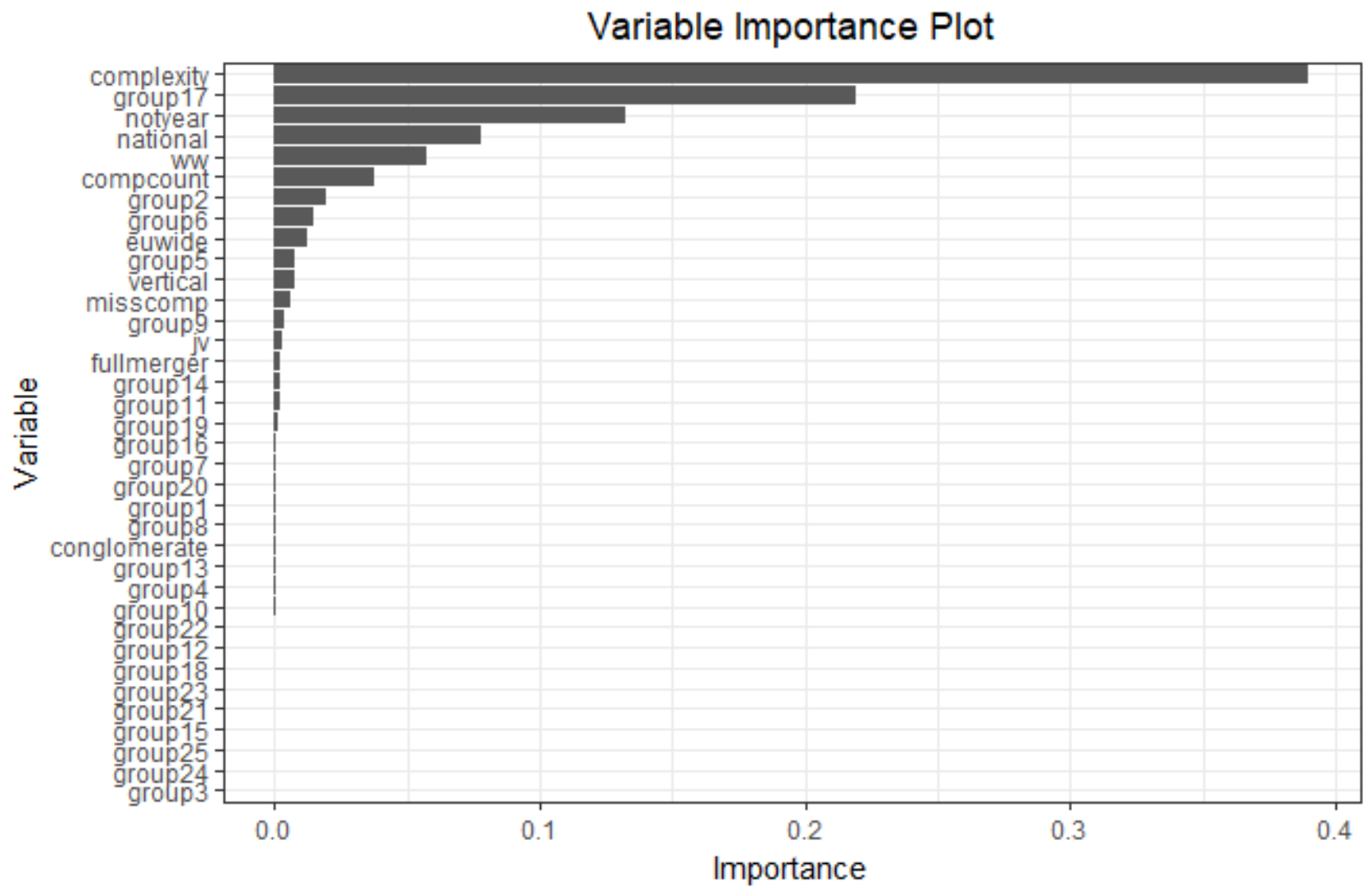




\section{A.4.4 Treatment - Risk of Foreclosure}

Figure 17: Variable Importance Plot for Correlation between Risk of Foreclosure and Concerns

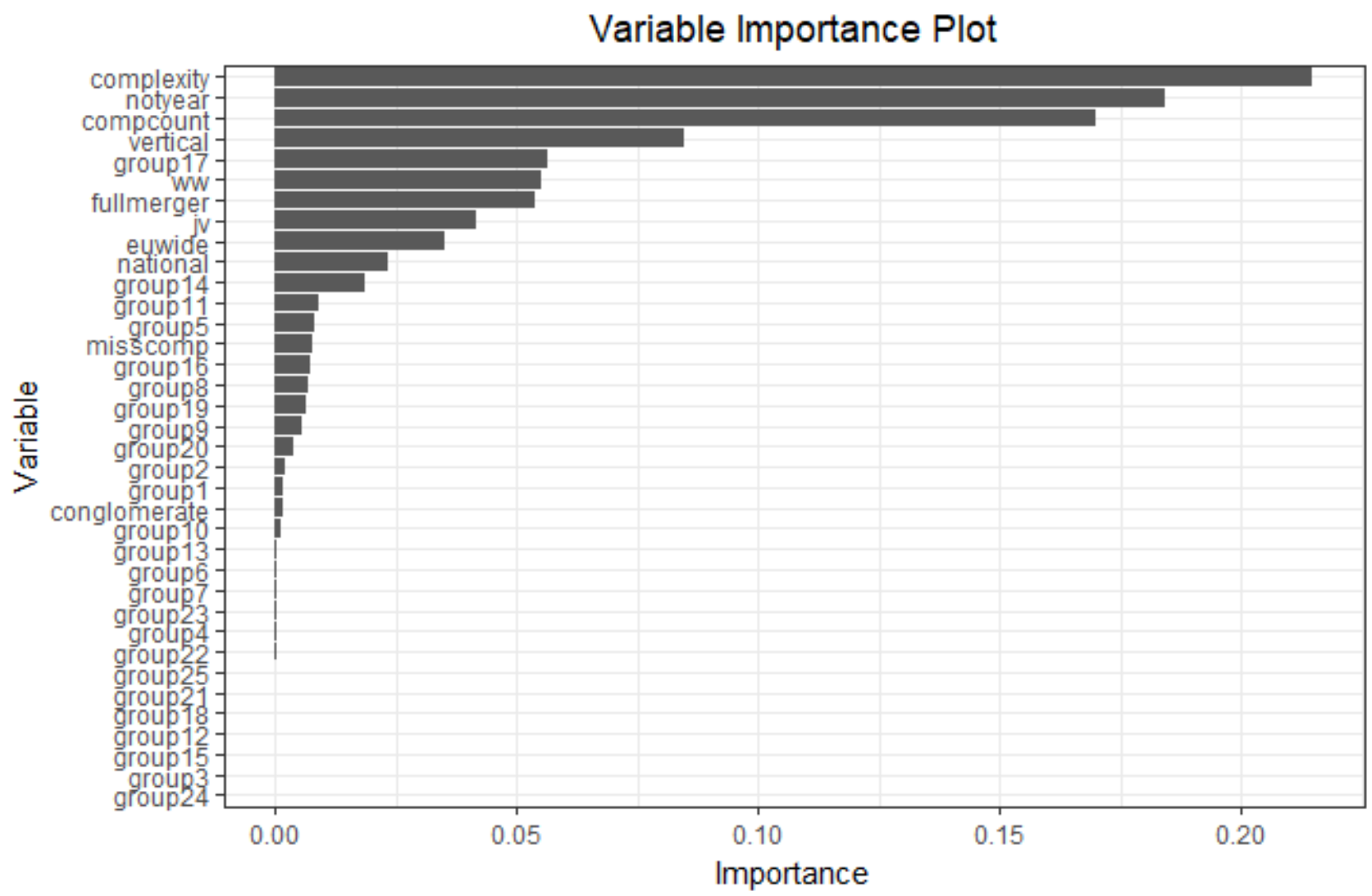




\section{A.5 Determinants of Concern - Causal Forest Predictions over Industries}

Figure 18: Effect of High Concentration on Concerns over Industries

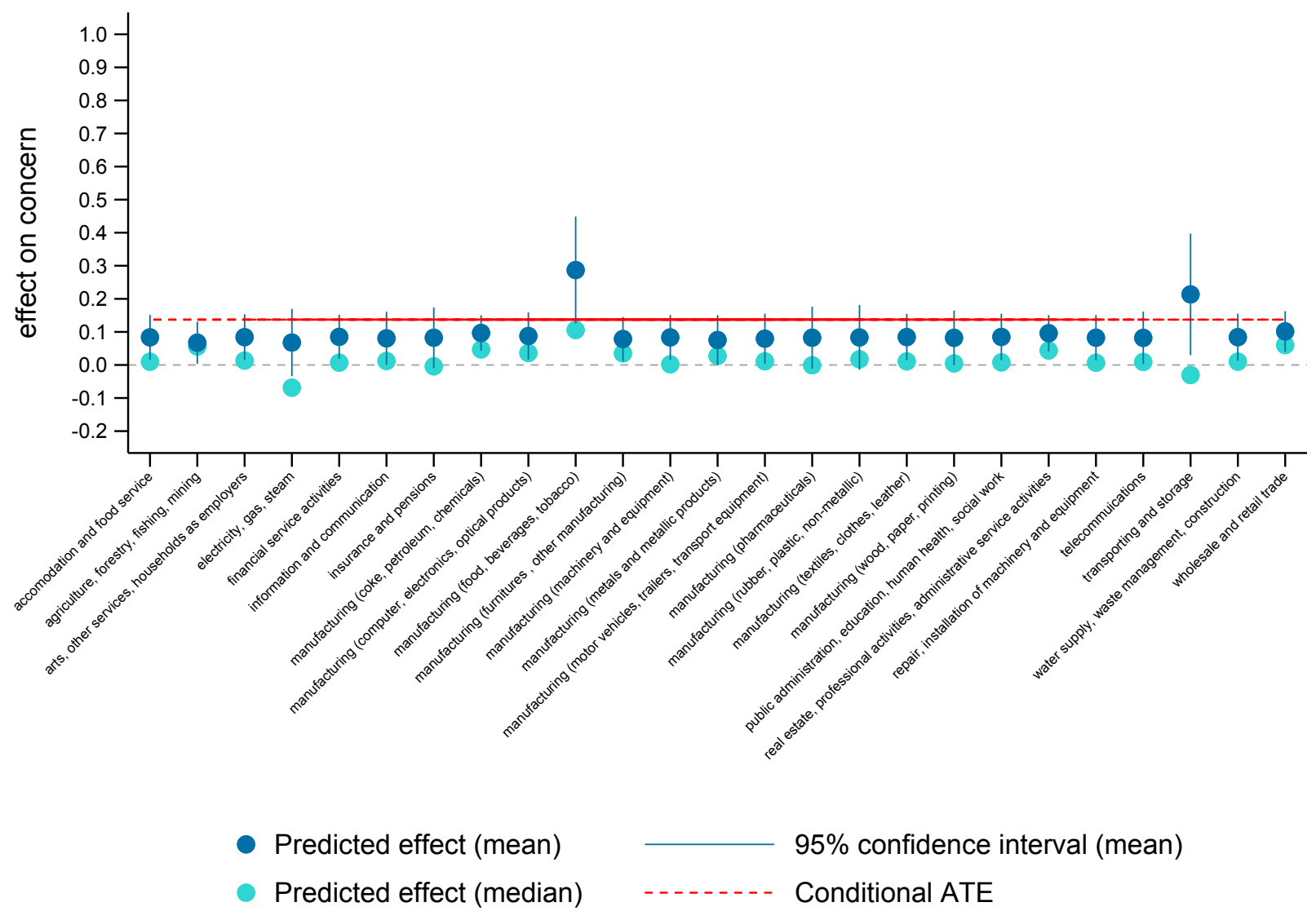

Predicted effect of indicator variable for post-merger HHI above 2000 and change in HHI larger than 150 on concerns over industries, setting all other included explanatory variables equal to the sample mean/median. 
Figure 19: Effect of Joint Market Share on Concerns over Industries

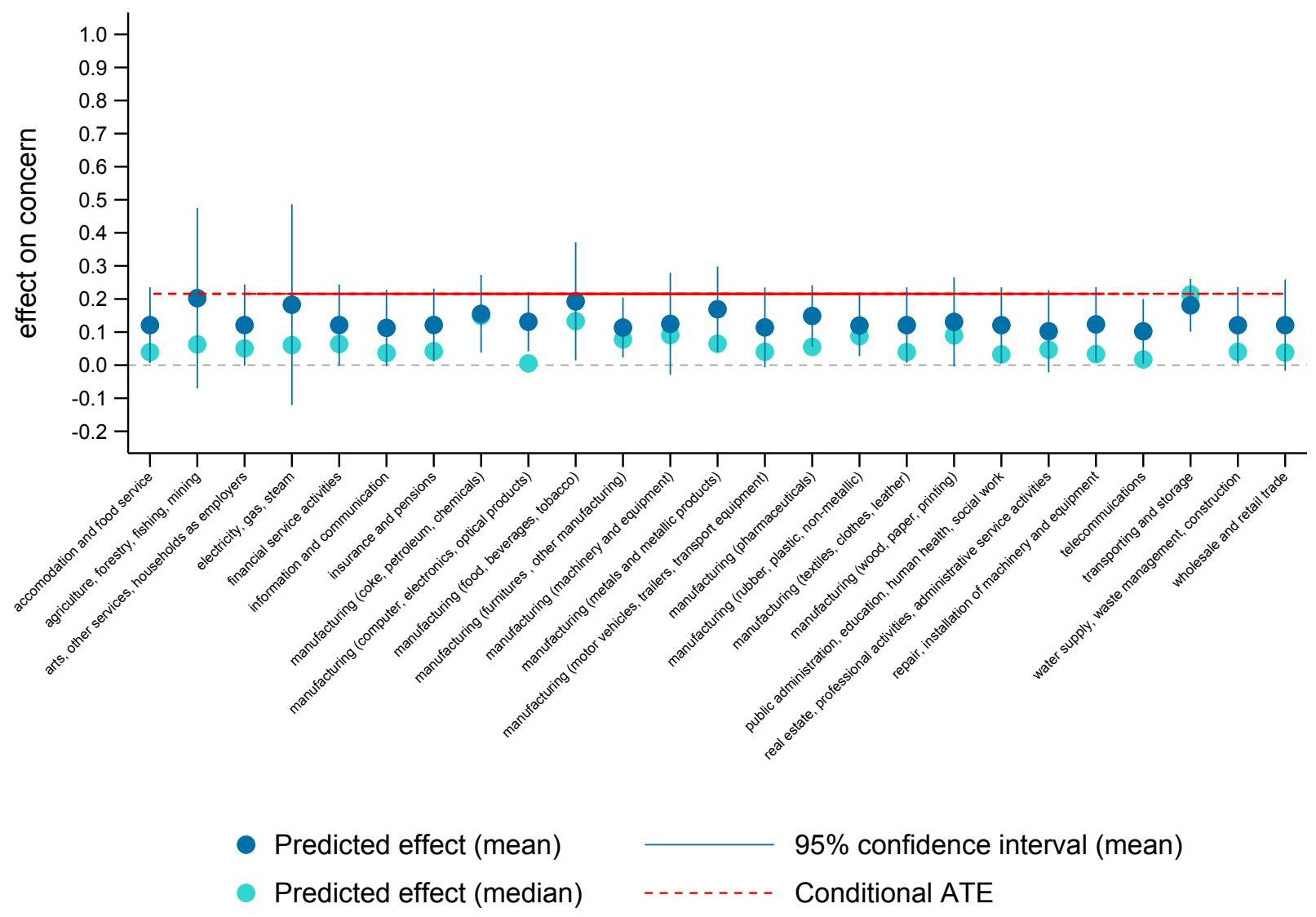

Predicted effect of indicator variable for joint market share above $50 \%$ on concerns over industries, setting all other included explanatory variables equal to the sample mean/median. 
Figure 20: Effect of Barriers to Entry on Concerns over Industries

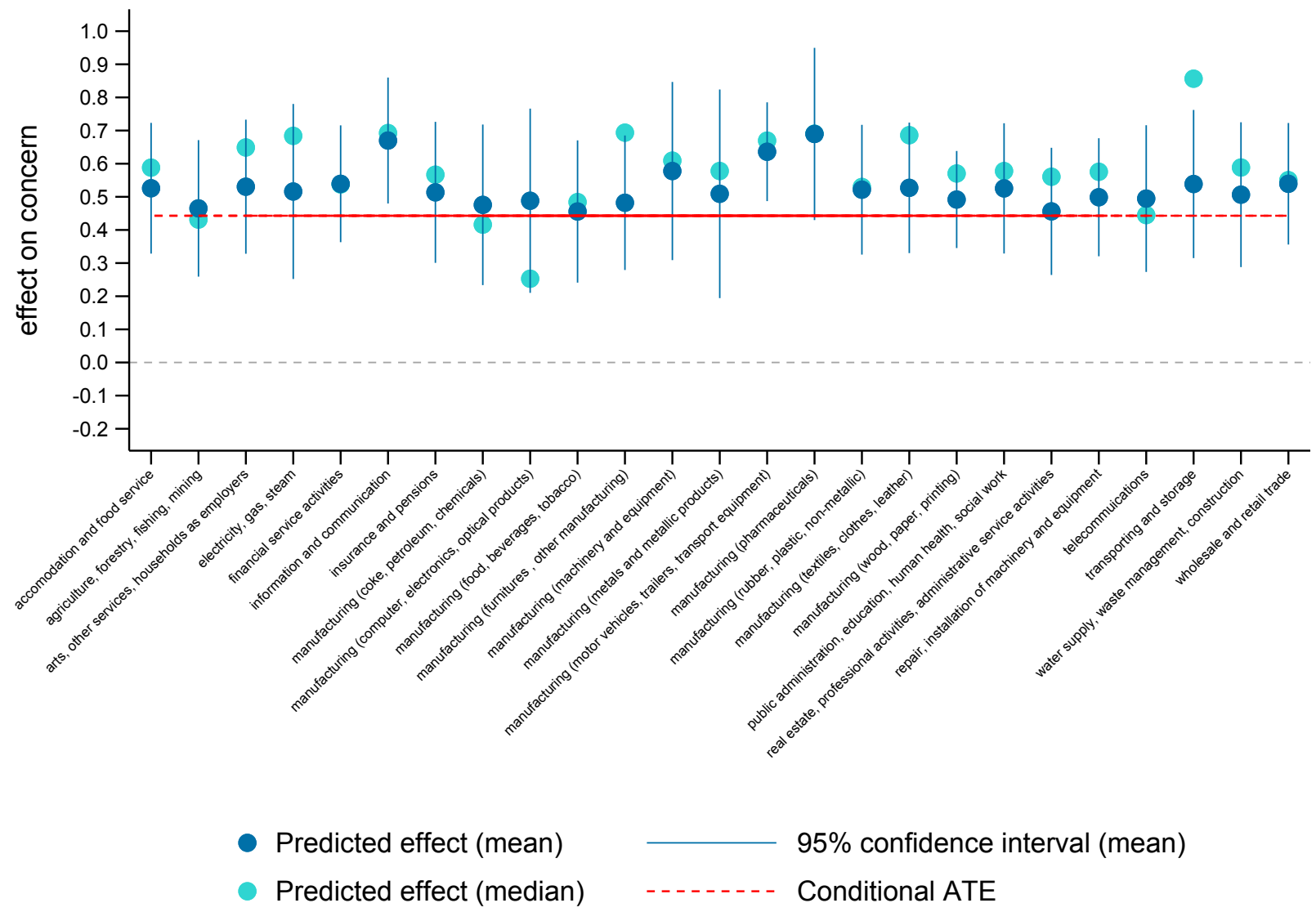

Predicted effect of barriers to entry on concerns over industries, setting all other included explanatory variables equal to the sample mean/median. 
Figure 21: Effect of Risk of Foreclosure on Concerns over Industries

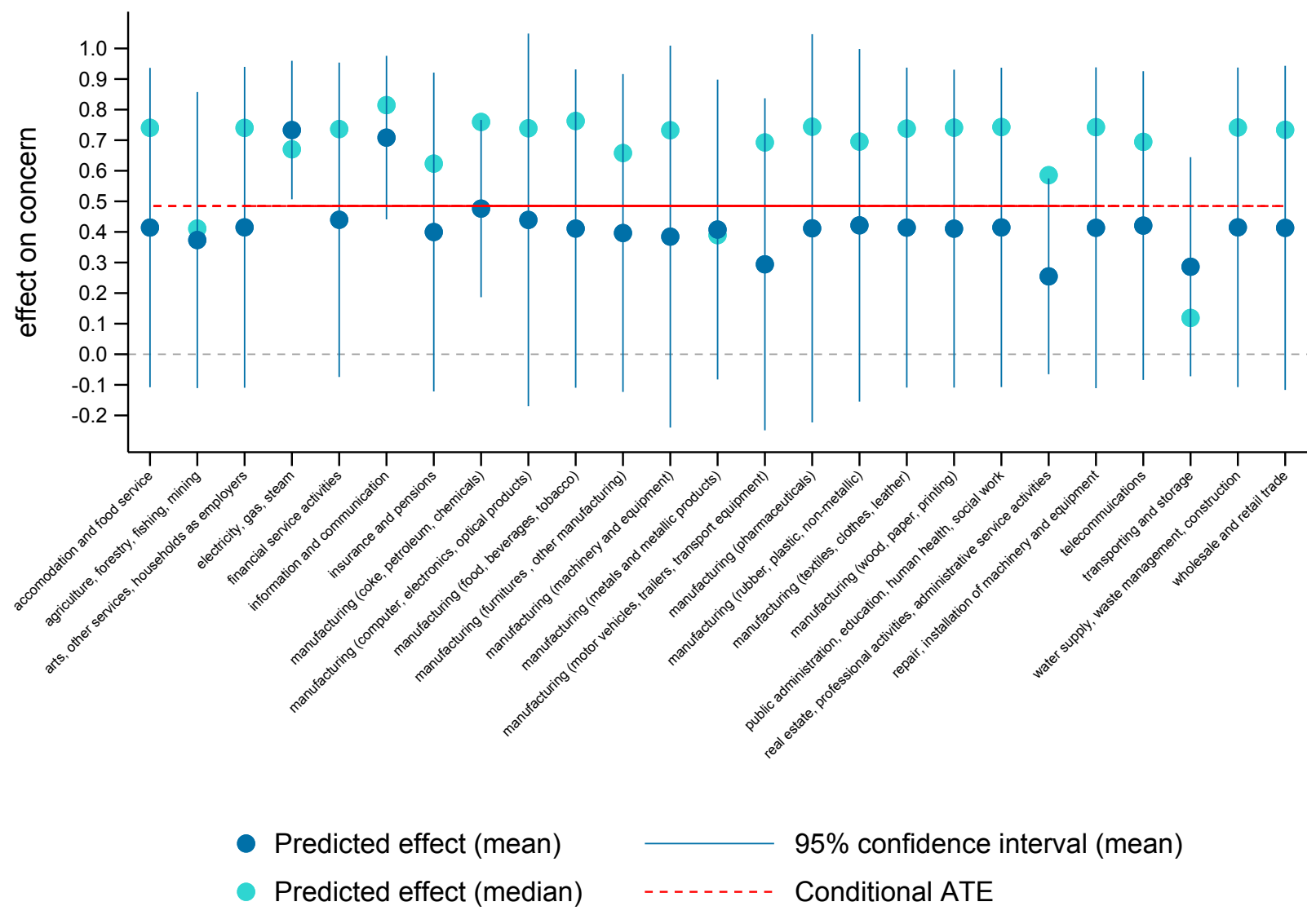

Predicted effect of risk of foreclosure on concerns over industries, setting all other included explanatory variables equal to the sample mean/median. 